\title{
The clinical symptomatology and comorbidity of attention-deficit / hyperactive disorder in a healthy school population
}

Citation for published version (APA):

Tremmery, S. (2007). The clinical symptomatology and comorbidity of attention-deficit / hyperactive disorder in a healthy school population. [Doctoral Thesis, Maastricht University]. Maastricht University. https://doi.org/10.26481/dis.20071217st

Document status and date:

Published: 01/01/2007

DOI:

10.26481/dis.20071217st

Document Version:

Publisher's PDF, also known as Version of record

Please check the document version of this publication:

- A submitted manuscript is the version of the article upon submission and before peer-review. There can be important differences between the submitted version and the official published version of record.

People interested in the research are advised to contact the author for the final version of the publication, or visit the DOI to the publisher's website.

- The final author version and the galley proof are versions of the publication after peer review.

- The final published version features the final layout of the paper including the volume, issue and page numbers.

Link to publication

\footnotetext{
General rights rights.

- You may freely distribute the URL identifying the publication in the public portal. please follow below link for the End User Agreement:

www.umlib.nl/taverne-license

Take down policy

If you believe that this document breaches copyright please contact us at:

repository@maastrichtuniversity.nl

providing details and we will investigate your claim.
}

Copyright and moral rights for the publications made accessible in the public portal are retained by the authors and/or other copyright owners and it is a condition of accessing publications that users recognise and abide by the legal requirements associated with these

- Users may download and print one copy of any publication from the public portal for the purpose of private study or research.

- You may not further distribute the material or use it for any profit-making activity or commercial gain

If the publication is distributed under the terms of Article $25 \mathrm{fa}$ of the Dutch Copyright Act, indicated by the "Taverne" license above, 


\section{THE CLINICAL SYMPTOMATOLOGY AND COMORBIDITY OF ATTENTION- DEFICIT/HYPERACTIVE DISORDER IN A HEALTHY SCHOOL POPULATION}

Sabine M.K.E. Tremmery 


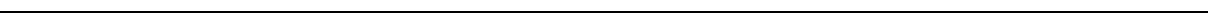




\title{
The clinical symptomatology and comorbidity of attention-deficit/hyperactive disorder in a healthy school population
}

\author{
Proefschrift \\ ter verkrijging van de graad van doctor aan de Universiteit Maastricht, \\ op gezag van de Rector Magnificus, Prof. Mr. G.P.M.F. Mols \\ volgens het besluit van het College van Decanen, \\ in het openbaar te verdedigen op maandag 17 december 2007 om 16:00 uur \\ door
}

Sabine Mia Kathy Estella Tremmery

Geboren op 5 oktober 1971 te Kortrijk 


\section{Promotores}

Prof. dr. J. Jolles

Prof. dr. J.K. Buitelaar, Radboud Universiteit Nijmegen

\section{Co-Promotor}

Prof. dr. G. Molenberghs, Universiteit Hasselt

\section{Beoordelingscommissie}

Prof. dr. J. Troost, Voorzitter

Prof. dr. A.M. Korebrits

Prof. dr. C. Kemner

Prof. dr. M. Danckaerts, Katolieke Universiteit Leuven

Prof. dr. H. Roeyers, Universiteit Gent

The studies described in the thesis are part of 'The Study of Attention Disorders Maastricht (SAM)', which was developed from a multidisciplinary collaboration of the Youth Health Care, Rehabilitation Center Franciscusoord, The institute of Brain and Behavior, The academic Hospital of Maastricht and the University of Maastricht.

This research was supported by the Academic Hospital of Maastricht (het Profileringsfonds), Zorg Onderzoek Nederland (Care Research the Netherlands; formally the Prevention Foundation of the Netherlands), the Brain \& Behavior Research Institute of Maastricht University and the St. Clemens Foundation of the Netherlands.

Janssen-Cilag BV, Eli Lilly Belgium and Novartis Belgium supported the publication of this thesis. 
Zoek

de zonkant,

kind.

Vul

uw ogen

met het licht

dat klaar en koel

in 't vroege voorjaar

schuw nog om de parklaan

draalt.

En groei

als uit uw eigen

Zon.

Paul Verbruggen, 'Gedichten’ 


\section{Contents}

\section{Chapter 1}

General Introduction

\section{Chapter 2}

Attention Deficit/Hyperactive Disorder (ADHD) Review

\section{Chapter 3}

Distribution of DSM IV symptoms of ADHD in a Large Community Sample of 7 Year Old Dutch School Children.

\section{Chapter 4}

Comorbidity Patterns in a Community Sample of 7 Year Old Dutch School Children

\section{Chapter 5}

Diagnostic Continuity of ADHD in a Community Sample of Primary School Children: a Three Year Follow-up Study

\section{Chapter 6}

The Use of Health Care Services and Psychotropic Medication in a Community 107 Sample of 9-Year-Old Schoolchildren with ADHD

\section{Chapter 7}

Concluding Remarks / General Discussion

\section{Chapter 8}

Summary

Samenvatting

Dankwoord

\section{Curriculum Vitae}


Chapter 1

AD/HD in early Childhood:

A General Introduction 


\section{Background}

Attention-deficit/hyperactivity disorder (AD/HD) is one of the most prevalent mental health problems of childhood and adolescence, affecting an estimated $3 \%$ to $5 \%$ of school-aged children (Buitelaar, 2002). It is characterized by a cross-situational pattern of inattentiveness and/or impulsiveness and hyperactivity, which is inappropriate for the developmental stage or age. Although mechanisms leading to the onset of the disease are unclear, this condition seriously interferes with children's' social and/or learning functions and predisposes children to psychiatric and social pathologic conditions in later life (Dulcan, 1997).

There are two diagnostic classification systems to describe this pattern of symptoms. The DSM-IV-TR (2000), which is the most frequently used internationally and particularly in the US, speaks of AD/HD and uses broader criteria than the ICD-10 (1990) diagnosis 'Hyperkinetic Disorder'. Unfortunately, as with most developmental and psychiatric disorders, there are thus far no definitive diagnostic tests or biological markers for AD/HD (Taylor et al., 2004). Although the published diagnostic criteria (DSM-IV-TR or ICD-10) "lend an aura of objectivity to the diagnostic process", the criteria rely largely on the diagnostician's subjective judgment of the information provided by parents and teachers (Wender, 2002). A recent survey of 1128 primary care physicians found that more than half did not even use DSM criteria in establishing the diagnosis of AD/HD (Rushton et al., 2004). In addition, the process of defining and identifying $\mathrm{AD} / \mathrm{HD}$ incident cases in epidemiological research studies can only approximate the clinical diagnostic processes (Rowland et al., 2001; Scahill and Schwab-Stone, 2000). Therefore, clear and explicit criteria for AD/HD case definition are of paramount importance in epidemiological studies of AD/HD. The distribution of the $\mathrm{AD} / \mathrm{HD}$ symptoms within a large, healthy population and the specific influence of the impairment and of the need of mental health support due to the symptoms are unknown. Until now, these epidemiological aspects of the diagnostic concept of AD/HD are unclear.

Several studies have shown that children with $\mathrm{AD} / \mathrm{HD}$ run an increased risk of developing other childhood psychiatric disorders besides AD/HD. We then speak of comorbidity, which means that two or more disorders occur simultaneously (Angold et al., 1999; Gillberg et al., 2004; Neale and Kendler, 1995). The incidence of comorbidity with AD/HD is more the rule than exception in both clinical and epidemiological studies (Buitelaar and Van Engeland, 1996). The occurrence of comorbidity determines to a considerable extent the prognosis and outcome of AD/HD. Despite the high prevalence of comorbidity, only few studies (Ford et al., 2003; Kroes et al., 2001) have examined diagnostic comorbidity in a general population of young children between 6 and 8 year old. Even fewer studies have examined epidemiological patterns of comorbidity, taking the presence of other psychiatric disorders into consi- 
deration. In order to investigate these patterns, a sufficiently large population and a psychiatric evaluation for several disorders are necessary.

AD/HD may be conceptualized as a developmental disorder (Krain and Castellanos, 2006). Although it is generally assumed that AD/HD has its basis in early childhood and continues into adulthood, it is usually first diagnosed during elementary school years, when children show poor adjustment to the school routine (American Psychiatric Association, 1994). The persistence, alternatively termed the diagnostic continuity, of AD/HD from early childhood into adolescence is estimated to be between $72 \%$ and $85 \%$ in clinically referred populations (Barkley et al., 1990; Biederman et al., 1996; Hart et al., 1995; Lahey et al., 2004). Data on the stability of $\mathrm{AD} / \mathrm{HD}$ generated by community-based research are sparse and results are often dependent on the diagnostic criteria used. Between the ages of 4 and 18, prevalence rates are highest between the ages of 6 and 11 (Pineda et al., 1999; Szatmari et al., 1989). No research has been done on the stability of AD/HD in community samples of children entering elementary school, an age at which peak-prevalence is found. For treatment and outcome reasons it is important to distinguish between problem behaviour that is transient and not clinically relevant and others (Campbell, 1995).

The treatment of $\mathrm{AD} / \mathrm{HD}$ is multimodal. A comprehensive therapeutic strategy involving medication, psycho-education and psychotherapy should be established for primary and secondary prevention. Barriers may occur at multiple levels, including identification and referral, parents' help-seeking behaviour, diagnosis by the medical provider, treatment decisions, and acceptance of treatment. Despite the many international and national clinical guidelines for $\mathrm{AD} / \mathrm{HD}$, it remains unclear how many children in a normal population are treated and which kind of treatment they receive, especially at a young age.

\section{Methodological issues in studying AD/HD}

Population-based epidemiological studies of $\mathrm{AD} / \mathrm{HD}$ are limited in number. Most of the $\mathrm{AD} / \mathrm{HD}$ research is based on clinic-referred samples of children (Buitelaar, 2002), which may not reflect the spectrum of $\mathrm{AD} / \mathrm{HD}$ in the population at large. Therefore, populationbased, non-referred samples of children with AD/HD are critically needed in order to increase our understanding of $\mathrm{AD} / \mathrm{HD}$ and increase the generalizability and comparability among studies (Rowland et al., 2001; Wolraich et al., 1996).

A population-based birth cohort such as a school cohort is a powerful tool in epidemiological research. A school cohort is sampled from the general population and theoretically includes all levels of exposure to environmental risk factors, as well as the possible levels of individual genetic risks, and the various combinations of environmental and genetic risk. 
Multiple outcomes can be studied, depending on the investigated risk factors. The large sample size required to analyse complex models with sufficient statistical power is a major methodological and financial limitation in this kind of research. It is possible, if a school cohort were completely comprehensive, to study the possible mechanisms by which disorder starts, progresses, remits, and relapses. It avoids many biases that can occur in studies based on prevalent members or other samples of convenience (Liddell, 1988).

As mentioned earlier, there are thus far no definitive diagnostic tests or biological markers for AD/HD (Taylor et al., 2004). Multiple studies have stressed the importance of using multiple informants to generate an AD/HD disorder. Another difficulty is that some of the key symptoms of $\mathrm{AD} / \mathrm{HD}$ pertain to normal behaviour at a young age. This phenomenon complicates the diagnostics at a young age. As persistence of $\mathrm{AD} / \mathrm{HD}$ is closely related to adverse adolescent outcome, it is important to identify the children at risk early in order to start early intervention and treatment, which could lead to an improved prognosis.

\section{Aims of the Study}

Attention-deficit/hyperactivity disorder (AD/HD) is a common behavioral disorder among children, yet at population level there is uncertainty about many aspects of it. The overall aim of this thesis was to improve our understanding of AD/HD in a large school-based population of 6-7 year old children.

The specific aims to be addressed were as follows:

- $\quad$ To examine the symptom distribution and the validity of the DSM-IV ADHD algorithm in a large school-based sample of 6-7 year old Dutch children

- To examine the prevalence of psychiatric disorders and comorbidity patterns in a large school-based sample of about 7 year old Dutch children

- $\quad$ To study diagnostic stability of ADHD and its subtypes in young children entering the elementary school.

- To examine the prevalence and the predictors of the use of health care services and psychotropic medication within a community sample of 9-year-old school children.

\section{Study of Attention disorders in Maastricht (SAM): Design}

In1996 a large research program entitled 'Study of Attention disorders in Maastricht' (SAM) has started. This multidisciplinary research program is carried out jointly by the University 
of Maastricht (Department of Psychiatry and Neuropsychology), the University Hospital of Maastricht (Department of Neurology, Department of Psychiatry, and Department of Pediatrics), the youth Health Care of the Municipal Health Center of Maastricht, and the Child Revalidation Center Franciscusoord.

SAM is a community study and has a prospective longitudinal design performed in four phases over a time span of 4 years. The sampling design of SAM and the instruments used are outlined in Table I. The main goal of SAM is to examine the developmental profile and risk factors of $\mathrm{AD} / \mathrm{HD}$ in a stage in which most children are not yet clinically diagnosed. The study uses standardized as well as experimental questionnaires and tests.

Children who attended second grade of normal kindergarten schools were recruited during a periodic systemic health examination performed by the Youth Health Care in the Dutch region of South Limburg.

The first phase started in October 1996. The parents of the children who agreed to participate in the study completed the Child Behaviour Checklist (CBCL) (Verhulst et al., 1996) as

Figure 1. Sampling Design for the first Cohort "Study of Attention Disorders in Maastricht” lection

CBCL Se-

At about 6

Follow-up Years

At about 7

Follow-up

At about 9

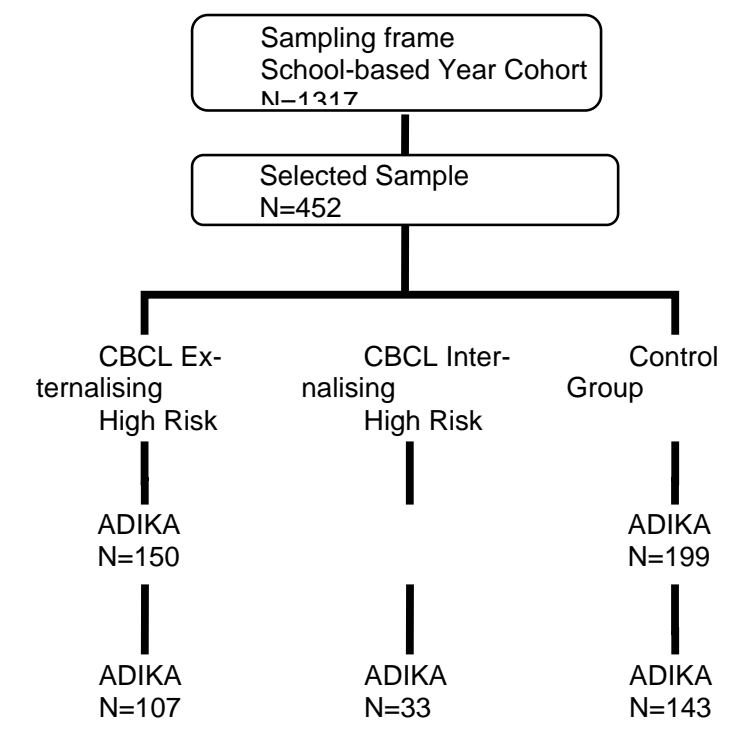
Years 
well as an experimental questionnaire for the early detection of children at risk of AD/HD, the Precursors of AD/HD Questionnaire (PAQ) (Hendriksen \& Steyaert, 1999). In addition, demographic information was collected anonymously from the medical records of the Youth Health Care and the school doctor filled in a short experimental behaviour observation list.

On the basis of the CBCL scores, children were selected for further assessment in phase two. This phase consisted of a neuropsychological examination and an assessment of the motoric performance of the child. In both test situations, the examiners completed the behaviour observation list. The teachers also filled in this observation list. In addition, an extensive developmental questionnaire including items related to pregnancy, neonatal period, developmental milestones, physical and psychiatric illnesses in the family, and sociodemographic items was filled in partly by the parents and partly by the school doctor.

In the third phase, 1.5 years later when children were 6-8 years old, detailed psychiatric information about the children was collected. The Diagnostic Interview for Children and Adolescents (DICA-R) (Reich et al., 1992) in its Dutch version (Amsterdam Diagnostisch Interview voor Kinderen - ADIKA) (Kortenbout van der Sluijs et al., 1993) was used for structured psychiatric assessment. The parents completed an additional questionnaire containing items concerning the upbringing of their child and their need for mental help, the

\section{Figure 2. Sampling Design for the first and second Cohort "Study of Attention} Disorders in Maastricht”

tion

CBCL Selec-

At about 6

Follow-up

Years
At about 7

\section{Sampling frame}

School-based Year Cohort

$\mathrm{N}=2 \Delta \mathrm{h} h$

Selected Sample

$\mathrm{N}=789$

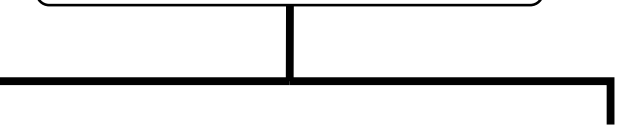

CBCL Externalising

High Risk

ADIKA

$\mathrm{N}=276$
CBCL Inter-

nalising

High Risk

Group

Control

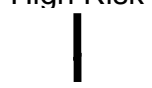

ADIKA

$\mathrm{N}=87$

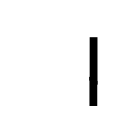

ADIKA

$\mathrm{N}=348$ 
Nijmegen Family Situation Questionnaire (NVOS) (Wels and Robbroeckx, 1996)The teachers of the children were asked to fill in the Teacher Report Form (TRF) (Verhulst et al., 1996)

Phase four took place 3 years after the start of the study and consisted of a follow-up neuropsychological assessment of the children as well as a follow-up ADIKA with the parents of the children.

In order to enlarge the study population, a second cohort of children was included in October 1998. Basically, the same procedure was followed as for the first cohort but the study ended with the third phase.

\section{The Outline of this Thesis}

The studies in this thesis deal with the results of the four phases of SAM using both cohorts and focus on the earlier mentioned aims of the study such as the distribution of the $\mathrm{AD} / \mathrm{HD}$ symptoms, the frequency of occurrence at young age, the presence of comorbid conditions, the diagnostic stability and the prevalence of treatment. A short overview of the chapters of this thesis is given below.

\section{Chapter 2: $\quad$ Attention Deficit/Hyperactive Disorder (ADHD) Review}

$\mathrm{AD} / \mathrm{HD}$ is currently the subject of public debate. In the public press, the validity of $\mathrm{AD} / \mathrm{HD}$ as a psychiatric syndrome is regularly called into question. Reference is made to various environmental factors that cause this disorder, while overdiagnosis and overtreatment are criticized. In contrast with public opinion, there has been a growing professional consensus during the past decade in the United States and in Europe, which is reflected in the publication of national and international protocols for the diagnosis and treatment of AD/HD (Brown et al., 2005; Buitelaar and Kooij, 2000; Greenhill et al., 2002; Taylor et al., 2004). The aim of this paper is to give an up-to-date overview of the scientific background of AD/HD.

Chapter 3: $\quad$ Distribution of DSM-IV symptoms in a Large Community Sample of 7 Year Old Dutch School Children

Since the release of the DSM-IV, ADHD is conceptualised as a discrete disorder of 18 symptoms clustered into 3 subtypes. This classification is based on several validity studies supporting the multidimensional approach in a 
two-factor model (inattention versus hyperactive-impulsive symptoms) of ADHD.

Recent validity studies of the DSM-IV diagnostic criteria among adults with ADHD have explored the possibility of a new conceptualisation of ADHD (Faraone et al., 2006; Kooij et al., 2005). In a large survey, Barkley and colleagues (2007 in press) found that a threshold of only 4 symptoms - instead of 6 symptoms in children - works well to identify the cases from the noncases in a normal adult population. There is one symptom, "often being easily distracted by extraneous stimuli" that rules out the normal adult sample with over $97 \%$ accuracy and a small set of 3 attention and 3 hyperactiveimpulsive items best distinguished the ADHD from the clinical control group. With respect to these findings, we describe the symptom distribution and examine the validity of the DSM-IV ADHD algorithm in a large schoolbased sample of about 7 year old Dutch children

\section{Chapter 4: $\quad$ Comorbidity Patterns in a Community Sample of 7 Year Old Dutch School Children}

Epidemiological data show that the co-occurrence or comorbidity of two or more supposedly separate child psychiatric conditions far exceeds that expected by chance. Generally, comorbidity refers to the presence of more than one mental disorder occurring in an individual at the same time. Few data is available on prevalence and comorbidity of psychiatric disorders at age 7 . This report describes the prevalence of psychiatric disorders and comorbidity patterns in a large school-based sample of about 7 year old Dutch children. It focuses on the question as to whether child psychiatric disorders are best described in well separated diagnostic categories or should be conceptualised as a continuous variation along a series of psychiatric vectors.

\section{Chapter 5: $\quad$ Diagnostic Continuity of ADHD in a Community Sample of Primary School Children: a Three Year Follow-up Study}

Persistence of ADHD over time is related to a poor long-term outcome in adolescence or adulthood. Children with persistent ADHD, thus children who continue to meet diagnostic criteria over a longer period of time, are characterized by a young age of onset, greater severity of hyperactivity and inattention symptoms, a positive family history of ADHD, high levels of psychosocial adversity, greater functional impairment, and comorbidity with a conduct disorder, bipolar disorder or multiple anxiety disorders and are 
over time related to a poor long-term outcome in adolescence or adulthood (August et al., 1998; Barkley et al., 1990; Biederman et al., 1996; Hart et al., 1995; Lavigne et al., 1998; Mannuzza et al., 1997). No research has been done on the stability of ADHD in community samples of children entering elementary school, an age at which peak-prevalence is found. The SAM study has shown, in an earlier paper, that problem behaviour in six year old children predicted psychopathology one year later (Kroes et al., 2002). However, the extent to which behavioural problems in preschool children contribute to a diagnosis of ADHD at a later stage remains unclear.

Chapter 6: The Use of Health Care Services and Psychotropic Medication in a Community Sample of 9-Year-Old School children with ADHD

In the last decade, several publications of national and international protocols show growing consensus in the diagnosis and treatment of $\mathrm{AD} / \mathrm{HD}$ (Brown et al., 2005; Buitelaar and Kooij, 2000; Greenhill et al., 2002; Taylor et al., 2004). Still, concerns have been raised about overprescription of medication and potential abuse of stimulant medication (Jensen et al., 1999; Wolraich, 1999). In Europe, no studies exist that examine the relationship between diagnostic correctness and the use of stimulants. A German study based on health insurance data gives little evidence for overtreatment because about two-thirds of the ADHD children did not receive drug therapy. (Schubert et al., 2003). In this chapter we examine the prevalence of the use of health care services and psychotropic medication within a community sample of 9-year-old school children and, more specifically, we evaluate the use of prescribed stimulants.

\section{Chapter 7: $\quad$ Concluding remarks}

In this chapter the results presented in this thesis are combined and discussed within the scope of the existing knowledge of ADHD, the implication for further research and the relevance for the clinician. 


\section{References}

Angold A, Costello EJ, Erkanli A (1999), Comorbidity. Journal of Child Psychology and Psychiatry and Allied Disciplines 40: 57-87

August G-J, Braswell L, Thuras P (1998), Diagnostic stability of ADHD in a community sample of school-age children screened for disruptive behavior. Journal of Abnormal Child Psychology 26: 345-356

Barkley RA, Fischer M, Edelbrock CS, Smallish L (1990), The adolescent outcome of hyperactive children diagnosed by research criteria: I. An 8-year prospective follow-up study. Journal of the American Academy of Child and Adolescent Psychiatry 29: 546-57.

Biederman J, Faraone S, Milberger S, Curtis S, Chen L, Marrs A, Ouellette C, Moore P, Spencer T (1996), Predictors of persistence and remission of ADHD into adolescence: results from a fouryear prospective follow-up study. Journal of the American Academy of Child and Adolescent Psychiatry 35: 343-51

Brown RT, Amler RW, Freeman WS, Perrin JM, Stein MT, Feldman HM, Pierce K, Wolraich ML (2005), Treatment of attention-deficit/hyperactivity disorder: overview of the evidence. Pediatrics 115: e749-57

Buitelaar JK (2002), Epidemiology of Attention - deficit / Hyperactivity Disorder: what have we learned over the last decade? In: Hyperactivity Disorders, Sandberg S, ed. Cambridge: Cambridge University Press, pp 30-63

Buitelaar JK, Kooij JJ (2000), [Attention deficit hyperactivity disorder (ADHD): etiology, diagnosis and treatment]. Nederlands Tijdschrift voor Geneeskunde 144: 1716-23

Buitelaar JK, Van Engeland H (1996), Epidemiological approaches to hyperactivity. In: Hyperactivity Disorders, Sandberg S, ed. Cambridge: Cambridge University Press, pp 26-68

Campbell S (1995), Behavior Problems in Preschool Children: A Review of Recent Research. Journal of Child Psychology and Psychiatry and Allied Disciplines 36: 113-149

Diagnostic and Statistical Manual of Mental Disorders, 4th ed. (1994) Washington DC: American Psychiatric Association (APA)

Dulcan M (1997), Practice parameters for the assessment and treatment of children, adolescents, and adults with attention-deficit/hyperactivity disorder. American Academy of Child and Adolescent Psychiatry. Journal of the American Academy of Child and Adolescent Psychiatry 36: 85S-121S

Faraone SV, Biederman J, Spencer T, Mick E, Murray K, Petty C, Adamson JJ, Monuteaux MC (2006), Diagnosing adult attention deficit hyperactivity disorder: are late onset and subthreshold diagnoses valid? American Journal of Psychiatry 163: 1720-9; quiz 1859

Ford T, Goodman R, Meltzer H (2003), The British child and adolescent mental health survey 1999: The prevalence of DSM-IV disorders. Journal Of The American Academy Of Child And Adolescent Psychiatry 42: 1203-1211

Gillberg C, Gillberg IC, Rasmussen P, Kadesjo B, Soderstrom H, Rastam M, Johnson M, Rothenberger A, Niklasson L (2004), Co-existing disorders in ADHD -- implications for diagnosis and intervention. European Child \& Adolescent Psychiatry 13 Suppl 1: I80-92

Greenhill LL, Pliszka S, Dulcan MK, Bernet W, Arnold V, Beitchman J, Benson RS, Bukstein O, Kinlan J, McClellan J, Rue D, Shaw JA, Stock S (2002), Practice parameter for the use of stimulant medications in the treatment of children, adolescents, and adults. Journal of the American Academy of Child and Adolescent Psychiatry 41: 26S-49S

Hart EL, Lahey BB, Loeber R, Applegate B, Frick PJ (1995), Developmental change in attentiondeficit hyperactivity disorder in boys: a four-year longitudinal study. Journal of Abnormal Child Psychology 23: 729-49.

International Classification of Diseases, 10 th. Ed. (1990) Geneva: World Health Assembly

Jensen PS, Kettle L, Roper MT, Sloan MT, Dulcan MK, Hoven C, Bird HR, Bauermeister JJ, Payne JD (1999), Are stimulants overprescribed? Treatment of ADHD in four U.S. communities. Journal of the American Academy of Child and Adolescent Psychiatry 38: 797-804

Kooij JJ, Buitelaar JK, van den Oord EJ, Furer JW, Rijnders CA, Hodiamont PP (2005), Internal and external validity of attention-deficit hyperactivity disorder in a population-based sample of adults. Psychol Med 35: 817-27

Kortenbout van der Sluijs M, Levita D, Manen R, Defares P (1993), In: ADIKA, Amsterdams Diagnostisch Interview voor Kinderen en Adolescenten Lisse: Swetz and Zeitlinger

Krain AL, Castellanos FX (2006), Brain development and ADHD. Clin Psychol Rev 8: 8 
Kroes M, Kalff AC, Kessels AG, Steyaert J, Feron FJ, van Someren AJ, Hurks PP, Hendriksen JG, van Zeben TM, Rozendaal N, Crolla IF, Troost J, Jolles J, Vles JS (2001), Child psychiatric diagnoses in a population of Dutch schoolchildren aged 6 to 8 years. Journal of the American Academy of Child and Adolescent Psychiatry 40: 1401-9Kroes M, Kalff AC, Steyaert J, Kessels AG, Feron FJ, Hendriksen JG, van Zeben TM, Troost J, Jolles J, Vles JS (2002), A longitudinal community study: do psychosocial risk factors and child behavior checklist scores at 5 years of age predict psychiatric diagnoses at a later age? Journal of the American Academy of Child and Adolescent Psychiatry 41: 955-63

Lahey BB, Pelham WE, Loney J, Kipp H, Ehrhardt A, Lee SS, Willcutt EG, Hartung CM, Chronis A, Massetti G (2004), Three-year predictive validity of DSM-IV attention deficit hyperactivity disorder in children diagnosed at 4-6 years of age. American Journal of Psychiatry 161: 2014-2020

Lavigne JV, Arend R, Rosenbaum D, Binns HJ, Christoffel KK, Gibbons RD (1998), Psychiatric disorders with onset in the preschool years: I. Stability of diagnoses. Journal of the American Academy of Child and Adolescent Psychiatry 37: 1246-54.

Liddell FDK (1988), The Development of Cohort Studies in Epidemiology - a Review. Journal of Clinical Epidemiology 41: 1217-1237

Mannuzza S, Klein R-G, Bessler A, Malloy P, Hynes M-E (1997), Educational and occupational outcome of hyperactive boys grown up. Journal of the American Academy of Child and Adolescent Psychiatry 36: 1222-1227

Neale MC, Kendler KS (1995), Models of Comorbidity for Multifactorial Disorders. American Journal of Human Genetics 57: 935-953

Pineda D-A, Ardila A, Rosselli M, Arias B-E, Henao G-C, Gomez L-F, Mejia S-E, Miranda M-L (1999), Prevalence of attention-deficit/hyperactivity disorder symptoms in 4- to 17-year-old children in the general population. Journal of Abnormal Child Psychology 27: 455-462

Reich W, Shayla JJ, Taibleson C (1992), The Diagnostic Interview for Children and Adolescents Revised (DICA-R) (structured psychiatric interview). St Louis, MO: Washington University.

Rowland AS, Umbach DM, Catoe KE, Stallone L, Long S, Rabiner D, Naftel AJ, Panke D, Faulk R, Sandler DP (2001), Studying the epidemiology of attention-deficit hyperactivity disorder: screening method and pilot results. Canadian Journal of Psychiatry 46: 931-40

Rushton JL, Fant KE, Clark SJ (2004), Use of practice guidelines in the primary care of children with attention-deficit/hyperactivity disorder. Pediatrics 114: E23-E28

Scahill L, Schwab-Stone M (2000), Epidemiology of ADHD in school-age children. Child and Adolescent Psychiatric Clinics of North America 9: 541-555

Schubert I, Köster I, Adam C, Ihle P, Döpfner M, Lehmkuhl G (2003), Psychotropic Drugs for Children with the Claims Diagnosis "Attention Deficit/Hyperkinetic Disorder". A Drug Utilisation Study of Outpatient Care with Person-Related Data of the Statutory Health Insurance (Versichertenstichprobe AOK Hessen/ KV Hessen, 1998-2001) Zeitschrift für Gesundheitswissenschaften 11: 306-324

Szatmari P, Offord D-R, Boyle M-H (1989), Ontario Child Health Study: Prevalence of attention deficit disorder with hyperactivity. Journal of Child Psychology and Psychiatry and Allied Disciplines 30: 219-230

Taylor E, Dopfner M, Sergeant J, Asherson P, Banaschewski T, Buitelaar J, Coghill D, Danckaerts M, Rothenberger A, Sonuga-Barke E, Steinhausen HC, Zuddas A (2004), European clinical guidelines for hyperkinetic disorder -- first upgrade. European Child \& Adolescent Psychiatry 13: I730

Verhulst F, Van der Ende J, Koot H (1996), In: Handleiding voor de CBCL Rotterdam: Erasmus University/ Departement of Child and Adolescent Psychiatry, Sophia Children's Hospital

Wels PMA, Robbroeckx LMH (1996), Manual of Nijmeegse Questionnaire for Educational Situation Lisse: Swets and Zeitlinger BV

Wender E-H (2002), Attention-deficit/hyperactivity disorder: Is it common? Is it overtreated? . Archives of Pediatrics \& Adolescent Medicine 156: 209-210

Wolraich M-L (1999), Attention deficit hyperactivity disorder: The most studied and yet most controversial diagnosis. Mental Retardation and Developmental Disabilities Research Reviews 5: 163168

Wolraich ML, Hannah JN, Pinnock TY, Baumgaertel A, Brown J (1996), Comparison of diagnostic criteria for attention-deficit hyperactivity disorder in a county-wide sample. Journal of the American Academy of Child and Adolescent Psychiatry 35: 319-324 
Chapter 2

ADHD Review: Symptomatology

Diagnosis and Treatment 


\section{Introduction}

Attention Deficit/Hyperactivity Disorder (ADHD) is a fairly common syndrome in child psychiatry: it disrupts the development of an estimated 3\% to $5 \%$ of school-age children (Buitelaar, 2002). ADHD is found to occur four times more frequently in boys than in girls of school age.

This childhood psychiatric disorder is currently the subject of public debate, and probably even more so than any other psychiatric disorder. In the public press, the validity of ADHD as a psychiatric syndrome is regularly called into question. Reference is made to various environmental factors that cause this disorder, while overdiagnosis and overtreatment is criticized. There is great concern about the increasing prescription of stimulants in the United States and in many European countries, including Belgium. Furthermore, the safety of this medication has been questioned more than once.

By contrast with public opinion, there has been a growing professional consensus during the past decade in the United States and in Europe, which is reflected in the publication of national and international protocols for the diagnosis and treatment of $\mathrm{AD} / \mathrm{HD}$ (Brown et al., 2005; Buitelaar and Kooij, 2000; Greenhill et al., 2002; Taylor et al., 2004).

The aim of this paper is to give an up-to-date overview of the scientific backgrounds of ADHD, the diagnosic criteria and treatment.

\section{A Definition of Attention Deficit Hyperactivity Disorder}

In terms of pattern of complaints, the syndrome belongs to the group of "externalizing behavior disorders”. Nosologically, ADHD is a developmental disorder (Barkley, 1998; Taylor, 1999). This means that it is a disorder which begins early in the child's development and will influence the development of the majority of the persons affected into adulthood. It has an impact on the way the child functions as an individual, the way he functions in his family and interacts with his peers, and on his performance at school. It is in this respect that children with ADHD differ from hyperactive children. Behavior problems such as inattention, busy or impulsive behavior occur now and then in most children, especially if they are tired or if they are confronted with exciting events, school trips, etc. However, not all hyperactive children have ADHD.

There are two diagnostic classification systems to describe this pattern of complaints. The DSM-IV-TR (2000), which is the most frequently used internationally and particularly in 
Table 1. Diagnostic Criteria of ADHD According to DSM-IV-TR

A. At least six of the following symptoms must have been present for at least six months to a point that is disruptive and inappropriate for developmental level:

Attention deficit Hyperactivity/impulsivity

No attention to details $\quad$ Fidgets with hands or feet

Trouble keeping attention

Often does not seem to listen

Often gets up from seat in classroom or in other places

Fails to finish tasks and ac-

Often runs about or climbs

tivities

Unable to organize tasks

Has trouble playing quietly

Avoids prolonged mental

Is often on the go

effort

Often loses things

Blurts out answers

Easily distracted by external

stimuli

Often forgetful

Has trouble waiting his/her turn

Interrupts or intrudes on others

Talks excessively

B. Some symptoms of hyperactivity/impulsivity or inattention that cause impairment were present before the age of seven.

C. Some impairment from the symptoms is present in two or more settings (e.g. at school, work and home).

D. Significant impairment in social, school, or work functioning.

E. The symptoms do not happen only during the course of a pervasive developmental disorder, schizophrenia, or other psychotic disorder, and are not better accounted for by another mental disorder (e.g. mood disorder, anxiety disorder, dissociative disorder, or a personality disorder).

the US, speaks of ADHD and uses broader criteria than the ICD-10 (1990) diagnosis 'Hyperkinetic Disorder'. An overview of the DSM-IV-TR criteria is given in Table 1. Both classification systems define the three symptom clusters of attention disorders, impulsivity and hyperactivity. All clusters must be present in the ICD-10 hyperkinetic disorder, whereas the DSM-IV-TR distinguishes three subtypes: the inattentive, the hyperactive/impulsive and the combined subtype. The hyperactive/impulsive subtype refers to impulsive hyperactive children without attention problems and was introduced in 1994. Not much is known yet about this subtype. It is mainly observed in children under 7 years of age and might be a precursor of the combined type (Lahey et al., 1994). The inattentive type often goes undiagnosed because there are relatively few external symptoms of troubled behavior. 
Further criteria for the two disorders are that the problems must manifest themselves for at least six months before the age of seven and that certain symptoms (pervasively) impede the child's functioning in various environments. Examples include deadlocked upbringing conditions, social isolation because other children start to avoid the hyperactive child, learning difficulties, and low self-esteem caused by a greater fear of failure. The criteria for this pervasiveness are stricter in the hyperkinetic syndrome, where the attention problems and the hyperactivity/impulsivity problems must be present in more than one situation. It is therefore clear that each diagnosis of hyperkinetic disorder must also satisfy the criteria of the combined ADHD subtype.

The ICD-10 is designed to arrive at a unique diagnosis; the presence of co-morbidity (the simultaneous occurrence of several disorders), however, does not in principle permit a diagnosis. The presence of another disorder, such as depression, will not influence the DSMIV-TR diagnosis, unless the pattern of behavior is more in keeping with that disorder. In the ICD-10, an autism-related disorder, a manic or depressive period and an anxiety disorder will rule out the diagnosis of hyperkinetic disorder. The high co-morbidity of ADHD and ODD/CD led in the ICD-10 to the combined diagnostic group "hyperkinetic conduct disorder" where the criteria for both hyperkinetic disorder and CD must be present.

\section{Clinical Implications}

Children with ADHD are troubled by their behavior in many different respects. This problem manifests itself at school, within the family and in contacts with peers.

The school results usually fall short of what can be expected from the child, or they are highly variable (Faraone et al., 1993). The reason for this is that the children fail to take in part of the subject material, or they find it difficult to organize themselves, or they do not study so well. Test results are poorer due to inattention and impulsivity. The children do not always manage to finish their homework and to hand it in on time. As a result, they often have to stay down a grade or they are referred to a less demanding type of education.

The behavior problems frequently lead to constant irritation of parents, teachers and peers. In the classroom, children with ADHD are more frequently punished, kept in detention or referred to classes with more intensive supervision (Faraone et al., 1993). Peers and adults will more readily repudiate such children because of their aggression, impulsivity and failure to obey rules and agreements (Hoza et al., 2005).

The extent to which the children themselves are troubled by their ADHD behavior is very much dependent on the seriousness and type of ADHD. Children with ADD without the 
hyperactivity (DSM III, corresponds roughly to ADHD inattentive type in DSM IV) are more readily characterized as lazy, absent-minded and withdrawn. They will more often stay down a grade and more frequently experience depression or anxiety disorders. They will show fewer antisocial behavior problems, they will be less aggressive or impulsive, and are better tolerated by the people around them (Lahey et al., 1994; Weiss et al., 2003).

Detailed research has been done into the clinical differences between boys with ADHD and girls with ADHD. Whereas initially there were thought to be very marked differences between the two gender groups, this view has been qualified by recent research (Biederman and Faraone, 2004; Biederman et al., 2005; Faraone et al., 2000a; Gaub and Carlson, 1997; Greene et al., 2001). Gaub and Carlson (1997) found that girls in both the treated and untreated group displayed less oppositional and antisocial behavior. The Massachusetts General Hospital study (Biederman and Faraone, 2004; Biederman et al., 2005) concluded that previously reported differences between boys and girls were due to the selection by clinical referral (referral bias). In a non-clinical population, no difference was found between the two genders in terms of DSM-IV subtype, psychiatric co-morbidity or treatment. Girls showed a similar cognitive, psychosocial, educational and family functioning profile.

\section{Aetiology and Pathogenesis}

The exact cause of the problematic behavior that is observed with ADHD is still unknown. Research into environmental factors, genetics, neurological imaging and neurobiological research suggest a neuro-bio-psychological explanatory model. Investigation into the causes of ADHD no longer focuses on a unique factor, but on the interaction between genes and environment.

A birth weight of less than 2500 grams (Mick et al., 2002), and especially a birth weight of less than 1500 grams and/or a pregnancy term of less than 32 weeks, complicated by periventricular white matter lesions (Whitaker et al., 1997), increases the risk of ADHD. Prenatal exposure to nicotine (Fergusson et al., 1998; Milberger et al., 1996) and alcohol (Huizink and Mulder, 2006), probably in combination with hereditary factors, are additional aggravating environmental factors. Biederman (Biederman et al., 1995) reports that a number of family factors strongly increase the incidence of ADHD, such as serious marital problems, a low socioeconomic status, large families, criminal behavior of the father, psychiatric disorders in the mother and placement with a foster family. A messy and chaotic household situation and a lack of regularity and structure are also conducive to the development of ADHD. The same goes for constant expressions of hostility, criticism and disapproval of the child (Woodward et al., 1997). 
Results of behavioral genetic and molecular genetic studies show that both genetic and nongenetic factors contribute to the development of ADHD (Bobb et al., 2004; Faraone et al., 2005). Family, twin and adoption studies demonstrate that genes play a significant role in the likelihood of developing ADHD. The likelihood of ADHD in brothers or sisters of a child with ADHD is three to five times greater than in the ordinary population. Among second-degree relatives the risk is two times greater (Faraone et al., 1994). There are 20 twin studies which on the basis of a meta-analysis estimate the hereditability of ADHD at 76\% (Faraone et al., 2005). Molecular genetic studies show that ADHD has a complex genetic architecture. The many studies investigating candidate genes for ADHD advance seven candidate genes: DRD4, DRD5, DAT, DBH, 5-HTT, HTR1B and SNAP-25, which are responsible for the dopamine D4 and D5 receptors, and the dopamine and serotonin transporters respectively (Bobb et al., 2004). The results that were published for certain candidate genes were combined in a meta-analysis in order to test their association with ADHD. The occurrence of DRD4 7-repeat (OR=1.34, 95\% CI 1.23-1.45) and 5-repeat (OR=1.68, 95\% CI 1.17-2.41) allele and of DRD5 148-bp allele (OR=1.34, 95\% CI 1.21-1.49) increased the risk of ADHD, whereas the DRD4 4-repeat (OR=0.90, 95\% CI 0.84-0.97) and DRD5 136-bp (OR=0.57, 95\% CI 0.34-0.96, $\mathrm{P}=0.022$ ) allele had a protective effect (Li et al., 2006). In this meta-analysis, no convincing association could be found of the 480-bp allele of DAT gene (OR=1.04, 95\% CI 0.98-1.11) with ADHD. These findings show that especially the dopamine metabolism is involved in the development of ADHD. The International Multi-center ADHD Genetics Project (IMAGE) investigates 51 candidate genes in a population of 776 children with DSM-IV ADHD combined subtype. The first analyses show that 18 genes have one or several significant alleles, including the most replicated candidate genes DRD4 and DAT1 (Brookes et al., 2006).

Several studies using structural (CT and MRI scan) and functional imaging (Functional MRI, PET and SPECT scan) investigated neuroanatomical and neurochemical differences in various areas of the brain.

Morphologically it was shown that several areas in the brain of children with ADHD are smaller than those of their peers. Differences were found in the prefrontal, temporal and parietal cortex, parts of the cerebellum, corpus callosum and at least two nuclei of the basal ganglia (Castellanos et al., 1996). Investigators have concluded from this that ADHD must be the result of a disruption very early on in the development of the brain.

The right prefrontal cortex is thought to be responsible for behavior modulation, resistance to distraction, and self-awareness. The nucleus caudatus and the globus pallidus help to inhibit automatic responses, so that the cortex can give a more carefully considered response to a stimulus and the neurological output can be coordinated by the different areas of the cortex. The precise role of the cerebellar vermis is not yet clear (Barkley, 1998). All these 
disorders originate early on in the development, they are non-progressive and are not the result of treatment with stimulants (Castellanos et al., 2002)

ADHD is probably a disorder of at least two neurotransmitter systems: the dopamine system and the noradrenalin system. Medicines for treating ADHD have an impact on those systems. Methylphenidate, the most commonly prescribed medication for ADHD, increases metabolic activity in the frontal areas of the brain (Vaidya et al., 1998) and the ventral basal ganglia (Shafritz et al., 2004). Because methylphenidate derives its action from binding to the dopamine transporter, it is assumed that the hypoactive frontostriatal circuits are due to a deficient dopaminergic neurotransmission. This is in line with the genetic findings.

\section{Child Psychiatric Comorbidity}

Several studies have shown that children with ADHD run an increased risk of developing other childhood psychiatric disorders besides ADHD. In that case we speak of comorbidity, which means that two or more disorders occur simultaneously (Angold et al., 1999; Gillberg et al., 2004). The incidence of comorbidity with ADHD is more the rule than exception in both clinical and epidemiological studies (Buitelaar and Van Engeland, 1996).

Half of those children will have an oppositional-defiant behavior disorder besides ADHD, while $30 \%$ to $50 \%$ will display antisocial behavior. The combination with rebellious and aggressive behavior is found especially in boys who have the combined or hyperactive/impulsive ADHD type; the prognosis is relatively unfavorable (Biederman et al., 2006).

Mood disorders are reported in $15 \%$ to $20 \%$ of the children, while anxiety is observed in $20 \%$ to $25 \%$. The combination with anxiety disorders is more frequent in the inattentive

Table 2. Prevalence of Comorbidity with ADHD

\begin{tabular}{ll}
\hline Comorbidity & Percentage \\
\hline & \\
Oppositional-defiant disorder & $50 \%$ \\
Antisocial behavior disorder & $30-50 \%$ \\
Mood disorders & $15-20 \%$ \\
Anxiety disorders & $20-25 \%$ \\
Problems with fine and gross motor skills & $25 \%$ \\
Learning disorders & $30-40 \%$ \\
Tic disorders & $10-30 \%$ \\
Autism and related disorders & $10-20 \%$ \\
Substance abuse (alcohol, drugs) & $10-20 \%$ \\
& \\
\hline
\end{tabular}


subtype and in girls with ADHD (Gaub and Carlson, 1997). Chronic tics and Gilles de la Tourette's syndrome are also often described with ADHD behavior (Biederman et al., 1991)

Depending on the criteria that are used, ADHD behavior is observed in $30 \%$ to $40 \%$ of children with learning disorders. Speech disorders and retarded linguistic development are frequently reported. Motor awkwardness in both gross and fine motor skills occurs in 25\% of the children (Taylor et al., 1991).

The link between ADHD and substance abuse is a complex one (Lynskey and Hall, 2001). There is an increased prevalence of ADHD among the group of drug addicts who seek help. The drug addicts with ADHD were younger when they first came into contact with care providers, and their addiction began earlier with more intense and extensive drug abuse and a higher comorbidity with alcoholism (Lambert and Hartsough, 1998). Several studies show a link between ADHD and substance abuse (Barkley et al., 1990; Biederman et al., 1998; Hechtman and Weiss, 1986; Mannuzza et al., 1988; Wilens and Biederman, 2006), yet the high correlation between childhood ADHD and drug abuse later in life is substantially explained by the association of a third disorder, namely antisocial behavior (Lynskey and Hall, 2001). In the absence of a comorbid antisocial behavior disorder, no increased risk of substance abuse is reported in men, whereas in women ADHD is thought to have an impact on substance abuse.

We will not discuss the comorbidity of bipolar disorders with ADHD any further in this article. The main criteria for mania are megalomania and increased activity. Whether or not those symptoms occur in childhood remains a controversial point.

The occurrence of comorbidity determines to a considerable extent the prognosis and outcome of ADHD. Children with ADHD and learning disorders will obviously have a more difficult time at school than children with ADHD only. The incidence of antisocial behavior can have a greater long-term impact than ADHD as such. It causes adolescents to get into trouble with the law and to end up in a criminal environment. Furthermore, children with ADHD and mood disorders are found to run a greater risk of suicide or prolonged debilitating admission to a psychiatric hospital. It is therefore very important that those children are detected and treated early (Biederman et al., 2006).

\section{Differential Diagnosis and Comorbidity}

An ADHD diagnosis can be complexed with another disorder (comorbidity); on the other hand, when a child is examined for ADHD, the possibility should be borne in mind that the child may suffer from a different psychiatric disorder (differential diagnosis). The distinction between comorbidity and differential diagnosis is not dependent on the disorder. A disorder can be a differential diagnosis or comorbidity. For example, ADHD may be accompa- 
nied by serious learning disorders, although conversely a learning disorder can be presented as a concentration problem.

Psychiatric disorders such as anxiety and depression can cause hyperactive behavior. Pervasive developmental disorders may be accompanied by hyperactivity, but the presence of autistiform behavior may justify an autism-related disorder. Acute adaptive and attachment disorders can be differentiated from ADHD by the difference in their course. Organic encephalopathy with hyperactivity should be seen as an etiological explanation for the hyperactivity rather than as a differential diagnosis. Similarly, mental retardation does not rule out an ADHD diagnosis if the attention deficit or hyperactivity is more marked than is justified by the functional age of the child.

\section{Diagnosis}

A distinction should be made between primary and secondary diagnosis. It is important that the primary care provider detects the symptoms of ADHD so that proper referral can take place. This can be done with the ADHD checklist for parents and teachers (Conners, 1998). A thoroughgoing physical examination of the child must take place in order to rule out any underlying pathologies, loss of hearing or eyesight, or epilepsy.

The secondary care provider must first assess whether the complaints are consistent with an ADHD problem and justify a more extensive examination or whether other recommendations may be formulated. An investigation into ADHD is always a multidisciplinary exercise and comprises a clinical interview with the parents and with the child individually, gathering of information about how the child functions at school or in the crèche, a physical assessment, and behavior observation during the clinical interviews and tests. If school and/or learning problems are reported, an intelligence test, determination of school performance level, and attention and impulsivity-related tasks may be performed if indicated. All of this should preferably take place in a multidisciplinary setting.

\section{Clinical Interview with the Parents}

The clinical interview with the parents should consist of a history of complaints or problems, a developmental history and a family history. It is important that, besides child factors, environmental factors in the broadest sense should be taken into consideration, with an inquiry into both protective and risk-enhancing influences on the child. Environmental factors such as upbringing and education as such will not cause ADHD, but they can influence the effects of ADHD. Children with ADHD who have positive experiences in social 
relations will develop a more positive self-image. Serious behavior problems at school as a result of ADHD will seriously hamper the child's school career.

The complaints history involves making an inventory of the problematic behavior in general and of the ADHD-related problems in particular. Apart from the core symptoms of ADHD, the presence of comorbidities, the discomfort caused by the symptoms and the level of dysfunction should be investigated as well.

It may be a good idea to let the parents formulate their opinion by means of a general behavior checklist, such as the CBCL of Achenbach (Achenbach, 1991a) or a specific ADHD behavior checklist, such as the Conners Rating Scales (Conners et al., 1998a). This allows the child to be assessed in an objective and standardized manner. Nevertheless, the parents ultimately remain responsible for the data input.

The purpose of the developmental history, besides obtaining a picture of the child's development in general, is to put the problematic behavior in the perspective of this development so that the course of this behavior can be evaluated. Perinatal complications, developmental milestones and the social development are charted along with the environmental factors that have an impact, such as life events and acute and chronic stressors.

In the family history, an attempt is made to trace hereditary factors that contribute to the development of the ADHD syndrome. The occurrence of ADHD in the family has consequences for the prognosis and treatment. The occurrence of ADHD in one of the parents is frequently associated with disrupted family relations and family dysfunction (Biederman et al., 2002). This family dysfunction will in turn adversely impact on the consequences of ADHD for the child, with an increase in the seriousness and impact of the symptoms. Very recent research, including investigation into genetic variations in the DAT1 gene (Gilbert et al., 2006), show differences in neurophysiological response to medication in the case of both methylphenidate and atomoxetine. Although such research findings cannot yet be immediately implemented in clinical practice, they do demonstrate the significance of the family history. In this connection, the response to medication in nephews and nieces should be investigated.

It is important to gain an insight into how the family functions. Family relations are often seriously disrupted as a result of the ADHD problem. 


\section{Clinical Interview with the Child}

The observation of and interview with the child should focus on specific aspects of the child's functioning such as making contact, mood, oppositional and aggressive behavior, linguistic and motor development, social functioning, attention span, specific oversensitivities or undersensitivities, play themes, anxiety, compulsiveness, rigidity, tics etc, besides the general problem definition. During the observations, specific attention will be paid to comorbid disorders and associated psychosocial problems. It is also important to gain an insight into the motivation for treatment and the level of suffering. The individual contacts with the child must include structured and free (play) moments. For older children and adolescents, observation may consist of one or several interviews.

Since children with ADHD generally display fewer or no ADHD symptoms in one-to-one contacts and in new situations, several contacts may be necessary.

\section{Information from the School or Crèche}

If parents agree, it is essential to obtain information from the teacher (or carer) about behavior problems, developmental and social functioning, situational differences in behavior, and behavior symptoms that suggest comorbid or differential diagnoses. The school is not only a second situation where the ADHD symptoms may or may not manifest themselves, but also the environment where children with ADHD experience many difficulties: their ability to concentrate, to be engaged in one and the same activity quietly and for a long time, and to think before answering is put to the test in that setting.

There are several standardized observation checklists. The most commonly used instrument to probe into general behavior problems is the Teacher Report Form (TRF) (Achenbach, 1991b), which is a teacher's version of the CBCL. In addition, there are many ADHDspecific observation checklists in use, such as the Conners Rating Scales for teachers (Conners et al., 1998b). It is advisable to use the two (general and specific) questionnaires. A problem-defining interview or questionnaire with the teacher and other relevant educational personnel is recommended to evaluate the teacher's coping style and the teacher-child relationship.

\section{Physical Evaluation}

The physical examination is primarily intended to detect a number of somatic disorders such as epilepsy, thyroid disease or more specific metabolic diseases and/or genetic disorders, 
such as phenylketonuria, G6PD deficiency, neurofibromatosis, Williams syndrome, fragile $\mathrm{X}$ syndrome. These disorders may explain the behavior disorders and/or be potential contraindications for medication. Somatic comorbidity also needs to be detected which may necessitate referral for a specialist somatic examination. A somatic examination is not necessary if a previous medical screening has revealed that the child is in general good health, has a normal growth, a clean medical history and developmental neurological history, no congenital abnormalities, normal hearing and normal vision.

The additional developmental neurological examination consists of a detailed medical history, an investigation into specific neurological characteristics, measurement of the cranial circumference, and determination of the neurological development level (motor skills). An EEG is only necessary in order to differentiate between ADHD and epilepsy and a number of other fairly rare neurological syndromes. Additional somatic examinations are performed if specifically indicated.

\section{Psychometric Tests}

A diagnostic psychometric test for ADHD does not exist. Additional psychometric tests may be indicated for various reasons. For example, it may be interesting to determine the intelligence level and profile of the child (e.g. WIPPSI-R, RAKIT, WISC III, WAIS III). Potential learning disorders or problems with school performance can be detected by appropriate testing procedures. All sorts of specific function tests are also available to determine attention, motivation to perform a task, impulsivity, structuring ability, and memory.

In these tests, not only the standard scores are relevant, but the observation of how the child behaves during the tests and how it sets about solving the tests will also be useful.

\section{Treatment Options}

The treatment of ADHD is multimodal (Brown et al., 2005; Buitelaar and Kooij, 2000; Greenhill et al., 2002; Taylor et al., 2004), with emphasis on breaking the negative spiral in the child's development as the core principle. Any treatment must be backed up by extensive information and psychoeducation and must be adequately geared to the child, care providers, parents and school.

However, there is no causal and definitive treatment for ADHD. The main goal of ADHD treatment is secondary prevention, which consists in timely treatment to try and limit the ADHD complaints to a functional minimum and to treat any comorbidity that occurs. It is 
the comorbidity which in the long term poses the greatest individual limitations and social burden (Taylor et al., 1996).

\section{Psycho education}

Making and explaining the diagnosis in itself already has a therapeutic effect. It is important to assess how the child and its parents come to terms with the diagnosis and what their expectations are in terms of treatment. The physician must be sufficiently familiar with the ADHD syndrome and its impact on the whole of everyday life, school performance and social functioning. Treatments must be designed to help the child, parent or teacher identify specific problem situations and to resolve those using specific behavior therapeutic techniques. Most of those techniques are based on encouraging and reinforcing behavior, offering a clear structure with clear instructions, and responding appropriately to problematic behavior.

\section{Medication}

Psychostimulants and preferably the long-acting psychostimulants are the preparations of first choice (Banaschewski et al., 2006; Taylor et al., 2004). In Belgium, methylphenidate is most commonly prescribed, and to a lesser extent dextroamphetamine. These products have a positive effect in more than $70 \%$ of children with ADHD (Cantwell, 1996). Doctors in Europe are traditionally more wary of psychostimulants than in the USA, where failure to prescribe psychostimulants is treated as a case of serious medical misconduct. The effect of methylphenidate has been extensively investigated. At the physiological level, psychostimulants in ADHD individuals are shown to stimulate the dopamine and noradrenalin in the synapse and to inhibit reabsorption by the transporter. These substances have an effect on the core symptoms of ADHD, comorbidity, educational performance, and the child's social functioning in the family and at school (Barkley, 1990; Pearson et al., 2004).

The efficacy of methylphenidate is not typical of or restricted to children with ADHD, but is also observed in 'normal' children. Children with sub-threshold ADHD who have relatively major problems in the family, at school or elsewhere can experience a positive effect from methylphenidate. Medication should only be given to those groups in individual cases, after a specialized diagnosis, and with careful evaluation in child psychiatry. The available data do not apply indiscriminately to other groups, such as very young children. Considerable caution should be observed when prescribing methylphenidate for young children, since no development-specific diagnostic criteria are available for this group, no scientifically valid guidelines exist for the dosage, and it is not known whether pharmacokinetic properties 
change when tablets are dissolved or pulverized for administration to very young children. In animal experiments, administration of methylphenidate at critical moments in the development of the brain resulted in unique biological changes (Penner et al., 2002). Treatment with methylphenidate is equally efficacious in adults with ADHD as in children, and an average dose of $1.1 \mathrm{mg} / \mathrm{kg} /$ day is suggested (Spencer et al., 2005). It is not advisable to test the effect of psychostimulants in children with non-specific behavior problems.

The clinical effect can be seen soon after intake; maximum efficacy is observed after 1.5 hours and the half-life is about 2 hours. The clinical effect is gone after 3 to 4 hours. In view of these pharmacokinetic properties, frequent dosing throughout the day is necessary for an optimal result, preferably according to a schedule of 3 doses, namely in the morning, at midday and when the child returns home from school in the late afternoon. The dose is 0.3-0.6 $\mathrm{mg} / \mathrm{kg}$ per intake, the third dose being somewhat lower than the morning and midday dose. Therapy adherence and timely dosing are important to avoid fluctuations in behavior. This is not always easy to accomplish in this patient group. A long-acting preparation is therefore always preferable for reasons of the clinical effect and patient compliance. There are two long-acting preparations available on the Belgian market. Rilatine MR exists in doses of $20 \mathrm{mg}$ and $30 \mathrm{mg}$ and is efficacious for 8 to 10 hours on average. Concerta has an effect that lasts for 10 to 12 hours and is available in doses of $18 \mathrm{mg}, 36 \mathrm{mg}$ and $54 \mathrm{mg}$.

The safety and efficacy of the product in the short term and for children aged 5 to 14 is well documented, whereas safety and efficacy in case of prolonged use and in the long term is not known (Prince, 2006). The most frequently reported adverse effects are inhibition of appetite, difficulty going to sleep, mood fluctuations, increased irritability and rebound phenomena. Contraindications are known hypersensitivity to methylphenidate, glaucoma, known cardiovascular disorders, hyperthyroidism and hypertension. Disturbing public reports have recently appeared about deaths from heart problems caused by the use of psychostimulants, yet thoroughgoing investigation by the FDA did not reveal any cardiovascular risk. Other controversial adverse effects are tics or a positive family history of tic disorders, epilepsy and retarded growth. The recent literature does not show any worsening of tics (Gadow et al., 1999; Kurlan and Group., 2002; Palumbo et al., 2004) or epilepsy caused by methylphenidate (Gross-Tsur et al., 1997; Gucuyener et al., 2003). However, growth may be retarded in childhood, so that medication-free periods could be advisable (Spencer et al., 1996). No adverse effects were reported in more than 35\% of the children who received medication in the MTA study (Jensen et al., 2001), and only mild side-effects in around half of the children; more than $11 \%$ had moderate and nearly $3 \%$ serious adverse effects. Lower medication dosage in combined treatment might therefore be advisable.

Dexamphetamine is available in Belgium as a magistral preparation only. Clinically, the effects closely resemble those of methylphenidate, except that the dose must be halved. 
Dexamphetamine may be indicated in children with ADHD who do not sufficiently respond to methylphenidate.

Atomoxetine, a non-stimulant, specific norepinephrine reuptake inhibitor with a structure similar to fluoxetine has only recently become available in Belgium. Its efficacy in the treatment of ADHD has already been extensively described (Michelson et al., 2001). It will come to replace the older conventional antidepressants such as imipramine and nortryptiline. The recommended dosage is $1.2 \mathrm{mg} / \mathrm{kg} /$ day given in a single dose with an effect lasting 24 hours. Optimal efficacy is achieved after six weeks. The most frequently reported adverse effects are drowsiness, diminished appetite, nausea, vomiting, tiredness and stomach complaints. The safety studies conducted among more than 4000 children and adults who used the medicine for up to 12 weeks did not reveal any serious problems. Since the product has not been investigated in children under 6 , caution is recommended for that age group.

Besides psychostimulants, clonidine, tricyclic antidepressants and moclobemide are used as medication for ADHD. They should be considered second or third choice preparations (Taylor et al., 2004).

\section{Behavior Therapeutic and Psychosocial Treatment}

It has been found that children with ADHD generally have a negative impact on the behavior of their educators (Anderson et al., 1994). The result is a vicious circle in which parents and children maintain each other's negative behavior (Fletcher et al., 1996). It has been shown that hyperactive and impulsive behavior, conflicts and contrariness of children with ADHD diminish significantly following behavior therapeutic training for parents (Anastopoulos et al., 1993; Hinshaw et al., 2000). The recent MTA study (MTA Cooperative Group, 1999) provides corroboration, albeit indirectly, of the effectiveness of behavior therapeutic training of parents in significantly reducing the core symptoms and the additional behavior problems, improving parental and family functioning, and permitting lower medication doses, yet points to the high cost of this form of therapy (see below).

\section{Diet}

So far there is insufficient evidence to recommend any particular diet schedule in the treatment of ADHD. The composition of these preparations is not supervised by the public authorities, and their use is not without risk (Taylor et al., 2004). 


\section{An Integrated Treatment Model for ADHD}

Generally speaking, the two cornerstones of ADHD treatment are medication and behavior therapeutic/psychosocial treatment. In 1996, the National Institute of Mental Health (NIH) in the US set up a Collaborative Multimodal Treatment Study of Children with ADHD, or MTA study for short (Arnold et al., 1997). The purpose of this study was to investigate the short- and long-term efficacy of medication and psychosocial treatment modes. In a multicenter design, 579 children aged 7 to 10 were assigned at random to one of four treatment lines: treatment with medication, psychosocial treatment and a combination of the two. A fourth, control group was given standard community care. The protocol of each treatment line pursued the best possible outcome according to the current views. The medication strategy provided, besides detailed information, that the optimal individual starting dose and adjustments be determined according to an algorithm (Greenhill et al., 1996). The psychosocial treatment strategy provided for several behavior therapeutic actions for parents, school and child, with a great deal of fine-tuning and personal continuity. The treatment phase lasted 14 months, whereas the follow-up study went on for another four years.

The three protocolled treatment lines proved to have a substantially greater effect than the community care, with the medication and combined treatment having a greater impact on the core symptoms (Group, 1999). In the combined treatment, the behavior therapy added very little to the effect of the medication component on the core symptoms of ADHD, whereas conversely medication added considerably to the effect of behavior therapy. A clear dose effect was observed with a lower dose in the combination group than in the medication group (Vitiello et al., 2001). In terms of outcomes in a number of other areas (oppositional disorder, depression, learning performance, parent-child relationship and social skills), the combined therapy consistently yielded the best outcome. These findings show that in the treatment of ADHD the physician must carefully weigh up the treatment goals. Given the high cost of the extensive behavior therapeutic package compared with its limited additional effect on the core symptoms, a combined treatment is not justified in all children with ADHD. Nevertheless, combined treatment is indicated if the child displays serious oppositional or aggressive behavior, serious internalizing symptoms, serious social problems reported by the teacher or serious parent-child relationship problems.

Generally speaking, we can say that children who satisfy the criteria of ICD-10 hyperkinetic disorder should be given medication. A long-acting preparation is preferable. For children with a milder form of ADHD, the physician may consider treatment with or without medication. Various factors such as the child's individual potential, school climate, relationship with friends, family functioning, parental preference etc. will influence the decision. Medication may be indicated, usually in a lower dosage, for the inattentive subtype where there is a sufficiently adverse impact on functioning. It is not advisable to continue any kind of 
psychological treatment without medication if the negative spiral in the child's development is not adequately broken, and the child's functioning at school, in the family and socially is seriously disrupted by the ADHD symptoms.

If the medication, with (long-acting) psychostimulants as the first choice, is not efficacious enough, compliance needs to be investigated first of all. Switching over to a different psychostimulant or a second- or third-choice preparation should only be considered if the psychostimulant was given in the maximum dose and the effect of long-acting preparations in sufficiently high doses has been evaluated.

Additional treatment of problems such as training in social skills, individual psychotherapy, remedial teaching and family support can be initiated together with medicinal treatment. As far as comorbidity is concerned, the nature of the comorbidity is decisive for its treatment. Since antisocial behavior is sometimes secondary to ADHD and medication can have a positive effect, it is advisable to assess the effect of the medication on antisocial behavior first. Anxiety and depression can be treated along with ADHD; in the case of serious tic disorders, co-medication with tic-reducing agents may be recommended. A medication trial for ADHD symptoms in an autism-related disorder may be valuable for reducing the ADHD symptoms (2005). In the case of substance abuse, treatment with psychostimulants is controversial. There has been little research in this area and the risk of abuse is considerable. Treatment plans must focus on psychosocial therapies to diminish the substance abuse. If the ADHD symptoms remain strongly prevalent, psychostimulants may be considered, although a long-acting formulation carrying a smaller risk of abuse should always be opted for. Atomoxetine is a good alternative for this target group.

The total length of treatment depends on the preparation opted for. Generally speaking, we can say that the treatment runs over several years. A regular follow-up, with at least one medication-free period per year, is necessary to evaluate the child's development and the necessity and effect of the medication. The effect and adverse reactions of the medicine, body weight, blood pressure, pulse and height have to be determined. Checklists such as the CBCL, Conners and TRF can be used as evaluation tools. The medication will have to be adjusted if necessary. Very often treatment is discontinued too soon or continued at a subtherapeutic dose. A child with ADHD will often require treatment in adulthood as well.

\section{Prognosis and Outcome}

ADHD is not a typical disorder in school-age children. In $30 \%$ to $80 \%$ of children who have been diagnosed with ADHD, at least one debilitating symptom is shown to persist into ado- 
lescence and in 65\% of children into adulthood (Biederman et al., 2006; Faraone et al., 2000b; Hechtman and Weiss, 1986; Ingram et al., 1999; Mannuzza et al., 2003).

Besides the continuity of ADHD as a disorder, comorbidity remains a fairly constant factor as well. Antisocial behavior or an antisocial personality in adolescence or adulthood has been observed in $25 \%$ to $40 \%$ of children with ADHD who were referred to mental healthcare centers (Babinski et al., 1999). A number of factors have been described which impact on the prognosis of a child with ADHD (Hechtman, 1991; Kessler et al., 2005; Weiss et al., 1985). Specific predictors of a poor prognosis are oppositional and aggressive behavior directed against adults, a low IQ, impaired relationship with peers, and persistence of the ADHD symptoms. The occurrence of oppositional-defiant behavior in children with ADHD increases the risk of antisocial behavior development. Children who no longer displayed ADD as adolescents and young adults (DSM III diagnosis) nevertheless recorded poorer school and academic performance than the control study population (Klein and Mannuzza, 1991). 


\section{References}

Achenbach T ed. (1991a), Manual for the Child Behavior Checklist 4-18 and 1991 Profile. Burlington: University of Vermont Department of Psychiatry

Achenbach T ed. (1991b), Manual for the Teacher's Report Form and 1991 Profile. Burlington: University of Vermont Department of Psychiatry

Anastopoulos AD, Shelton TL, DuPaul GJ, Guevremont DC (1993), Parent training for attentiondeficit hyperactivity disorder: its impact on parent functioning. Journal of Abnormal Child Psychology 21: 581-96

Anderson CA, Hinshaw SP, Simmel C (1994), Mother-child interactions in ADHD and comparison boys: relationships with overt and covert externalizing behavior. Journal of Abnormal Child Psychology 22: 247-65

Angold A, Costello EJ, Erkanli A (1999), Comorbidity. Journal of Child Psychology and Psychiatry and Allied Disciplines 40: 57-87

Arnold LE, Abikoff HB, Cantwell DP, Conners CK, Elliott G, Greenhill LL, Hechtman L, Hinshaw SP, Hoza B, Jensen PS, Kraemer HC, March JS, Newcorn JH, Pelham WE, Richters JE, Schiller E, Severe JB, Swanson JM, Vereen D, Wells KC (1997), National Institute of Mental Health Collaborative Multimodal Treatment Study of Children with ADHD (the MTA). Design challenges and choices. Archives of General Psychiatry 54: 865-70

Babinski L-M, Hartsough C-S, Lambert N-M (1999), Childhood conduct problems, hyperactivityimpulsivity, and inattention as predictors of adult criminal activity. Journal of Child Psychology and Psychiatry and Allied Disciplines 40: 347-355

Banaschewski T, Coghill D, Santosh P, Zuddas A, Asherson P, Buitelaar J, Danckaerts M, Dopfner M, Faraone SV, Rothenberger A, Sergeant J, Steinhausen HC, Sonuga-Barke EJ, Taylor E (2006), Long-acting medications for the hyperkinetic disorders : A systematic review and European treatment guideline. European Child \& Adolescent Psychiatry

Barkley R-A (1990), Attention-deficit hyperactivity disorder: A handbook for diagnosis and treatment New York: The Guilford Press

Barkley R-A (1998), Attention-deficit hyperactivity disorder: A handbook for diagnosis and treatment, Sec. Ed. New York: The Guilford Press

Barkley RA, Fischer M, Edelbrock CS, Smallish L (1990), The adolescent outcome of hyperactive children diagnosed by research criteria: I. An 8-year prospective follow-up study. Journal of the American Academy of Child and Adolescent Psychiatry 29: 546-57.

Biederman J, Faraone SV (2004), The Massachusetts General Hospital studies of gender influences on attention-deficit/hyperactivity disorder in youth and relatives. Psychiatric Clinics of North America 27: 225-32

Biederman J, Faraone SV, Monuteaux MC (2002), Impact of exposure to parental attention-deficit hyperactivity disorder on clinical features and dysfunction in the offspring. Psychological Medicine 32: 817-27

Biederman J, Kwon A, Aleardi M, Chouinard VA, Marino T, Cole H, Mick E, Faraone SV (2005), Absence of gender effects on attention deficit hyperactivity disorder: findings in nonreferred subjects. American Journal of Psychiatry 162: 1083-9

Biederman J, Milberger S, Faraone SV, Kiely K, Guite J, Mick E, Ablon S, Warburton R, Reed E (1995), Family-environment risk factors for attention-deficit hyperactivity disorder. A test of Rutter's indicators of adversity. Archives of General Psychiatry 52: 464-70

Biederman J, Monuteaux MC, Mick E, Spencer T, Wilens TE, Silva JM, Snyder LE, Faraone SV (2006), Young adult outcome of attention deficit hyperactivity disorder: a controlled 10-year follow-up study. Psychological Medicine 36: 167-79

Biederman J, Newcorn J, Sprich S (1991), Comorbidity of attention deficit hyperactivity disorder with conduct, depressive, anxiety, and other disorders. American Journal of Psychiatry 148: 564-577

Biederman J, Wilens TE, Mick E, Faraone SV, Spencer T (1998), Does attention-deficit hyperactivity disorder impact the developmental course of drug and alcohol abuse and dependence? Biological Psychiatry 44: 269-73 
Bobb AJ, Castellanos FX, Addington AM, Rapoport JL (2004), Molecular genetic studies of ADHD: 1991 to 2004. American Journal of Medical Genetics 29: 29

Brookes K, Xu X, Chen W, Zhou K, Neale B, Lowe N, Aneey R, Franke B, Gill M, Ebstein R, Buitelaar J, Sham P, Campbell D, Knight J, Andreou P, Altink M, Arnold R, Boer F, Buschgens C, Butler L, Christiansen H, Feldman L, Fleischman K, Fliers E, Howe-Forbes R, Goldfarb A, Heise A, Gabriels I, Korn-Lubetzki I, Marco R, Medad S, Minderaa R, Mulas F, Muller U, Mulligan A, Rabin K, Rommelse N, Sethna V, Sorohan J, Uebel H, Psychogiou L, Weeks A, Barrett R, Craig I, Banaschewski T, Sonuga-Barke E, Eisenberg J, Kuntsi J, Manor I, McGuffin P, Miranda A, D Oades R, Plomin R, Roeyers H, Rothenberger A, Sergeant J, Steinhausen HC, Taylor E, Thompson M, Faraone SV, Asherson P, Johansson L (2006), The analysis of 51 genes in DSM-IV combined type attention deficit hyperactivity disorder: association signals in DRD4, DAT1 and 16 other genes. Molecular Psychiatry 11: 934-953

Brown RT, Amler RW, Freeman WS, Perrin JM, Stein MT, Feldman HM, Pierce K, Wolraich ML (2005), Treatment of attention-deficit/hyperactivity disorder: overview of the evidence. Pediatrics 115: e749-57

Buitelaar JK (2002), Epidemiology of Attention - deficit / Hyperactivity Disorder: what have we learned over the last decade? In: Hyperactivity Disorders, Sandberg S, ed. Cambridge: Cambridge University Press, pp 30-63

Buitelaar JK, Kooij JJ (2000), [Attention deficit hyperactivity disorder (ADHD): etiology, diagnosis and treatment]. Nederlands Tijdschrift voor Geneeskunde 144: 1716-23

Buitelaar JK, Van Engeland H (1996), Epidemiological approaches to hyperactivity. In: Hyperactivity Disorders, Sandberg S, ed. Cambridge: Cambridge University Press, pp 26-68

Cantwell DP (1996), Attention deficit disorder: a review of the past 10 years. Journal of the American Academy of Child and Adolescent Psychiatry 35: 978-87

Castellanos FX, Giedd JN, Marsh WL, Hamburger SD, Vaituzis AC, Dickstein DP, Sarfatti SE, Vauss YC, Snell JW, Lange N, Kaysen D, Krain AL, Ritchie GF, Rajapakse JC, Rapoport JL (1996), Quantitative brain magnetic resonance imaging in attention-deficit hyperactivity disorder. Archives of General Psychiatry 53: 607-16

Castellanos FX, Lee PP, Sharp W, Jeffries NO, Greenstein DK, Clasen LS, Blumenthal JD, James RS, Ebens CL, Walter JM, Zijdenbos A, Evans AC, Giedd JN, Rapoport JL (2002), Developmental trajectories of brain volume abnormalities in children and adolescents with attentiondeficit/hyperactivity disorder. Journal of The American Medical Association 288: 1740-8

Conners CK (1998), Rating scales in attention-deficit/hyperactivity disorder: use in assessment and treatment monitoring. Journal of Clinical Psychiatry 59 Suppl 7: 24-30

Conners CK, Sitarenios G, Parker JD, Epstein JN (1998a), The revised Conners' Parent Rating Scale (CPRS-R): factor structure, reliability, and criterion validity. Journal of Abnormal Child Psychology 26: 257-68

Conners CK, Sitarenios G, Parker JD, Epstein JN (1998b), Revision and restandardization of the Conners Teacher Rating Scale (CTRS-R): factor structure, reliability, and criterion validity. Journal of Abnormal Child Psychology 26: 279-91

Faraone SV, Biederman J, Lehman BK, Spencer T, Norman D, Seidman LJ, Kraus I, Perrin J, Chen WJ, Tsuang MT (1993), Intellectual performance and school failure in children with attention deficit hyperactivity disorder and in their siblings. Journal of Abnormal Psychology 102: 616-23

Faraone SV, Biederman J, Mick E, Williamson S, Wilens T, Spencer T, Weber W, Jetton J, Kraus I, Pert J, Zallen B (2000a), Family study of girls with attention deficit hyperactivity disorder. American Journal of Psychiatry 157: 1077-83

Faraone SV, Biederman J, Milberger S (1994), An exploratory study of ADHD among second-degree relatives of ADHD children. Biological Psychiatry 35: 398-402

Faraone SV, Biederman J, Spencer T, Wilens T, Seidman LJ, Mick E, Doyle AE (2000b), Attentiondeficit/hyperactivity disorder in adults: an overview. Biological Psychiatry 48: 9-20

Faraone SV, Perlis RH, Doyle AE, Smoller JW, Goralnick JJ, Holmgren MA, Sklar P (2005), Molecular genetics of attention-deficit/hyperactivity disorder. Biological Psychiatry 57: 1313-23

Fergusson DM, Woodward LJ, Horwood LJ (1998), Maternal smoking during pregnancy and psychiatric adjustment in late adolescence. Archives of General Psychiatry 55: 721-7

Fletcher KE, Fischer M, Barkley RA, Smallish L (1996), A sequential analysis of the motheradolescent interactions of ADHD, ADHD/ODD, and normal teenagers during neutral and conflict discussions. Journal of Abnormal Child Psychology 24: 271-97 
Gadow KD, Sverd J, Sprafkin J, Nolan EE, Grossman S (1999), Long-term methylphenidate therapy in children with comorbid attention-deficit hyperactivity disorder and chronic multiple tic disorder. Archives of General Psychiatry 56: 330-6

Gaub M, Carlson C-L (1997), Gender differences in ADHD: A meta-analysis and critical review. Journal of the American Academy of Child and Adolescent Psychiatry 36: 1036-1045

Gilbert DL, Wang ZW, Sallee FR, Ridel KR, Merhar S, Zhang J, Lipps TD, White C, Badreldin N, Wassermann EM (2006), Dopamine transporter genotype influences the physiological response to medication in ADHD. Brain 129: 2038-2046

Gillberg C, Gillberg IC, Rasmussen P, Kadesjo B, Soderstrom H, Rastam M, Johnson M, Rothenberger A, Niklasson L (2004), Co-existing disorders in ADHD -- implications for diagnosis and intervention. European Child \& Adolescent Psychiatry 13 Suppl 1: I80-92

Greene RW, Biederman J, Faraone SV, Monuteaux MC, Mick E, DuPre EP, Fine CS, Goring JC (2001), Social impairment in girls with ADHD: patterns, gender comparisons, and correlates. Journal of the American Academy of Child and Adolescent Psychiatry 40: 704-10

Greenhill LL, Abikoff HB, Arnold LE, Cantwell DP, Conners CK, Elliott G, Hechtman L, Hinshaw SP, Hoza B, Jensen PS, March JS, Newcorn J, Pelham WE, Severe JB, Swanson JM, Vitiello B, Wells K (1996), Medication treatment strategies in the MTA Study: relevance to clinicians and researchers. Journal of the American Academy of Child and Adolescent Psychiatry 35: 1304-13

Greenhill LL, Pliszka S, Dulcan MK, Bernet W, Arnold V, Beitchman J, Benson RS, Bukstein O, Kinlan J, McClellan J, Rue D, Shaw JA, Stock S (2002), Practice parameter for the use of stimulant medications in the treatment of children, adolescents, and adults. Journal of the American Academy of Child and Adolescent Psychiatry 41: 26S-49S

Gross-Tsur V, Manor O, van der Meere J, Joseph A, Shalev RS (1997), Epilepsy and attention deficit hyperactivity disorder: is methylphenidate safe and effective? Journal of Pediatrics 130: 670-4

Group TMC (1999), A 14-month randomized clinical trial of treatment strategies for attentiondeficit/hyperactivity disorder. Archives of General Psychiatry 56: 1073-1086

Gucuyener K, Erdemoglu AK, Senol S, Serdaroglu A, Soysal S, Kockar AI (2003), Use of methylphenidate for attention-deficit hyperactivity disorder in patients with epilepsy or electroencephalographic abnormalities. Journal of Child Neurology 18: 109-12

Hechtman L (1991), Resilience and vulnerability in long term outcome of attention deficit hyperactive disorder. Canadian Journal of Psychiatry 36: 415-421

Hechtman L, Weiss G (1986), Controlled prospective fifteen year follow-up of hyperactives as adults: non-medical drug and alcohol use and anti-social behavior. Canadian Journal of Psychiatry 31: 557-67.

Hinshaw SP, Owens EB, Wells KC, Kraemer HC, Abikoff HB, Arnold LE, Conners CK, Elliott G, Greenhill LL, Hechtman L, Hoza B, Jensen PS, March JS, Newcorn JH, Pelham WE, Swanson JM, Vitiello B, Wigal T (2000), Family processes and treatment outcome in the MTA: negative/ineffective parenting practices in relation to multimodal treatment. Journal of Abnormal Child Psychology 28: 555-68

Hoza B, Mrug S, Gerdes AC, Hinshaw SP, Bukowski WM, Gold JA, Kraemer HC, Pelham WE, Jr., Wigal T, Arnold LE (2005), What aspects of peer relationships are impaired in children with attention-deficit/hyperactivity disorder? Journal of Consulting and Clinical Psychology 73: 411-23

Huizink AC, Mulder EJ (2006), Maternal smoking, drinking or cannabis use during pregnancy and neurobehavioral and cognitive functioning in human offspring. Neuroscience and Biobehavioral Reviews 30: 24-41

Ingram S, Hechtman L, Morgenstern G (1999), Outcome issues in ADHD: Adolescent and adult longterm outcome. Mental Retardation and Developmental Disabilities Research Reviews 5: 243-250

International Classification of Diseases, 10 th. Ed. (1990) Geneva: World Health Assembly

Jensen PS, Hinshaw SP, Swanson JM, Greenhill LL, Conners CK, Arnold LE, Abikoff HB, Elliott G, Hechtman L, Hoza B, March JS, Newcorn JH, Severe JB, Vitiello B, Wells K, Wigal T (2001), Findings from the NIMH Multimodal Treatment Study of ADHD (MTA): implications and applications for primary care providers. Journal of Developmental and Behavioral Pediatrics 22: 6073

Kessler RC, Adler LA, Barkley R, Biederman J, Conners CK, Faraone SV, Greenhill LL, Jaeger S, Secnik K, Spencer T, Ustun TB, Zaslavsky AM (2005), Patterns and predictors of attentiondeficit/hyperactivity disorder persistence into adulthood: results from the national comorbidity survey replication. Biological Psychiatry 57: 1442-51 
Klein R-G, Mannuzza S (1991), Long-term outcome of hyperactive children: A review. Journal of the American Academy of Child and Adolescent Psychiatry 30: 383-387

Kurlan R, Group. TsSS (2002), Treatment of ADHD in children with tics: a randomized controlled trial. Neurology 58: 527-36

Lahey B-B, Applegate B, McBurnett K, Biederman J, Greenhill L, Hynd G-W, Barkley R-A, Newcorn J, Jensen P, Richters J, et al. (1994), DSM-IV field trials for attention deficit hyperactivity disorder in children and adolescents. American Journal of Psychiatry 151: 1673-85

Lambert N-M, Hartsough C-S (1998), Prospective study of tobacco smoking and substance dependencies among samples of ADHD and non-ADHD participants. Journal of Learning Disabilities 31: 533-544

Li DW, Sham PC, Owen MJ, He L (2006), Meta-analysis shows significant association between dopamine system genes and attention deficit hyperactivity disorder (ADHD). Human Molecular Genetics 15: 2276-2284

Lynskey MT, Hall W (2001), Attention deficit hyperactivity disorder and substance use disorders: Is there a causal link? Addiction 96: 815-22

Mannuzza S, Klein RG, Bonagura N, Konig PH, Shenker R (1988), Hyperactive boys almost grown up. II. Status of subjects without a mental disorder. Archives of General Psychiatry 45: 13-8.

Mannuzza S, Klein RG, Moulton JL, 3rd (2003), Persistence of Attention-Deficit/Hyperactivity Disorder into adulthood: what have we learned from the prospective follow-up studies? Journal of Attention Disorders 7: 93-100

Michelson D, Faries D, Wernicke J, Kelsey D, Kendrick K, Sallee FR, Spencer T (2001), Atomoxetine in the treatment of children and adolescents with attention-deficit/hyperactivity disorder: a randomized, placebo-controlled, dose-response study. Pediatrics 108: E83

Mick E, Biederman J, Prince J, Fischer MJ, Faraone SV (2002), Impact of low birth weight on attention-deficit hyperactivity disorder. Journal of Developmental and Behavioral Pediatrics 23: 16-22

Milberger S, Biederman J, Faraone SV, Chen L, Jones J (1996), Is maternal smoking during pregnancy a risk factor for attention deficit hyperactivity disorder in children? American Journal of Psychiatry 153: $1138-42$

Palumbo D, Spencer T, Lynch J, Co-Chien H, Faraone SV (2004), Emergence of tics in children with ADHD: impact of once-daily OROS methylphenidate therapy. Journal of Child and Adolescent Psychopharmacology 14: 185-94

Pearson DA, Santos CW, Roache JD, Casat CD, Loveland KA, Lachar D, Lane DM, Faria LP, Cleveland LA, Vitiello B, Severe JB, Greenhill LL, Arnold LE, Abikoff HB, Bukstein OG, Elliott GR, Hechtman L, Jensen PS, Hinshaw SP, March JS, Newcorn JH, Swanson JM, Cantwell DP, Davies M, Clevenger W, Wu M, Conners CK, Hoza B, Kraemer HC, Wells K, Wigal T, Elliott G, Newcorn J, Pelham WE (2004), National Institute of Mental Health Multimodal Treatment Study of ADHD follow-up: 24-month outcomes of treatment strategies for attention-deficit/hyperactivity disorder. Pediatrics 113: 754-61

Penner MR, McFadyen MP, Pinaud R, Carrey N, Robertson HA, Brown RE (2002), Age-related distribution of c-fos expression in the striatum of CD-1 mice after acute methylphenidate administration. Brain Research. Developmental Brain Research 135: 71-7

Prince JB (2006), Pharmacotherapy of attention-deficit hyperactivity disorder in children and adolescents: update on new stimulant preparations, atomoxetine, and novel treatments. Child and Adolescent Psychiatric Clinics of North America 15: 13-50

Research Units on Pediatric Psychopharmacology (RUPP) Autism Network (2005) Randomized, controlled, crossover trial of methylphenidate in pervasive developmental disorders with hyperactivity. Archives of General Psychiatry 62: 1266-74

Shafritz KM, Marchione KE, Gore JC, Shaywitz SE, Shaywitz BA (2004), The effects of methylphenidate on neural systems of attention in attention deficit hyperactivity disorder. American Journal of Psychiatry 161: 1990-7

Spencer T, Biederman J, Wilens T, Doyle R, Surman C, Prince J, Mick E, Aleardi M, Herzig K, Faraone S (2005), A large, double-blind, randomized clinical trial of methylphenidate in the treatment of adults with attention-deficit/hyperactivity disorder. Biological Psychiatry 57: 456-63

Spencer TJ, Biederman J, Harding M, O'Donnell D, Faraone SV, Wilens TE (1996), Growth deficits in ADHD children revisited: evidence for disorder-associated growth delays? Journal of the American Academy of Child and Adolescent Psychiatry 35: 1460-9 
Taylor E (1999), Development of clinical services for attention-deficit/hyperactivity disorder. Archives of General Psychiatry 56: 1097-1099

Taylor E, Chadwick O, Heptinstall E, Danckaerts M (1996), Hyperactivity and conduct problems as risk factors for adolescent development. Journal of the American Academy of Child and Adolescent Psychiatry 35: 1213-26

Taylor E, Dopfner M, Sergeant J, Asherson P, Banaschewski T, Buitelaar J, Coghill D, Danckaerts M, Rothenberger A, Sonuga-Barke E, Steinhausen HC, Zuddas A (2004), European clinical guidelines for hyperkinetic disorder -- first upgrade. European Child \& Adolescent Psychiatry 13: I730

Taylor E, Sandberg S, Thorley G, Giles S (1991), The Epidemiology of Childhood Hyperactivity Oxford: Oxford University Press

Vaidya CJ, Austin G, Kirkorian G, Ridlehuber HW, Desmond JE, Glover GH, Gabrieli JD (1998), Selective effects of methylphenidate in attention deficit hyperactivity disorder: a functional magnetic resonance study. Proceedings of the National Academy of Sciences of the United States of America 95: 14494-9

Vitiello B, Severe JB, Greenhill LL, Arnold LE, Abikoff HB, Bukstein OG, Elliott GR, Hechtman L, Jensen PS, Hinshaw SP, March JS, Newcorn JH, Swanson JM, Cantwell DP, Davies M, Clevenger W, Wu M, Conners CK, Hoza B, Kraemer HC, Wells K, Wigal T, Elliott G, Newcorn J, Pelham WE (2001), Methylphenidate dosage for children with ADHD over time under controlled conditions: lessons from the MTA. Journal of the American Academy of Child and Adolescent Psychiatry 40: 188-96

Weiss G, Hechtman L, Milroy T, Perlman T (1985), Psychiatric status of hyperactives as adults: a controlled prospective 15-year follow-up of 63 hyperactive children. Journal of the American Academy of Child and Adolescent Psychiatry 24: 211-20.

Weiss M, Worling D, Wasdell M (2003), A chart review study of the inattentive and combined types of ADHD. Journal of Attention Disorders 7: 1-9

Whitaker AH, Van Rossem R, Feldman JF, Schonfeld IS, Pinto-Martin JA, Tore C, Shaffer D, Paneth N (1997), Psychiatric outcomes in low-birth-weight children at age 6 years: relation to neonatal cranial ultrasound abnormalities. Archives of General Psychiatry 54: 847-56

Wilens TE, Biederman J (2006), Alcohol, drugs, and attention-deficit/hyperactivity disorder: a model for the study of addictions in youth. Journal of Psychopharmacology 20: 580-588

Woodward L, Dowdney L, Taylor E (1997), Child and family factors influencing the clinical referral of children with hyperactivity: a research note. Journal of Child Psychology and Psychiatry and Allied Disciplines 38: 479-85 


\title{
Chapter 3
}

\section{Distribution of DSM-IV symptoms of ADHD in a}

\author{
Large Sample of 6 to 8 Year Old Dutch
}

School Children ${ }^{1}$

${ }^{1}$ Sabine Tremmery, Jan K. Buitelaar, Jean Steyaert, Geert Molenberghs, Frans J.M. Feron, Ariane C. Kalff, Petra P.M. Hurks, Jos G.M. Hendriksen, Johan S.H. Vles, Jelle Jolles. Submitted for publication 


\section{Abstract}

Objective: To describe the distribution of ADHD symptoms and to examine the validity of the ADHD DSM-IV algorithm in a school-based sample of about 7 year old Dutch children.

Methods: In a two-stage design 2,466 eligible children were screened with the Child Behavior Checklist (CBCL). Next, 789 (400 high risk and 389 low risk) children were assessed using the Dutch Diagnostic Interview for Children and Adolescents (DICA-R, DSM-IIIR/ IV).

Results: Four of the 18 ADHD DSM-IV symptoms (difficulty sustaining attention, difficulty organizing tasks, avoiding sustained attention, and difficulty playing quietly) were endorsed in less than $10 \%$ of the children at age 7 . A model including only 6 instead of 18 ADHD symptoms was sufficient to separate cases from non-cases. No gender specific symptoms were found. The distribution of Inattentive and Hyperactive and Impulsive symptoms did not lead to well distinguished subtypes of ADHD. The need for mental health support was predicted by 3 symptoms (doesn't seem to listen, runs/climbs, and interrupts or intrudes)..

Conclusion: There is clear redundancy in the18 DSM-IV symptoms for ADHD. Single symptoms vary widely in their contribution to a measure of impairment of functioning. These results may be useful in developing an algorithm for ADHD in DSM-V. 


\section{Introduction}

Attention-deficit/hyperactivity disorder (ADHD) is one of the most common neurodevelopmental disorders in childhood. ADHD has been firmly established as a psychiatric disorder, meeting the criteria for the validation of psychiatric diagnoses as outlined by Robins and Guze (Faraone, 2005; Robins \& Guze, 1970). Since the release of DSM-IV, ADHD has been conceptualised as a discrete disorder of 18 symptoms which are clustered into two dimensions (inattention and hyperactivity-impulsivity) with each 9 symptoms. Setting a threshold at 6 or more out of 9 symptoms for each dimension leads to three subtypes: the predominantly inattentive subtype (ADHD:IA), the predominantly hyperactive/impulsive subtype (ADHD:HI), and the combined subtype (ADHD:C). This classification is based on several validation studies which support this two-factor model of inattention versus hyperactive-impulsive symptoms of ADHD (B.-B. Lahey et al., 1994; Lahey et al., 1998).

A recent study of the utility and validity of the DSM-IV symptoms in adults with ADHD found that a threshold of only 4 symptoms - instead of 6 symptoms - worked well to identify cases with ADHD from non-cases in a normal adult population 8. Further, the presence of absence of just one symptom "is often easily distracted by extraneous stimuli" ruled out ADHD in the normal adult sample with over 97\% accuracy. Finally, a small set of three inattention and three hyperactive-impulsive symptoms best distinguished adults with ADHD from a clinical control group 8 .

Despite an extensive ADHD DSM-IV field trial among children and adolescents in clinical settings, little is known about the distribution of ADHD symptoms and their discriminating validity in the general population of children and adolescents.

Another issue of interest is the relationship between symptomatic and functional impairment in ADHD. Epidemiological studies have indicated that the prevalence estimates of ADHD vary widely, depending on whether impairment of functioning is taken into account or not (Canino et al., 2004; Shaffer et al., 1996). Although there is no consensus on how to operationalize clinically important impairment in epidemiologic studies (Costello, Egger, \& Angold, 2005) problem perception and perceived need for mental health services were found to be positively associated with child symptomatology and can be used as a measure of impairment (Teagle, 2002). So far, research has been focused on the relationship between ADHD at the syndrome level and impairment of functioning. It is unknown whether single ADHD symptoms all contribute to impairment of functioning, and which symptoms contribute most.

This study was developed to examine 1) the prevalence and validity of the different ADHD symptoms; 2) the distribution of the number of ADHD symptoms with respect to the three 
ADHD subtypes; and 3) the contribution of single ADHD symptoms to impairment of functioning and need for mental health services. We used the data of a school-based population of six to eight year old children from the Study of Attention Disorders in Maastricht (SAM). The strengths of the SAM study include the large number of subjects within one age range, the young age of the children, diagnostic interviewing by clinicians supervised by a child psychiatrist, the large amount of socio-demographic data, the inclusion of impairment and impact criteria, and the intention-to-treat biostatistical analysis taking the properties of the design into account.

\section{Method}

\section{Subjects and Procedure}

\section{Phase 1: Children enrolled at approximately six years of age}

The methodology has been reported in detail elsewhere (Kalff et al., 2001). This study was approved by the Medical Ethical Committee at the Academic Hospital Maastricht. All parents of a school-based population of 4,390 children were approached to participate. The selection happened in two year cohorts. Of the first cohort (start 1996-1997), the parents of $1,317(57.5 \%)$ of 2,290 children (699 boys and 618 girls, mean age $\pm \mathrm{SD} ; 5.87 \pm 0.41$ year) agreed to participate and, of the second cohort (start 1998-1999), the parents of 1,149 (54.7 $\%$ ) of 2,100 children (592 boys and 557 girls, mean age \pm SD; $5.87 \pm 0.49$ year) agreed to participate, resulting in a total of 2,466 (56.2\%) participants. Written informed consent was obtained for both phases in the two cohorts. Parents did not have to explain why they refused participation. No significant differences were observed between the participants and non-participants in terms of age, sex, and demographic factors in the first cohort (Kroes et al., 2001). In the first phase, the parents of all 2,466 children completed the Child Behavior Cheklist (CBCL) (Achenbach, 1991) and a questionnaire on sociodemographic characteristics.

\section{Phase 2: First follow-up at six to eight years of age.}

On the basis of CBCL scores in phase 1, two groups of children (in total N=789) were selected for follow up. The first, a high-risk group, consisted of 400 children with scores on the CBCL broadband externalizing and/or internalizing scales above the $90^{\text {th }}$ percentile $(\mathrm{T}>63)$ and/or scores on the inattention scale of the CBCL above the $95^{\text {th }}$ percentile $(\mathrm{T}>67)$. The cut-off points chosen represented the clinical cut-off scores for the CBCL broadband and inattention scales determined in earlier Dutch epidemiological studies (Verhulst, Van der Ende, \& Koot, 1996). Finally, a control (low risk) group of 389 children who did not meet 
selection criteria for the two high-risk groups was selected and matched for age, sex, and geographic area (urban versus rural).

The parents of all children were invited to participate in structured psychiatric interviews (see below). Parents of 711 (90.1\%; 410 boys and 301 girls) of the 789 children agreed to participate. Of these, $363(90.7 \%)$ were from the high-risk group and 348 (90\%) were from the control group. The participating and non-participating children did not differ in terms of CBCL scores, sex, or demographic characteristics.

\section{Measures}

The Child Behaviour Checklist (CBCL) (Achenbach, 1991) designed to assess social competence and behavior problems in children in different scales, was completed by parents in the first phase when the children were six years old. The CBCL was computer scored, using appropriate age and sex norms for the Dutch population (De Groot, Koot, \& Verhulst, 1996).

Demographic information was assessed in the first phase. The level of parental occupation was scored on a seven point scale, ranging from low skilled labour to a scientific profession, and was divided into three levels for the present study: low $(1,2$, and 3), moderate (4 and 5), and high (6 and 7) (van den Brandt et al., 1990). Other demographic information included the country of the parent's birth, family intactness (child living with one versus two parents), living area (Maastricht urban area versus surrounding towns and suburbs), and psychiatric illness of the father or mother.

The Diagnostic Interview for Children and Adolescents (DICA-R) (W. Reich, Shayla, \& Taibleson, 1992) in its Dutch version (Amsterdam Diagnostisch Interview voor Kinderen - ADIKA) (Kortenbout van der Sluijs, Levita, Manen, \& Defares, 1993) was used for structured psychiatric assessment in the second phase, when children were approximately seven years of age. The DICA-R is based on the criteria of DSM-III-R (American Psychiatric Association, 1994) and was adapted to the criteria of DSM-IV (American Psychiatric Association, 1994) for diagnosing ADHD (Van Grimbergen, 1999). The reliability and validity of ADHD for the DSM-IV criteria are good to average (Van Grimbergen, 1999). Although no reliability studies have been performed with the ADIKA, the DICA-R has been described recently as a useful measure for both research and clinical settings to provide reliable psychiatric information about children (Wendy Reich, 2000). Parents were the most stable in reporting disorders in a six to nine year old population (Boyle et al., 1993). The test-retest reliability of DICA-R in a sample of 251 (Boyle et al., 1993) and 110 subjects (Ezpeleta, de la Osa, Domenech, Navarro, \& Losilla, 1997) was good to very good (ADHD 
$0.51-0.86$; ODD $0.61-0.92$; CD $0.66-0.87$; DEP $0.31-0.35$; dysthymia $0.49-0.51$; anxiety disorder $0.62-0.69$; separation anxiety disorder 0.62 ; enuresis 0.73 ; encopresis 0.74). Agreement between trained lay interviewers and child psychiatrists was generally high (any diagnosis 0.78-1.0)(G.-J. August, Braswell, \& Thuras, 1998; Boyle et al., 1993). The convergent validity using the $\mathrm{CBCL}$ as a criterion to discriminate between psychiatric $(\mathrm{N}=196)$ and control $(\mathrm{N}=130)$ groups showed that the DICA-R is a valid instrument for the assessment of the most common child psychological disorders (de la Osa, Ezpeleta, Domenech, Navarro, \& Losilla, 1997).

The ADIKA was administered to the parents of six to eight year old children by three clinically trained interviewers for the first cohort and by two trained interviewers for the second cohort. To reach consensus and improve the reliability and validity of our diagnosis, the results were discussed weekly during an intensive supervision session of the interviewers by the research senior child psychiatrist (J.S.). Discrepancy in scoring was resolved by consensus. When questions arose, parents were contacted for further clarification.

All interviewers were blinded to the results of prior assessments. The DICA-R assesses symptoms of axis-I psychiatric disorders such as disruptive, emotional, anxiety, and elimination disorders, and their duration, impairment, and possible consultation with health professionals. Diagnoses were generated by a computer algorithm that ignores the hierarchical DSM structure. For example, Oppositional Defiant Disorder (ODD) and Conduct Disorder (CD) could be diagnosed in the same patient.

The ADHD module of the Dutch DICA-R contains ten binary items that measure inattention and 11 items that measure hyperactivity and impulsivity(HI). Positive answers were used to compute the number of inattention symptoms (range 0-10) and the number of hyperactivity and impulsivity symptoms (range 0-11). The DICA-R includes four binary items on impairment. These items measure problems at home, problems at school, social problems, and overall performance impairment. Using these items, a total impairment score was derived (range 0-4). An ADHD diagnosis was generated when the DSM-IV criteria for ADHD were present with at least six hyperactivity and impulsivity symptoms, inattention symptoms, or both; two positive scores on impairment; and onset prior to seven years of age. If an ADHD diagnosis was made, the ADHD subtype was based on threshold score (minimum 6) for the two symptom groups. For analysis of the symptom distribution, the structure of the ADIKA was taken into account. The first inattention item I1 'Often does not pay close attention to details or makes careless mistakes in schoolwork, work, or other activities' resulted in the ADIKA in two questions: 'Often does not pay close attention to details' and 'makes careless mistakes in schoolwork, work, or other activities'. The DSM-IV I1 item was scored positive if one of the two questions was affirmative. The same happened for the H1 and H2 DSM-IV items 'Often fidgets with hands or feet or squirms in seat' and 'Often leaves seat in class- 
room or in other situations in which remaining seated is expected', as the were questioned by 2 questions. Only diagnoses in the present (no lifetime diagnosis) were used in the analyses.

Subjective Family Burden and Assessment of Educational Situation was measured by a Dutch questionnaire, the Nijmegen Family Situation Questionnaire (NVOS). The reliability and validity have been found to be good to excellent (Wels \& Robbroeckx, 1996). Parents choose from eight descriptions of the current educational situation, with the highest score indicating that there were no problems and no need for educational or mental health support and the lowest score indicating that there were severe problems, that parents were desperate, and that support was urgently needed. The norm score for a clinically referred population is 4.07 and the norm score for a control group 2.07. To obtain a binary measure of need for educational or mental health support for the present study, the eight point scale was divided into two levels, namely no need for educational or mental health support (1 to 3), i.e. no need, and need for educational or mental health support (4 to 8), i.e. need.

\section{Statistical procedures}

The distribution of our study sample was influenced by the two stage sample design and attrition. The non-random selection of the control group due to matching forced us to use adjusted weights in order to return to the original size. A backward logistic regression analysis including gender, age, living area, parental occupation, cohort, and the different behaviour subscales of the CBCL was used to estimate the selection probability for each individual control child. Tests for collinearity (highly correlated variables) showed no conflicts. The final model, including the inattention and thought problem subscales of the CBCL, gender, age and living area, had a a correct prediction of $81.1 \%$. Cross-validation in different observation subsets showed equal a correct prediction (78.9-82.2\%). The individual inverse predictive values served as a weight measurement for the control group. The attrition rate was too small for modelling, but univariate analysis did not show a specific trend, and the assumption that the outcomes for the non-responders are "missing at random" was made.

The weights obtained were used to extrapolate the symptom distribution and other diagnostic criteria of the different ADHD diagnoses in the selected sample of the responder group $(\mathrm{N}=711)$ to the entire cohort (Weighted $\mathrm{N}=2,225$ ). This was done using SAS Proc SURVEYFREQ and SURVEYLOGISTIC (Woodruff, 1971). Data were analysed with logistic regression and the Wald confidence interval for adjusted odds ratios was reported. The area under the ROC curve, a representation of the tradeoffs between sensitivity and specificity is 
used to test the validity of the reduced models. The goodness of fit statistic for overall models and independent variables was satisfactory in all analyses.

\section{Results}

\section{Distribution of the different ADHD Symptoms}

The distribution of the inattentive, hyperactive, and impulsive symptoms in the total population is provided in table 1 . The presence of the different symptoms varied from $4.7 \%$ (difficulty sustaining attention) to $47.7 \%$ (often fidgets or squirms). The large variability in the distribution of the symptoms led to doubts regarding symptom specificity.

In order to investigate how the different symptoms were related to ADHD, three logistic regression models were built (table 2). The first logistic regression model investigated the relationship between the inattentive (IA) symptoms and the ADHD outcome; the second model investigated the pattern of the hyperactive/ impulsive (HI) symptoms; and the third model included the combined ADHD symptoms. The odds ratio (O.R.) with 95\% confidence interval $(95 \%$ C.I.) for each symptom of the first two models is reported in table 1 . The influence of gender was considered in each model. The accuracy of each model was investigated at a probability of occurrence of $5 \%$, which was the prevalence of ADHD in this sample.

In the first model, four of the nine symptoms remained significant (table 1). These were: 'Often fails to attend to details', 'Often does not seem to listen', 'Often avoids sustained mental effort', and 'Often easily distracted'. This model did not include the impairment criteria, but $78.6 \%$ of the cases were well classified. The reduced model, which only included the four mentioned inattention symptoms, diminished the correct classification rate by only $1 \%$, thereby indicating that the reduced model was nearly as good as the full model. The area under the curve obtained by the ROC analysis was good (0.89).

The second, HI model selected the four symptoms 'Often runs/climbs', 'Often on the go', 'Often blurts out answers', and 'Often interrupts or intrudes'. It predicted the ADHD outcome with an accuracy of $80 \%$. This reduced model predicted ADHD status even better than the full model $(78.2 \%)$. The area under the curve is the ROC analysis was good (0.86).

The final model, which consisted of six significant symptoms, Often fails to attend to details', 'Often does not seem to listen', 'Often easily distracted', 'Often runs/climbs', 'Often on the go', and 'Often interrupts or intrudes', showed that one inattention symptom, namely 
Table 1. Distribution of the ADHD Symptoms in a Population of 6 to 8 years old Children ( $\mathrm{N}=2224)$ and the Odds Ratio (O.R.) with 95\% Confidence Interval (95\%CI) for each Symptom to a Positive ADHD outcome

\begin{tabular}{llllll}
\hline Inattentive Symptoms & $\mathrm{N}$ & $\%$ & $\mathrm{O} . \mathrm{R}$. & $95 \% \mathrm{CI}$ \\
\hline A1 & Often fails to attend to details & 598,7 & 26,9 & 4,5 & $2,0-10,2$ \\
$\mathrm{~A} 2$ & Often difficulty sustaining attention & 105,0 & 4,7 & 1,5 & $0,4-5,4$ \\
$\mathrm{~A} 3$ & Often doesn't seem to listen & 417,2 & 18,8 & 5,9 & $2,8-12,3$ \\
A4 & Often doesn't follow instructions & 899,9 & 40,5 & 1,8 & $0,7-4,6$ \\
A5 & Often difficulty organizing tasks & 136,6 & 6,1 & 1,9 & $0,7-4,7$ \\
A6 & Often avoids sustained mental effort & 208,7 & 9,4 & 2,9 & $1,3-6,6$ \\
A7 & Often loses things & 430,8 & 19,4 & 1,5 & $0,7-3,1$ \\
A8 & Often easily distracted & 752,8 & 33,8 & 3,6 & $1,8-7,4$ \\
A9 & Often forgetful & 356,4 & 16,0 & 1,0 & $0,4-2,2$ \\
& & & & & \\
\hline Hyperactive \& Impulsive Symptoms & & & & \\
\hline H1 & Often fidgets or squirms & 1061,0 & 47,7 & 2,0 & $0,8-5,1$ \\
H2 & Often leaves seat & 669,1 & 30,1 & 1,6 & $0,6-3,8$ \\
H3 & Often runs/climbs & 294,9 & 13,3 & 3,4 & $1,6-7,4$ \\
H4 & Often has difficulty playing quietly & 162,6 & 7,3 & 1,9 & $0,8-4,3$ \\
H5 & Often 'on the go' & 368,0 & 16,5 & 3,8 & $1,7-8,1$ \\
H6 & Often talks excessively & 706,2 & 31,8 & 1,1 & $0,6-2,1$ \\
I1 & Often blurts answers & 407,2 & 18,3 & 2,2 & $1,1-4,4$ \\
I2 & Often difficulty waiting turn & 613,1 & 27,6 & 1,4 & $0,7-3,0$ \\
I3 & Often interrupts or intrudes & 414,3 & 18,6 & 4,2 & $2,1-8,8$ \\
\hline
\end{tabular}

'Often avoids sustained mental effort', and one impulsive symptom, namely 'Often blurts out answers', were not significant. This model had a correct prediction of $81.7 \%$ compared to $82.8 \%$ for the full model. The area under the curve found by the ROC analysis was very $\operatorname{good}(0.92)$.

Gender was included in the explorative phase of all models but was never significant.

Indirectly, the influence of the impairment criterion on the ADHD diagnosis was investigated. All models had classification accuracy between $77.6 \%$ and $82.8 \%$. The inclusion of the impairment factor increased this accuracy to nearly $100 \%$. As such, about $20 \%$ of the variance was explained by the impairment factor. 
Table 2. Logistic Regression Models of ADHD Symptoms that best Discriminate the ADHD Group from the Community Group with Odds Ratio (O.R.) and 95\% Confidence Interval (95\%CI).

\begin{tabular}{|c|c|c|c|c|c|c|c|c|}
\hline \multicolumn{2}{|c|}{ Symptom } & \multirow[t]{2}{*}{ Beta } & \multirow[t]{2}{*}{ S.E. } & \multirow[t]{2}{*}{ Wald } & \multirow[t]{2}{*}{$\mathrm{p}$} & \multirow[t]{2}{*}{ O.R. } & \multicolumn{2}{|c|}{$95 \% \mathrm{CI}$} \\
\hline \multicolumn{4}{|c|}{ Inattention Symptoms } & & & & & \\
\hline A1 & Often fails to attend to details & 1.5 & 0.4 & 13.2 & $<.001$ & 4.5 & 2.0 & 10.2 \\
\hline A3 & Often doesn't seem to listen & 1.8 & 0.4 & 22.1 & $<.001$ & 5.9 & 2.8 & 12.3 \\
\hline A6 & Often avoids sustained mental effort & 1.1 & 0.4 & 6.6 & 0.01 & 2.9 & 1.3 & 6.6 \\
\hline A 8 & Often easily distracted & 1.3 & 0.4 & 12.4 & $<.001$ & 3.6 & 1.8 & 7.4 \\
\hline \multicolumn{9}{|c|}{ Hyperactive-Impulsive Symptoms } \\
\hline H5 & Often 'on the go' & 1.3 & 0.4 & 11.4 & $<.001$ & 3.8 & 1.7 & 8.1 \\
\hline I1 & Often blurts answers & 0.8 & 0.4 & 4.7 & 0.03 & 2.2 & 1.1 & 4.4 \\
\hline $\mathrm{I} 3$ & Often interrupts or intrudes & 1.4 & 0.4 & 15.3 & $<.001$ & 4.2 & 2.1 & 8.8 \\
\hline \multicolumn{9}{|c|}{ All Symptoms Analyzed Together } \\
\hline H3 & Often runs/climbs & 1.1 & 0.4 & 7.3 & 0.007 & 3.1 & 1.4 & 7.0 \\
\hline H5 & Often 'on the go' & 1.0 & 0.5 & 4.3 & 0.04 & 2.6 & 1.1 & 6.3 \\
\hline $\mathrm{I} 3$ & Often interrupts or intrudes & 1.4 & 0.4 & 12.3 & $<.001$ & 4.2 & 1.9 & 9.4 \\
\hline
\end{tabular}

\section{Distribution of the total Number of Inattentive and Hyperactive \& Im- pulsive Symptoms}

The distribution (\%) of the number of IA and HI symptoms is provided in table 3 and visualised in figure 1 . About $6.1 \%$ of the children in a normal representative population had six or more IA symptoms, and $8.1 \%$ had six or more HI symptoms. Figure 1 shows that the distribution of the number of the IA versus the HI symptoms did not lead to well distinguished groups or to a division in subtypes. Additionally, there was no evidence to support the presence of one simple homogeneous distribution depending on the number of symptoms of one cluster. In contrast, there was evidence for a heterogeneous distribution with questionable relevance for sub-grouping or sub-typing at the symptom level, which resulted in a high number of borderline, false positive, and false negative cases.

\section{Distribution of the other DSM-IV criteria: influence of the age of onset, impairment and need for mental health}

Once again, the adjusted weights were used to investigate the distribution of the other DSM-IV criteria. Only the point prevalence is given but the confidence intervals were small. The symptom ADHD cut-off, based on the ADIKA interview, was reached for 441 of the 2224 (19.8\%) children (figure 2). This interview differs from the DSM-IV diagnostic 
criteria in the number of questions (10 questions for the IA symptoms, 11 questions for the HI symptoms; confer methodology). In this group $(\mathrm{n}=441), 85(19.3 \%)$ only met the IA symptom threshold, $221(50.1 \%)$ only met the HI symptom threshold, and 135 (30.6\%) met the combined $(\mathrm{C})$ threshold.

The "age of onset before age seven" criterion was fulfilled for all threshold children. The criterion that symptoms needed to be present for at least six months led to a subdivision only in the HI group; six children (2.7\%) of this group were separated. This small group had no impairment but a need for mental health was present for all of these children.

One hundred and thirteen of the $441(25.6 \%)$ threshold children had impairment in at least two areas. Half of the children (47.4\%) with C threshold symptoms were impaired compared to only $22.4 \%$ of the IA group and $13.9 \%$ of the HI group. This difference was significant (Chi-square 19.3; $\mathrm{dF}=2, \mathrm{p}<.001)$.

A subsequent analysis to determine if the three different ADHD subtypes had a similar need for mental health support, showed that from a total group of $106(24.0 \%)$ threshold children with a specific need, $50 \%$ were from the $\mathrm{C}$ group, $25 \%$ were from the HI group, and $21 \%$ were from the IA group. This difference was not significant (Chi-square 4.9; $\mathrm{dF}=2, \mathrm{p}=.09$ ).

Table 3. Distribution (\%) of Number of Inattentive and Hyperactive \& Impulsive Symptoms in a Population of 6 to 8 years old Children $(\mathrm{N}=2224)$

\begin{tabular}{|c|c|c|c|c|c|c|c|c|c|c|c|c|c|}
\hline & & \multicolumn{12}{|c|}{ Hyperactive \& Impulsive Symptoms } \\
\hline & & 0 & 1 & 2 & 3 & 4 & 5 & 6 & 7 & 8 & 9 & Total \% & Cum. \% \\
\hline \multirow{12}{*}{ 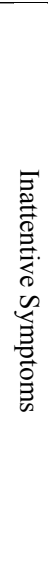 } & 0 & 16.3 & 7.5 & 4.4 & 1.9 & 1.1 & 0.4 & 0.1 & 0 & 0 & 0 & 31.7 & 31.7 \\
\hline & 1 & 5.4 & 7.9 & 5.5 & 3 & 0.7 & 1.6 & 0.2 & 0.1 & 0 & 0 & 24.4 & 56.0 \\
\hline & 2 & 2.6 & 4.2 & 3 & 2.5 & 2 & 0.9 & 0.7 & 0.1 & 0.1 & 0 & 16.1 & 72.1 \\
\hline & 3 & 1.2 & 1.8 & 1.6 & 1.3 & 2.1 & 1.8 & 0.6 & 0.4 & 0.2 & 0.3 & 11.3 & 83.3 \\
\hline & 4 & 0.8 & 1.1 & 0.9 & 1.7 & 0.8 & 1.4 & 0.4 & 0.2 & 0.1 & 0 & 7.4 & 90.8 \\
\hline & 5 & 0 & 0.1 & 0.1 & 0.6 & 0.6 & 0.4 & 0.7 & 0.2 & 0.3 & 0 & 3 & 93.9 \\
\hline & 6 & 0.3 & 0.2 & 0.6 & 0.3 & 0.3 & 0.3 & 0.9 & 1 & 0.1 & 0.2 & 4.2 & 98.1 \\
\hline & 7 & 0 & 0 & 0 & 0 & 0.1 & 0.3 & 0.1 & 0.3 & 0 & 0 & 0.8 & 99.1 \\
\hline & 8 & 0.2 & 0 & 0 & 0 & 0 & 0 & 0 & 0 & 0 & 0.2 & 0.4 & 99.7 \\
\hline & 9 & 0 & 0 & 0 & 0 & 0 & 0 & 0 & 0.3 & 0 & 0.1 & 0.4 & 100.0 \\
\hline & $\begin{array}{c}\text { Total } \\
\%\end{array}$ & 26.8 & 22.8 & 16.1 & 11.3 & 7.7 & 7.1 & 3.7 & 2.6 & 0.8 & 0.8 & & \\
\hline & $\underset{\%}{\mathrm{Cum}}$ & 26.8 & 49.5 & 65.7 & 77.1 & 84.9 & 91.9 & 95.6 & 98.3 & 99.1 & 100.0 & & \\
\hline
\end{tabular}


Figure 1. Plot of the Distribution (\%) of the Inattentive and Hyperactive \& Impulsive Symptoms in a Population of 6 to 8 years old Children $(\mathrm{N}=2224)$

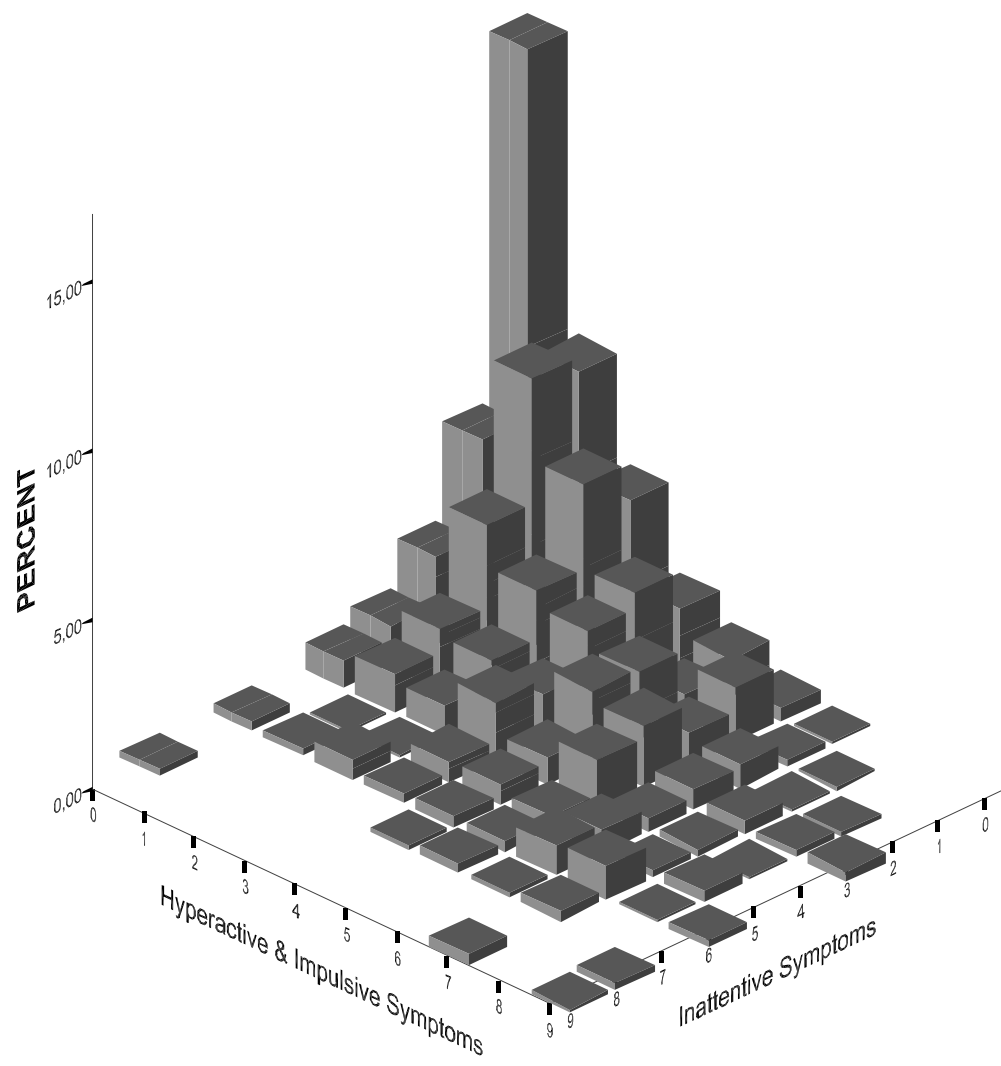

For the group without impairment, this distribution decreased to $35 \%$ for the $\mathrm{C}$ group, $13.5 \%$ for the HI group, and $1.5 \%$ for the IA group. A logistic model including all the symptoms and gender built to predict the need of mental health support, showed a different symptom pattern with 'Often doesn't seem to listen' (odds ratio OR 3.7; C.I. 95\% 1.5-9.4); 'Often runs/climbs' (OR 3.6; C.I. 95\% 1.3-10.1), and 'Often interrupts or intrudes' (OR 4.3; C.I. $95 \% 1.7-10.9)$ as the best predictors 
Figure 2. Flow Chart starting from threshold ADHD symptoms to examine the impact of the DSM criteria in a 6-8 year old population.

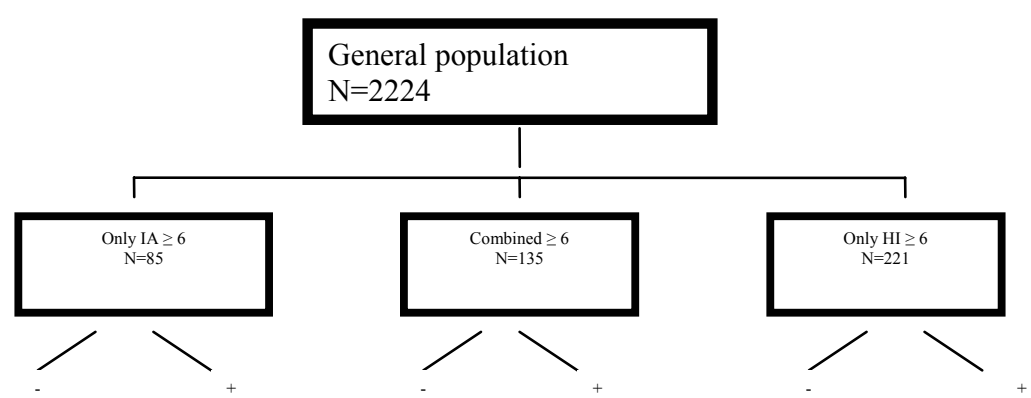

Symptoms for at least 60
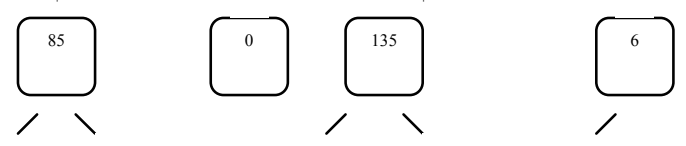

Impairment score
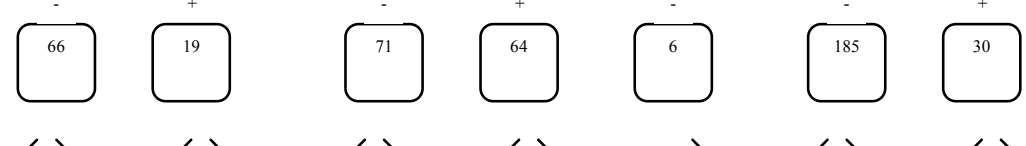

Need for Mental Health Care*
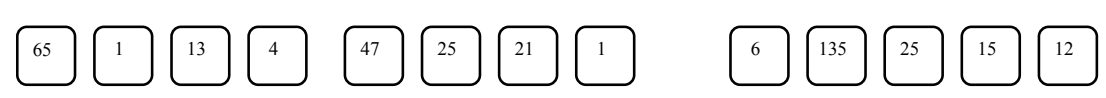

*17 NVOS questionnaires are 


\section{Discussion}

Multiple field trials, primarily based on clinically referred children within a wide age range of 7 to 18 years, have been performed to define and evaluate the DSM-IV criteria for ADHD (Burns, Walsh, \& Gomez, 2003; Faraone, Biederman, \& Friedman, 2000; Graetz, Sawyer, Hazell, Arney, \& Baghurst, 2001; Hartman et al., 2001; Lahey \& Applegate, 2001; B. B. Lahey et al., 1994; McBurnett et al., 1999; Morgan, Hynd, Riccio, \& Hall, 1996; Muris \& Meesters, 2003; Rohde et al., 2001; Woo \& Rey, 2005). Less is known about the distribution of ADHD symptoms and the influence of the ADHD diagnostic criteria in the general population. To our knowledge, this is the first study that has examined the properties of the DSM-IV algorithm in a large population of six to eight year old children, and shown that the distribution of the total number of Inattentive (IA) and Hyperactive \& Impulsive (HI) symptoms does not lead to a well distinguished clinical identity, but rather supports a heterogeneous distribution. Additionally, we found that the total set of 18 DSM-IV symptoms for ADHD appeared to be redundant, and that a smaller subset of 6 symptoms is sufficient to reliably differentiate ADHD children from normal children.

Symptoms of ADHD at a young age are commonly considered to be part of normal development and within the repertoire of healthy developing children. Our results show that this is true for some symptoms such as 'fidgets or squirms', which appeared in about half of the six to eight year old children in our population. However, about $25 \%$ of ADHD symptoms, such as difficulty in sustaining attention, difficulty organising tasks, avoiding sustained attention, and having difficulty playing quietly, were rare, and present in less than $10 \%$ of the children.

The differing symptom prevalence suggests that ADHD symptoms have different predictive powers for the ADHD outcome. Our analyses showed that a subset of four inattentive or four hyperactive symptoms predicted the inattentive, hyperactive and impulsive, or combined ADHD outcome equally well. For the oerall outcome of ADHD, independent of the subtype, a reduction to 6 of the 18 items was sufficient. These were 'Often fails to attend to details', 'Often doesn't seem to listen', and 'Often easily distracted' for the IA symptoms, and 'Often runs/climbs', 'Often on the go', and 'Often interrupts or intrudes' for the HI symptoms. Barkley and his colleagues (Barkley, Murphy, \& Fischer, In press) found a similar result in an adult population. Three of the six symptoms overlapped in both subsets ('Often easily distracted', 'Often doesn't seem to listen' and 'Often on the go'). These findings question whether the DSM-IV symptom list comprises the best possible symptoms for identifying ADHD. Effective screening for ADHD may be quicker and more economic if only a few items are completed by parents and teachers (G. J. August, Realmuto, MacDonald, Nugent, \& Crosby, 1996). 
The requirement for a diagnostic cut-off or threshold score for the number of symptoms was investigated. In our young population, a cut-off of six symptoms in each cluster corresponded to about $10 \%$ in the general population. Statistically, this is a well accepted boundary for the general population. However, no phenotypical boundaries or distinguished subgroups were found to legitimize the clinical identity of ADHD cases or subtypes. The clinical phenotype of ADHD is strongly related to the multivariate distribution of a complex ADHD trait in the population. A too strong focus on a categorical or syndromic approach complicates neurobiological, neuropsychological, and genetic research. For example, in an extensive review, Baeyens concluded that the more fundamental the measurement level, the less unambiguous evidence is found for subtype differences (Baeyens, Roeyers, \& Walle, 2006).

Our data lend further support to working on new algorithms for ADHD that are more developmentally sensitive. These algorithms may differ in terms of key symptoms that characterize certain age ranges and in terms of the symptom threshold level. Similar arguments have been made with regard to the algorithm and symptom threshold level for ADHD in adults (Kooij et al., 2005; Murphy \& Barkley, 1996). Previous studies have examined the role of gender in the symptom pattern but outcomes have varied (Biederman et al., 1999; Biederman, Faraone, \& Monuteaux, 2002; Breen, 1989; Graetz, Sawyer, \& Baghurst, 2005; Greene et al., 2001; Newcorn et al., 2001; Sharp et al., 1999). In all of our statistical models, gender did not play a significant role in the symptom specificity of ADHD.

Another remarkable finding was that the impairment criteria and the need for mental health services criteria generated different groups. Research on clinically referred research groups is commonly described as the Berkson bias population. However, ours is the first study to shed light on how a clinical population differs from the general population and how the Berkson bias may influence the presented ADHD symptoms. The three best predictive symptoms to distinguish both groups reflect a certain interactive aspect of the child-parent relationship (doesn't listen, runs or climbs, interrupts or intrudes) and are different from the best predictive symptoms for the ADHD outcome.

Overall, our findings could be important for the further conceptualization of ADHD in the next generation of diagnostic manuals. More research on the symptom specificity and relevance of the threshold score in different age groups in a general population can lead to a better differentiation between ADHD cases and non-cases, or between subtypes. Our findings in a young population correspond with the results in Barkley's adult population, but should also be replicated in other age groups. The phenotypic DSM-IV concept of ADHD does not lead to a well defined disorder with a homogeneous distribution and clear boundaries. Rather, it provides support for the multidimensional approach suggested by several authors (Banaschewski et al., 2005; Biederman \& Faraone, 2005; Buitelaar, 2005; Castella- 
nos et al., 2005; Faraone, 2005; Sergeant, 2005; Sonuga-Barke, 2005; Swanson et al., 2000). This may also have implications for research on causal models of ADHD.

A major limitation of this study was the lack of multiple informants. This could have led to over or under representation of some disorders (Ezpeleta, de la Osa, Domenech, Navarro, Losilla et al., 1997; Fergusson, Horwood, \& Lynskey, 1993). Although the data did not suggest selective attrition, the low response rate (56.2\%) is still a limitation of the study. The prevalence of ADIKA diagnoses in the non-responder group showed similar prevalence rates (Kroes et al., 2001), giving some support to the validity of our results for an entire population. The specific structure of the ADIKA, with 10 questions for the IA symptoms and 11 questions for the HI symptoms, led to some adaptation. This could have influenced the distribution of the symptoms.

Clinical implications. At a young age, ADHD symptoms are believed to be very common. We found that the prevalence of the ADHD symptoms vary. Approximately 25\% of the symptoms are very rare (present in less than $10 \%$ of children). When impairment is not taken into account, six or more IA or HI symptoms appear in less than $10 \%$ of children. These findings may shed new light on the issue of over diagnosing ADHD. They also stress the importance of carefully questioning the ADHD symptoms described by the caregiver. Specific evaluation of the symptoms 'Often fails to attend to details', 'Often doesn't seem to listen', and 'Often easily distracted' for the IA symptoms, and 'Often runs/climbs', 'Often on the go', and 'Often interrupts or intrudes' for the HI symptoms can help to better distinguish ADHD patients from others. It appears that these six symptoms can reduce the symptom list to a more manageable number, and may also help to maximize accuracy when classifying children with ADHD. 


\section{References}

Achenbach T ed. (1991), Manual for the Child Behavior Checklist 4-18 and 1991 Profile. Burlington: University of Vermont Department of Psychiatry

August G-J, Braswell L, Thuras P (1998), Diagnostic stability of ADHD in a community sample of school-age children screened for disruptive behavior. Journal of Abnormal Child Psychology 26: 345-356

August GJ, Realmuto GM, MacDonald AW, 3rd, Nugent SM, Crosby R (1996), Prevalence of ADHD and comorbid disorders among elementary school children screened for disruptive behavior. Journal of Abnormal Child Psychology 24: 571-95

Baeyens D, Roeyers H, Walle JV (2006), Subtypes of Attention-Deficit/Hyperactivity disorder (ADHD): Distinct or related disorders across measurement levels? Child Psychiatry \& Human Development 36: 403-417

Banaschewski T, Hollis C, Oosterlaan J, Roeyers H, Rubia K, Willcutt E, Taylor E (2005), Towards an understanding of unique and shared pathways in the psychopathophysiology of ADHD. Developmental Science 8: 132-40

Barkley RA, Murphy KR, Fischer M (In press), The Science of ADHD in Adults: ClinicReferred Adults and Children Grown Up. New York: Guilford Press

Biederman J, Faraone SV (2005), Attention-deficit hyperactivity disorder. Lancet 366: 237 48

Biederman J, Faraone SV, Mick E, Williamson S, Wilens TE, Spencer TJ, Weber W, Jetton J, Kraus I, Pert J, Zallen B (1999), Clinical correlates of ADHD in females: findings from a large group of girls ascertained from pediatric and psychiatric referral sources. Journal of the American Academy of Child and Adolescent Psychiatry 38: 966-75

Biederman J, Faraone SV, Monuteaux MC (2002), Differential effect of environmental adversity by gender: Rutter's index of adversity in a group of boys and girls with and without ADHD. American Journal of Psychiatry 159: 1556-1562

Boyle MH, Offord DR, Racine Y, Sanford M, Szatmari P, Fleming JE, Price-Munn N (1993), Evaluation of the Diagnostic Interview for Children and Adolescents for use in general population samples. Journal of Abnormal Child Psychology 21: 663-81

Breen M-J (1989), Cognitive and behavioral differences in AdHD boys and girls. Journal of Child Psychology and Psychiatry and Allied Disciplines 30: 711-716

Buitelaar JK (2005), ADHD: strategies to unravel its genetic architecture. Journal of Neural Transmission-Supplement: 1-17

Burns GL, Walsh JA, Gomez R (2003), Convergent and discriminant validity of trait and source effects in ADHD-inattention and hyperactivity/impulsivity measures across a 3month interval. Journal of Abnormal Child Psychology 31: 529-541

Canino, G., Shrout, P. E., Rubio-Stipec, M., Bird, H. R., Bravo, M., Ramirez, R., et al. (2004). The DSM-IV rates of child and adolescent disorders in Puerto Rico - Prevalence, correlates, service use, and the effects of impairment. Archives of General Psychiatry, 61(1), 85-93.

Castellanos FX, Sonuga-Barke EJ, Scheres A, Di Martino A, Hyde C, Walters JR (2005), Varieties of attention-deficit/hyperactivity disorder-related intra-individual variability. Biological Psychiatry 57: 1416-23

De Groot A, Koot H, Verhulst F (1996), Cross-cultural generalizability of the Youth SelfReport and Teacher's Report Form cross informant syndromes. Journal of Abnormal Child Psychology 24: 651-664 
de la Osa N, Ezpeleta L, Domenech JM, Navarro JB, Losilla JM (1997), Convergent and Discriminant Validity of the Structured Diagnostic Interview for Children and Adolescents (DICA-R). Psychology in Spain 1: 37-44

Ezpeleta L, de la Osa N, Domenech JM, Navarro JB, Losilla JM (1997a), Test-retest reliability of the Spanish adaptation of the Diagnostic Interview of Children and Adolescents. Psicothema 9: 529-539

Ezpeleta L, de la Osa N, Domenech JM, Navarro JB, Losilla JM, Judez J (1997b), Diagnostic agreement between clinicians and the Diagnostic Interview for Children and Adolescents--DICA-R--in an outpatient sample. Journal of Child Psychology and Psychiatry and Allied Disciplines 38: 431-40

Faraone SV (2005), The scientific foundation for understanding attentiondeficit/hyperactivity disorder as a valid psychiatric disorder. European Child \& Adolescent Psychiatry 14: 1-10

Faraone SV, Biederman J (2005), What is the prevalence of adult ADHD? Results of a population screen of 966 adults. Journal of Attention Disorders 9: 384-91

Faraone SV, Biederman J, Friedman D (2000), Validity of DSM-IV subtypes of attentiondeficit/hyperactivity disorder: a family study perspective. Journal of the American Academy of Child and Adolescent Psychiatry 39: 300-7

Fergusson D-M, Horwood L-J, Lynskey M-T (1993), Prevalence and comorbidity of DSMIII-R diagnoses in a birth cohort of 15 year olds. Journal of the American Academy of Child and Adolescent Psychiatry 32: 1127-34

Graetz BW, Sawyer MG, Baghurst P (2005), Gender differences among children with DSMIV ADHD in Australia. Journal of the American Academy of Child and Adolescent Psychiatry 44: 159-168

Graetz BW, Sawyer MG, Hazell PL, Arney F, Baghurst P (2001), Validity of DSM-IVADHD subtypes in a nationally representative sample of Australian children and adolescents. Journal of the American Academy of Child and Adolescent Psychiatry 40: 1410-7

Greene RW, Biederman J, Faraone SV, Monuteaux MC, Mick E, DuPre EP, Fine CS, Goring JC (2001), Social impairment in girls with ADHD: patterns, gender comparisons, and correlates. Journal of the American Academy of Child and Adolescent Psychiatry 40: 704-10

Hartman CA, Hox J, Mellenbergh GJ, Boyle MH, Offord DR, Racine Y, McNamee J, Gadow KD, Sprafkin J, Kelly KL, Nolan EE, Tannock R, Schachar R, Schut H, Postma I, Drost R, Sergeant JA (2001), DSM-IV internal construct validity: when a taxonomy meets data. Journal of Child Psychology and Psychiatry and Allied Disciplines 42: 81736

Kalff AC, Kroes M, Vles JS, Bosma H, Feron FJ, Hendriksen JG, Steyaert J, van Zeben TM, Crolla IF, Jolles J (2001), Factors affecting the relation between parental education as well as occupation and problem behavior in Dutch 5- to 6-year-old children. Social Psychiatry and Psychiatric Epidemiology 36: 324-31

Kooij JJ, Buitelaar JK, van den Oord EJ, Furer JW, Rijnders CA, Hodiamont PP (2005), Internal and external validity of attention-deficit hyperactivity disorder in a populationbased sample of adults. Psychological Medicine 35: 817-27

Kortenbout van der Sluijs M, Levita D, Manen R, Defares P (1993), In: ADIKA, Amsterdams Diagnostisch Interview voor Kinderen en Adolescenten Lisse: Swetz and Zeitlinger

Kroes M, Kalff AC, Kessels AG, Steyaert J, Feron FJ, van Someren AJ, Hurks PP, Hendriksen JG, van Zeben TM, Rozendaal N, Crolla IF, Troost J, Jolles J, Vles JS (2001), Child psychiatric diagnoses in a population of Dutch schoolchildren aged 6 to 8 years. Journal of the American Academy of Child and Adolescent Psychiatry 40: 1401-9 
Lahey B-B, Applegate B, McBurnett K, Biederman J, Greenhill L, Hynd G-W, Barkley R-A, Newcorn J, Jensen P, Richters J, et al. (1994a), DSM-IV field trials for attention deficit hyperactivity disorder in children and adolescents. American Journal of Psychiatry 151: 1673-85

Lahey BB, Applegate B (2001), Validity of DSM-IV ADHD. Journal of the American Academy of Child and Adolescent Psychiatry 40: 502-503

Lahey BB, Pelham WE, Stein MA, Loney J, Trapani C, Nugent K, Kipp H, Schmidt E, Lee S, Cale M, Gold E, Hartung CM, Willcutt E, Baumann B (1998), Validity of DSM-IV attention-deficit/hyperactivity disorder for younger children. Journal of the American Academy of Child and Adolescent Psychiatry 37: 695-702

McBurnett K, Pfiffner LJ, Willcutt E, Tamm L, Lerner M, Ottolini YL, Furman MB (1999), Experimental cross-validation of DSM-IV types of attention-deficit/hyperactivity disorder. Journal of the American Academy of Child and Adolescent Psychiatry 38: 17-24

Morgan AE, Hynd GW, Riccio CA, Hall J (1996), Validity of DSM-IV ADHD predominantly inattentive and combined types: relationship to previous DSM diagnoses/subtype differences. Journal of the American Academy of Child and Adolescent Psychiatry 35: 325-33

Muris P, Meesters C (2003), The validity of attention deficit hyperactivity and hyperkinetic disorder symptom domains in nonclinical Dutch children. Journal of Clinical Child and Adolescent Psychology 32: 460-6

Murphy KR, Barkley RA (1996), Prevalence of DSM-IV ADHD symptoms in adult licensed drivers. Journal of Attention Disorders 1: 147-161

Newcorn JH, Halperin JM, Jensen PS, Abikoff HB, Arnold LE, Cantwell DP, Conners CK, Elliott GR, Epstein JN, Greenhill LL, Hechtman L, Hinshaw SP, Hoza B, Kraemer HC, Pelham WE, Severe JB, Swanson JM, Wells KC, Wigal T, Vitiello B (2001), Symptom profiles in children with ADHD: Effects of comorbidity and gender. Journal of the American Academy of Child and Adolescent Psychiatry 40: 137-146

Reich, W. (2000). Diagnostic Interview for Children and Adolescents (DICA). Journal of the American Academy of Child and Adolescent Psychiatry, 39(1), 59-66.

Reich W, Shayla JJ, Taibleson C (1992), The Diagnostic Interview for Children and Adolescents - Revised (DICA-R) (structured psychiatric interview). St Louis, MO: Washington University.

Robins E, Guze SB (1970), Establishment of diagnostic validity in psychiatric illness: its application to schizophrenia. American Journal of Psychiatry 126: 983-987

Rohde LA, Barbosa G, Polanczyk G, Eizirik M, Rasmussen ER, Neuman RJ, Todd RD (2001), Factor and latent class analysis of DSM-IV ADHD symptoms in a school sample of Brazilian adolescents. Journal of the American Academy of Child and Adolescent Psychiatry 40: 711-718

Sergeant JA (2005), Modeling attention-deficit/hyperactivity disorder: a critical appraisal of the cognitive-energetic model. Biological Psychiatry 57: 1248-55

Sharp WS, Walter JM, Marsh WL, Ritchie GF, Hamburger SD, Castellanos FX (1999), ADHD in girls: clinical comparability of a research sample. Journal of the American Academy of Child and Adolescent Psychiatry 38: 40-7

Sonuga-Barke EJS (2005), Causal models of attention-deficit/hyperactivity disorder: From common simple deficits to multiple developmental pathways. Biological Psychiatry 57: 1231-1238

Swanson J-M, Flodman P, Kennedy J, Spence M-A, Moyzis R, Schuck S, Murias M, Moriarty J, Barr C, Smith M, Posner M (2000), Dopamine genes and ADHD. Neuroscience and Biobehavioral Reviews 24: 21-25 
van den Brandt P-A, Goldbohm R-A, van 't Veer P, Volovics A, Hermus R-J, Sturmans F (1990), A large-scale prospective cohort study on diet and cancer in The Netherlands. Journal of Clinical Epidemiology 43: 285-95

Van Grimbergen I, Célestin-Westreich, S \& Ponjaert-Kristofferson, I (1999), Validering van ADIKA-IV (deel externaliserend gedrag) bij een klinische populatie kinderen tussen 6 en 18 jaar. In: De kinderschoenen ontgroeid? Tweede Vlaams Congres Kinder- en jeugdpsychiatrie en -psychotherapie., Garant ed. Leuven, pp p.76

Verhulst F, Van der Ende J, Koot H (1996), In: Handleiding voor de CBCL Rotterdam: Erasmus University/ Departement of Child and Adolescent Psychiatry, Sophia Children's Hospital

Wels PMA, Robbroeckx LMH (1996), Manual of Nijmeegse Questionnaire for Educational Situation Lisse: Swets and Zeitlinger BV

Woo BSC, Rey JM (2005), The validity of the DSM-IV subtypes of attentiondeficit/hyperactivity disorder. Australian and New Zealand Journal of Psychiatry 39: 344-353

Woodruff R (1971), A Simple Method for Approximating the Variance of a Complicated Estimate. Journal of the American Statistical Association 66: 411-414 
Chapter 4

\title{
Comorbidity Patterns in a Community Sample of
}

\author{
Seven Year Old Dutch School Children ${ }^{1}$
}

${ }^{1}$ Sabine Tremmery, Jan K. Buitelaar, Jean Steyaert, Geert Molenberghs, Frans J.M. Feron, Ariane C. Kalff, Petra P.M. Hurks, Jos G.M. Hendriksen, Johan S.H. Vles, Jelle Jolles. Submitted for publication 


\section{Abstract}

Objective: There is limited data on the prevalence and comorbidity of psychiatric disorders at among very young children. This report describes the prevalence of psychiatric disorders and comorbidity patterns in a large school-based sample of Dutch children around age 7.

Methods: In a two stage design involving two cohorts, 2,466 eligible children were screened using the Child Behavior Checklist (CBCL). Next, 789 (400 high risk and 389 low risk) children were assessed using the Amsterdam Diagnostic Interview for Children and Adolescents (ADIKA, DSM-IIIR / IV). Prevalence rates were weighted to the study population $(\mathrm{N}=2,466)$. Comorbidity patterns were examined using univariate and multivariate logistic regression.

Results: ADIKA diagnoses, including disruptive behavior disorders, mood disorders, anxiety disorders (including simple phobia) and elimination disorders were present in $55.7 \%$ of the respondents. When the need for mental health support was used as an impairment criterion, the prevalence decreased to 5\%. Comorbidity was present in between $41 \%$ and $75 \%$ of the disorders, was more frequent in boys, and was associated with more impairment. Only the comorbidities between ADHD-ODD/CD and ODD/CD-anxiety disorder were strong and remained in multivariate models, controlling for the presence of other psychiatric disorders. Elimination disorder was not predicted by any psychiatric disorder, but was associated with ODD/CD when clinical impairment was taken into account.

Conclusion: The high prevalence of comorbid psychopathology shows that child psychiatric disorders cannot be described well by unique separate diagnostic categories. Extended analysis proves that statistical artefacts are present in many 2 by 2 comorbid associations. These findings are important for the validation of future models of psychopathology. 


\section{Introduction}

Epidemiological data show that the co-occurrence or comorbidity of two or more supposedly separate child psychiatric conditions far exceeds that expected by chance. Generally, comorbidity refers to the presence of more than one mental disorder occurring in an individual at the same time. The first quantitative description of comorbidity between classes of child and adolescent psychiatric disorders in the general population, assessed with structured diagnostics, appeared only in 1987 (Anderson et al., 1987). Many reviews have detailed the importance of taking comorbidity into account when endeavouring to understand the aetiology, classification, course, and treatment of psychiatric disorders (Angold et al., 1999; Jensen, 2003; Lilienfeld, 2003; Rutter and Sroufe, 2000).

For the majority of research performed using clinically referred samples, the strength of associations between disorders cannot be generalised due to an artefact of referral bias. Research in the past decade has made it also clear that prevalence rates and associated comorbidity are highly dependent on the extent to which the algorithms used to make the diagnosis include or ignore functional impairment. In the DSM-IV some symptoms and diagnoses require impaired functioning to be present, and others do not. It is clear that prevalence estimates which do and which do not take into account impairment of functioning vary widely (Canino et al., 2004; Shaffer et al., 1996). However, there is no consensus on how to operationalize clinically important impairment in epidemiologic studies ((Angold et al., 1999). The CGAS is an example of an assessment strategy that has proven useful, but it has not been widely used in epidemiologic studies and there is variation in its application across studies. Other studies have found that problem perception and impact were positively associated with child symptomatology and impairment and can be a good alternative (Teagle, 2002).

Different hypotheses on the concept of comorbidity have been proposed. Hypotheses have included detection artefacts (overlapping diagnostic criteria, artificial subdivision of a syndrome), or true comorbidity (with either shared risk factors, overlap of risk factors, or one disorder creating increased risk for the other) (Angold et al., 1999; Gillberg et al., 2004; Lilienfeld, 2003; Meehl, 2001; Rhee et al., 2003). Other authors have proposed rather similar models of comorbidity, including: (a) alternate forms of the same disorder; (b) multiformity, where the presence of one disorder increases the risk of another disorder; (c) three independent disorders, where the presence of two disorders are due to the third disorder; (d) correlated liabilities where the risk factors of two disorders correlate; and (e) direct causal models (Neale and Kendler, 1995). A meta-analysis of general population studies in children and adolescents showed that risk for comorbidity was highest within the externalising domain (between ADHD and Conduct Disorder-Oppositional Defiant Disorder (CD-ODD); median odds ratio (OR) of 10.7) and the internalising domain (between depression (DEP) 
and anxiety disorders (AD); median OR of 8.2) (Angold et al., 1999). The relationship between DEP and CD-ODD was almost as strong as that between DEP and AD, and DEP rather than AD showed a stronger relationship with externalising disorders.

Despite the high prevalence of comorbidity, only a few studies (Ford et al., 2003; Kroes et al., 2001) have examined diagnostic comorbidity in a general population of young children. Furthermore, to date, comorbidity research has mostly been performed using univariate or single factor logistic regression analyses. In order to examine the patterns of overlap between psychiatric disorders, adjustment for the presence of other disorders is required. By using multilogistic models, the main research question changes from 'Is comorbidity present?' to 'What are the best predictors for the presence of a disorder?' For example, as a result of epiphenomenal comorbidity, high associations can be found in a two- by-two analysis between all three conditions A, B, and C. However, condition A may be the link between conditions B and C. In a multilogistic analysis, the link between B and C will then disappear.

In this article, we aim to examine the comorbidity patterns in a population of school children all aged approximately seven. This population was derived from the "Study of Attention Disorders in Maastricht” study (SAM). The strengths of the SAM study include the large number of subjects within one age range and the young age of the children.. This age range is a critical period in the development of scholastic learning and further development of emotional, language and mathematic skills and important to understand the course of psychiatric disorders. Additional strengths are the assessment of a wide range of disorders including elimination disorder, the inclusion of impairment and impact criteria, and the 'intention to treat' biostatistical analysis that took the properties of the design into account. In order to examine the consistency of our results, we first examine the two-by-two comorbidity patterns with well known univariate logistic techniques. To test the robustness of the comorbid relationships between single disorders found by Angold (1999), we explored the comorbidity patterns with respect to multiple influencing factors, such as the presence of other psychopathology and the influence of environmental factors. In this way, this paper elaborates further on the findings described on ADHD comorbidity in an earlier paper of our research group (Kroes et al., 2001), by -first- investigating the possible impact of additional medical factors and comorbidity and -second- elaborating on the need for mental health care support as a global measure to determine the impairment. 


\section{Method}

\section{Subjects and Procedure}

\section{Phase One: Children enrolled at approximately six years of age}

The methodology has been reported in detail elsewhere (Kalff et al., 2001). This study was approved by the Medical Ethical Committee at the Academic Hospital Maastricht. All parents of a school-based population of 4,390 children were approached to participate. All children were enrolled in kindergarten (year before the first grade of the elementary school) in the southern region of the Netherlands, namely Maastricht. The selection took place in two year cohorts. Of the first cohort (start 1996-1997), the parents of 1,317 (57.5\%; 699 boys and 618 girls, mean age $\pm_{-}$SD $5.87 \pm 0.49$ year ) of the 2,290 children initially approached agreed to participate. Of the second cohort (start 1998-1999), the parents of 1,149 ( $54.7 \%$, 592 boys and 557 girls, $5.87 \pm 0.49$ year) of 2,100 children initially approached agreed to participate. Together, the two cohorts resulted in a total of 2,466 (56.2\%) participants. Written informed consent was obtained for phases one and two. When parents declined to participate, no explanation was required. No significant differences were observed for the first cohort between the participants and the non-participants in terms of age, sex, and demographic factors (Kroes et al., 2001). In the first phase, the parents of all 2,466 children completed the Child Behavior Checklist (CBCL) (Achenbach, 1991; Verhulst et al., 1996) and a questionnaire that measured sociodemographic characteristics.

\section{Phase Two: First follow-up at seven years of age.}

On the basis of CBCL scores in phase one, three groups of children (in total $N=789$ ) were selected for follow-up. The first, an externalising high risk group, comprised 306 children with scores on the CBCL broadband externalising scale above the $90^{\text {th }}$ percentile $(\mathrm{T}>63)$, scores on the inattention scale of the CBCL above the $95^{\text {th }}$ percentile $(T>67)$, or both. The second, an internalising high risk group, consisted of 94 children with scores on the broadband internalising scale of the CBCL above the $90^{\text {th }}$ percentile $(T>63)$ and who did not meet the selection criteria for the externalising high risk group. The cut-off points chosen represent the clinical cut-off scores for the CBCL broadband and inattention scales determined in earlier Dutch epidemiological studies (Verhulst et al., 1996).Lastly, a control group of 389 children with CBCL total scores below the $90^{\text {th }}$ percentile who did not meet selection criteria for the two high risk groups was selected. These children were matched to the children of the two high risk groups for age, sex, and geographic area (urban versus rural). The decision to use the attention problems subscale of the CBCL and the selection of the three groups was based on the original research questions from the SAM study (Hurks et al., 2004; Hurks et al., 2006; Kalff et al., 2003; Kalff et al., 2005; Kalff et al., 2002; Kroes et al., 2002) in which precursors of attention deficits were studied. 
The parents of all children were invited to participate in structured psychiatric interviews (see below). The time elapsed between CBCL and ADIKA was about one school year. The parents of 711 (91.4\%) of the 789 children (410 boys and 301 girls) agreed to have their child participate in an interview. Among these were 276 (90.2\%) from the first group, 87 (91\%) from the second group, and 348 (90\%) from the third group. The participating and non-participating children did not differ significantly in terms of CBCL scores, sex, or demographic characteristics.

\section{Figure 1. Sampling Design for the "Study of Attention Disorders in Maastricht"}

CBCL Selection

At about 6 Years

$\mathrm{N}=789$

Follow-up

At about 7 Years

$\mathrm{N}=711$

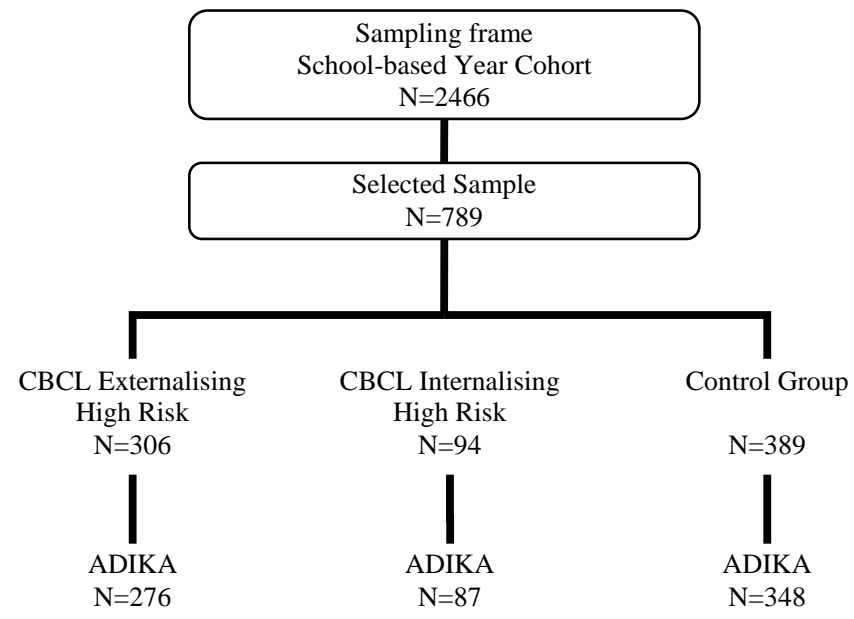

\section{Measures}

The Child Behavior Checklist (CBCL) (Achenbach, 1991) was completed by parents in the first phase when the children were around six years old. The CBCL is scored by computer and uses appropriate age and sex norms for the Dutch population (Verhulst et al., 1996).

Demographic information was assessed in the first phase. The level of parental occupation was scored on a seven-point scale, ranging from low skilled labour to scientific/academic employment. For the purposes of this study, education was divided into three levels: low (1,2, and 3), moderate (4 and 5), and high (6 and 7) (van den Brandt et al., 1990). Additional demographic information included the country of the parents' birth, family intactness (child 
living with one versus two parents), living area (urban area of Maastricht versus surrounding rural towns), and the presence of psychiatric illness in one or more parent.

The Diagnostic Interview for Children and Adolescents (DICA-R) (Reich et al., 1992) in its Dutch version (Amsterdam Diagnostisch Interview voor Kinderen - ADIKA) (Kortenbout van der Sluijs et al., 1993) was used for structured psychiatric assessment in the second phase, when children were approximately seven years of age. The ADIKA is based on DSMIII-R criteria (American Psychiatric Association, 1994) and was adapted to include the DSM-IV criteria (APA, 1994) for diagnosing ADHD (Van Grimbergen, 1999). The reliability and validity of the DSM-IV criteria for diagnosing ADHD are good to average.

Although no reliability studies have been performed with the ADIKA, the DICA-R has been described recently as a useful measure for providing reliable psychiatric information about children in both research and clinical settings (Reich, 2000). Parents were the most stable in reporting disorders in a six to nine year old population (Boyle et al., 1993). The test-retest reliability of DICA-R in samples of 251 (Boyle et al., 1993) and 110 subjects (Ezpeleta et al., 1997a)) was good to very good for the majority of diagnoses (ADHD $0.51-0.86$; ODD 0.61 - 0.92; CD 0.66 - 0.87; mood disorder 0.31 - 0.35; dysthymia 0.49 - 0.51; anxiety disorder 0.62 - 0.69 ; separation anxiety disorder 0.62 ; enuresis 0.73 ; encopresis 0.74 ). Additionally, agreement between trained lay interviewers and child psychiatrists was generally high (any diagnosis 0.78-1.0) (August et al., 1998; Boyle et al., 1993). The convergent validity using the CBCL as a criterion to discriminate between psychiatric $(\mathrm{N}=196)$ and control ( $\mathrm{N}=130)$ groups showed that the DICA-R is a valid instrument for the assessment of the most common child psychological disorders (de la Osa et al., 1997).

In the first cohort, the ADIKA was administered at home or at the university to the parents of the seven year old children by three different interviewers, namely a medical doctor, a psychologist and a health-care worker. In the second cohort, the test was administered by two different interviewers, namely a child-psychiatry trainee and a psychologist. All interviewers had received prior training. To reach consensus and improve the reliability and validity of the diagnoses, the results were discussed weekly by the interviewers and the researching child psychiatrist during an intensive guidance session. Discrepancy in scoring was resolved by consensus. When questions arose, parents were reassessed for further clarification.

All interviewers were blind to the results of prior assessments. The ADIKA assess symptoms of axis-I psychiatric disorders, such as disruptive (ADHD, ODD and CD), mood (depression and dysthymia), anxiety (separation anxiety disorder, generalized anxiety disorder, obsessive-compulsive disorder, social phobia, simple phobia and post-traumatic stress disorder), and elimination disorders (enuresis and encopresis), as well as their duration, im- 
pairment, and possible consultation with health professionals. Diagnoses were generated by a computer algorithm that ignores the hierarchical DSM structure (Rozendaal, 1998). For example, ODD and CD could be diagnosed in the same patient. Only diagnoses in the present were used for this article.

Subjective Family Burden and Assessment of Educational Situation was measured by a Dutch questionnaire entitled the Nijmegen Family Situation Questionnaire (NVOS). The reliability and validity of this questionnaire are good to excellent (Wels and Robbroeckx, 1996). Parents can choose between eight descriptions of the current educational situation, with the highest score indicating that there are no problems and that there is no need for educational or mental health support and the lowest score indicating that there are severe problems and that support is urgently needed. The norm score for a clinically referred population is 4.07 and the norm score for a control group is 2.07. The eight-point scale was divided into two levels for the present study: (a) no need for educational or mental health support (1, 2, and 3); and (b) need for educational or mental health support (4-8).

\section{Statistical procedures}

The distribution of our sample was influenced by the two stage sample design and the process of attrition. On the basis of CBCL scores in phase one, three groups of children $(\mathrm{N}=789)$ were selected for the second phase. These groups were: (a) an externalising high risk group; (b) an internalising high risk group, and (c) a control (i.e. low risk) group that was matched to the children of the two high risk groups for age, sex, and type of school (urban versus rural). As such, the children in the first and second group represented all children with severe behavioural problems and no adjustment was needed (weight=1). However, because we choose to match the control group to the high risk groups, thereby making selection nonrandom, we were obliged to use adjusted weights in order to return to the original size. A backward logistic regression analysis including gender, age, living area, parental occupation, cohort, and the different behaviour subscales of the CBCL was used to estimate the selection probability for each individual control child in phase two. Tests for co-linearity showed no conflicts. The final model, including the inattention and thought problem subscales of the CBCL, gender, age, and living area, had a sensitivity of $81.1 \%$. Crossvalidation in different observation subsets had equal sensitivity (78.9-82.2\%). The individual inverse predictive values served as a weight measurement for the control group. All three selected groups had some attrition and/or missing data which was too small to build robust statistical models that could predict the attrition process. Univariate analysis did not show any specific trends. The assumption was therefore that the outcomes for the nonrespondents were "missing at random". 
The weights obtained were used to extrapolate the prevalence and comorbidity rates of the different ADIKA diagnoses in the selected sample $(\mathrm{N}=711)$ to the entire cohort $(\mathrm{N}=2,225)$ by using SAS Proc SURVEYFREQ and SURVEYLOGISTIC. For statistical inferences, this procedure incorporates complex survey sample designs, including unequal weighting, and uses the Taylor expansion method to estimate the variances of the regression parameters and odds ratios (Woodruff, 1971). Data were analysed using single and multivariable logistic regression. Additionally, the Wald confidence interval for adjusted odds ratios is reported. The goodness-of-fit statistic for the overall models and independent variables were satisfactory in all models.

\section{Results}

\section{Estimated Prevalence of Childhood Psychiatric Disorders}

Table 1 presents the prevalence rates in the sample survey and the generalised DSM-III-R / DSM-IV disorder prevalence rates for the participants with and without the "need for mental health support”. By introducing this criterion, we created two dimensions. Firstly, in the absence of the need for mental health support, we considered the disorders to represent the distribution of symptoms with impairment in functioning but without severity dimensions. We therefore refer to this dimension as general prevalence or comorbidity. Secondly, when the need for mental health support was present, we considered this group to be a more representative clinical sample within a general population without referral bias. As mentioned earlier, problem perception and impact were positively associated with child symptomatology and impairment.(Teagle, 2002). We refer to this dimension as clinical prevalence or comorbidity. The disorders were grouped in five major categories: namely ADHD, disruptive disorder (ODD/CD), mood disorder (MD), anxiety disorder (AD), and elimination disorder (ED). At least one diagnosis was present in 487 children, representing a weighted general prevalence of $55.7 \%$ (95\% confidence interval (CI) 51-60.4\%). The presence of enuresis and simple phobia is included in this prevalence rate. The weighted clinical prevalence was much lower, at only 5\% (95\% CI 3.4-6.5).

The gender ratio for each population is also provided in table 1 . More boys were represented in the clinical population (ratio 2.8/1) than in the general population (ratio 1.2/1). Additional analyses showed that, in comparison to the general population, boys in the clinical population had more multiple comorbidities (Cochran-Mantel-Haenszel Statistics=5.5, $\mathrm{dF}=1, \mathrm{p}=.02)$. 
Table 1. DSM-III/IV Disorder Prevalence Rates (\%) with and without "need for mental health support" criteria of 6-8 Year Old Children in the Sample and Generalized Prevalence Rates (\%)

\begin{tabular}{|c|c|c|c|c|c|c|c|c|}
\hline \multirow{2}{*}{ Disorder } & \multicolumn{2}{|c|}{ Sample Survey $(\mathrm{N}=711)$} & \multicolumn{3}{|c|}{$\begin{array}{l}\text { Responder group without "need for mental } \\
\text { health support" criteria }(\mathrm{N}=2224)\end{array}$} & \multicolumn{3}{|c|}{$\begin{array}{l}\text { Responder group with "need for mental health } \\
\text { support" criteria (N=2189) }\end{array}$} \\
\hline & $\mathrm{N}$ & $\%$ & $\%$ & C.I. & Male/female & $\%$ & C.I. & Male/female \\
\hline \multicolumn{9}{|c|}{ Attention Deficit Hyperactive Disorder } \\
\hline ADHD & 89 & 12.5 & 5.0 & $(3.7-6.3)$ & $1.9 / 1$ & 2.2 & $(1.3-3.0)$ & $4.3 / 1$ \\
\hline \multicolumn{9}{|l|}{ Disruptive Disorder } \\
\hline Oppositional Defiant Disorder & 124 & 17.4 & 8.9 & $(6.8-10.9)$ & $2.7 / 1$ & 3.1 & $(1.8-4.3)$ & $4.5 / 1$ \\
\hline Conduct Disorder & 33 & 4.64 & 2.0 & $(1.2-2.9)$ & $3 / 1$ & 0.8 & $(0.3-1.3)$ & $3.4 / 1$ \\
\hline Any Disruptive Disorder & 157 & 22.1 & 10.9 & $(8.7-13.1)$ & $2.8 / 1$ & 3.9 & $(2.6-5.2)$ & $4.2 / 1$ \\
\hline \multicolumn{9}{|l|}{ Mood Disorder } \\
\hline Major Depressive Disorder & 57 & 8.0 & 5.2 & $(3.4-6.9)$ & $2.9 / 1$ & 0.6 & $(0.3-1.0)$ & $6 / 1$ \\
\hline Dysthemic Disorder & 39 & 5.5 & 3.0 & $(1.7-4.3)$ & $5.1 / 1$ & 0.6 & $(0.3-1.0)$ & $6 / 1$ \\
\hline Any mood Disorder & 64 & 9.0 & 5.7 & $(3.8-7.5)$ & $3.1 / 1$ & 0.8 & $(0.4-1.2)$ & $7.5 / 1$ \\
\hline \multicolumn{9}{|l|}{ Anxiety Disorder } \\
\hline Generalized Anxiety Disorder & 46 & 6.5 & 3.5 & $(2.0-4.9)$ & $1.3 / 1$ & 0.4 & $(0.1-0.7)$ & $2 / 1$ \\
\hline Social Fobia & 31 & 4.4 & 2.2 & $(1.1-3.4)$ & $1 / 1.1$ & 0.3 & $(0.1-0.5)$ & $5 / 1$ \\
\hline Simple Phobia & 197 & 27.7 & 20.9 & $(17.3-24.6)$ & $1 / 1$ & 2.3 & $(1.2-3.4)$ & $1.8 / 1$ \\
\hline Separation Anxiety Disorder & 101 & 14.2 & 11.8 & $(8.9-14.7)$ & $1 / 1.1$ & 1.4 & $(0.6-2.1)$ & $2.7 / 1$ \\
\hline Obsessive-Compulsive Disorder & 33 & 4.6 & 3.9 & $(2.3-5.6)$ & $1.1 / 1$ & 0.6 & $(0-1.2)$ & -* \\
\hline Post-Traumatic Stress Disorder & 20 & 2.8 & 1.9 & $(0.83-3.05)$ & $3.7 / 1$ & 0.1 & $(0-0.3)$ & -* \\
\hline Any Anxiety Disorder & 280 & 39.4 & 30.9 & $(26.8-35.2)$ & $1 / 1.2$ & 3.2 & $(2.0-4.5)$ & $2.4 / 1$ \\
\hline \multicolumn{9}{|l|}{ Elimination Disorder } \\
\hline Functional enuresis & 112 & 15.7 & 13.5 & $(10.6-16.5)$ & $3 / 1$ & 0.9 & $(0.2-1.6)$ & $18.7 / 1$ \\
\hline Functional encopresis & 32 & 4.5 & 2.9 & $(1.6-4.1)$ & $3.1 / 1$ & 0.2 & $(0-0.4)$ & $1.5 / 1$ \\
\hline Any Disorder of Elimination & 132 & 18.6 & 15.2 & $(12.1-18.3)$ & $2.8 / 1$ & 1 & $(0.3-1.7)$ & $10.3 / 1$ \\
\hline At least one Disorder & 487 & 68.5 & 55.7 & $(51-60.4)$ & $1.2 / 1$ & 5 & $(3.4-6.5)$ & $2.8 / 1$ \\
\hline 1 Disorder & 229 & 32.9 & 32.9 & $(28.5-37.2)$ & $1.1 / 1$ & 1.5 & $(0.5-2.5)$ & $1.1 / 1$ \\
\hline 2 Disorders & 141 & 14.8 & 14.8 & $(11.7-17.9)$ & $1 / 1$ & 1.2 & $(0.5-1.9)$ & $4.2 / 1$ \\
\hline 3 Disorders & 79 & 6.0 & 6.0 & $(4.3-7.8)$ & $3.4 / 1$ & 2.0 & $(1.1-2.9)$ & $5.2 / 1$ \\
\hline 4 Disorders & 34 & 1.8 & 1.8 & $(1.1-2.6)$ & $1.4 / 1$ & 0.3 & $(0.05-0.5)$ & $5 / 1$ \\
\hline 5 Disorders & 4 & 0.1 & 0.2 & $(0-0.4)$ & -* & 0.05 & $(0-0.1)$ & -* \\
\hline
\end{tabular}

* No girls. 


\section{Diagnostic Comorbidity in the General Population}

\section{Univariate analyses}

The results of the univariate two-by-two and multivariate logistic analyses are presented in Table 2 and 3. The two-by-two analysis demonstrated strong associations between disorders, with the strongest being between ADHD and ODD/CD (OR 26, 95\% CI 14.1-48). The OR for ADHD was 5.4 (95\% CI 2.7-10.9), the OR for ODD/CD was 3.3 (95\% CI 1.8-6.2) and the OR for $\mathrm{AD}$ was 2.3 (95\% CI 2-5.2). These ORs suggest that, at age seven, MD is more strongly related to externalising than to internalising disorders. Only ED was not specifically related to other psychiatric disorders. The ORs were low for ODD/CD (1.8, 95\% CI 1.1-3.12), MD (2.4, 95\% CI 1.1-5.4), and AD (1.8, 95\% CI 1.1-2.9). For ADHD, the ORs were not significant.

\section{Multivariate analyses}

When adjusting for the presence of other disorders, only three comorbidity patterns remained. Listed according to the strength of their association, the comorbidity patterns were ADHD-ODD/CD (OR 21.7, 95\% CI 11.9-40), ADHD-MD (OR 3.3, 95\% CI 1.7-6.4) and ODD/CD-AD (OR 2.8, 95\% CI 1.6-4.7).

The stepwise introduction of sociodemographic variables, such as gender, age, level of parental occupation, country of the parents' birth, family intactness, living area, and psychiatric illness of one or more parents, into the multivariate logistic model did not have any influence on the overall comorbidity patterns. Due to missing data, the weighted sample dropped to 1881 children. No significant predictors could be added in the ADHD or AD model. For ODD/CD, additional risk factors included the child being of male gender (OR 2.7, 95\% CI 1.4-5.1) and the child's parents being born in a foreign country (OR 3.2, 95\% CI 1.2- 8.3). The chance of having MD was also increased in males (OR 2.5, 95\% CI 1.16.1) as well as the absence of family intactness (OR 2.9, 95\% CI 1.1-8.2). The only predictor for ED was male gender (OR 3.3, 95\% CI 1.8- 6.1). No psychiatric disorder further predicted ED significantly. 
Table 2. Generalized Diagnostic Comorbidity with and without “need for mental health support" criteria among the 6-8 Year Old Children

\begin{tabular}{|c|c|c|c|c|c|c|c|c|c|c|c|c|}
\hline & \multicolumn{2}{|c|}{ Comorbidity } & \multicolumn{2}{|c|}{ ADHD } & \multicolumn{2}{|c|}{ Disruptive Disorder } & \multicolumn{2}{|c|}{ Mood Disorder } & \multicolumn{2}{|c|}{ Anxiety Disorder } & \multicolumn{2}{|c|}{ Elimination Disorder } \\
\hline & $\%$ & (s.e.) & $\%$ & (s.e.) & $\%$ & (s.e.) & $\%$ & (s.e.) & $\%$ & (s.e.) & $\%$ & (s.e.) \\
\hline \multicolumn{13}{|l|}{ ADHD } \\
\hline $\begin{array}{l}\text { With need for mental } \\
\text { health support }\end{array}$ & 100 & - & - & & 91.6 & $(4.2)$ & 25.2 & $(7.2)$ & 53.8 & $(10)$ & 29.4 & $(9.8)$ \\
\hline \multicolumn{13}{|l|}{ Disruptive Disorder } \\
\hline $\begin{array}{l}\text { With need for mental } \\
\text { health support }\end{array}$ & 84.3 & $(7.3)$ & 51.5 & $(8.6)$ & - & & 17.7 & $(4.8)$ & 57.1 & $(8.5)$ & 23.2 & $(7.6)$ \\
\hline \multicolumn{13}{|l|}{ Mood Disorder } \\
\hline $\begin{array}{l}\text { Without need for men- } \\
\text { tal health support }\end{array}$ & 75 & (7.3) & 19 & $(4.9)$ & 26.9 & $(5.8)$ & - & & 49.0 & $(8.4)$ & 28.7 & $(8.1)$ \\
\hline $\begin{array}{l}\text { With need for mental } \\
\text { health support }\end{array}$ & 100 & - & 70.6 & $(11.1)$ & 88.2 & $(7.8)$ & - & & 47.1 & $(12.1)$ & 29.4 & $(11.1)$ \\
\hline \multicolumn{13}{|l|}{ Anxiety Disorder } \\
\hline $\begin{array}{l}\text { With need for mental } \\
\text { health support }\end{array}$ & 73.7 & $(10.1)$ & 36.0 & $(8.8)$ & 68 & $(10)$ & 11.2 & $(4.2)$ & - & & 15.0 & $(6.9)$ \\
\hline \multicolumn{13}{|l|}{ Elimination Disorder } \\
\hline $\begin{array}{l}\text { Without need for men- } \\
\text { tal health support }\end{array}$ & 55.5 & $(5.5)$ & 7.4 & $(2.0)$ & 16.7 & $(3.4)$ & 10.7 & $(3.5)$ & 42.2 & $(5.4)$ & - & \\
\hline $\begin{array}{l}\text { With need for mental } \\
\text { health support }\end{array}$ & 100 & - & 61.7 & $(17)$ & 86.8 & (8) & 22.1 & $(10.5)$ & 47.1 & (17) & - & \\
\hline
\end{tabular}




\section{Diagnostic Comorbidity in the Clinical Population}

\section{Univariate analyses}

All two-by-two correlations were highly significant and the ORs were large despite the large sample size and low prevalence rate (table 2 and 3).

\section{Multivariate analysis}

By adjusting for the presence of other disorders, specific comorbidity patterns became visible. Independent of the type of psychopathology, the chance of having ODD/CD increased significantly and was strongest for ADHD (OR 265, 95\% CI 31->999), AD (OR 121, 95\% CI 26-555), and ED (OR 106, 95\% CI 6.6->999). The chance of having ODD/CD was least strong for MD (OR 68, 95\% CI 3.2->999). Additionally, the presence of ODD/CD led to an increased risk of having ADHD (OR 159, 95\% CI 25->999), AD (OR 86, 95\% CI 20-362) and ED (OR 7.4, 95\% CI 1.04-54). No other pair-wise associations remained significant in the multivariate analysis.

Figure 2. Schematic Presentation of Comorbidity Pattern for the population when the criteria 'need for mental health support' is included.

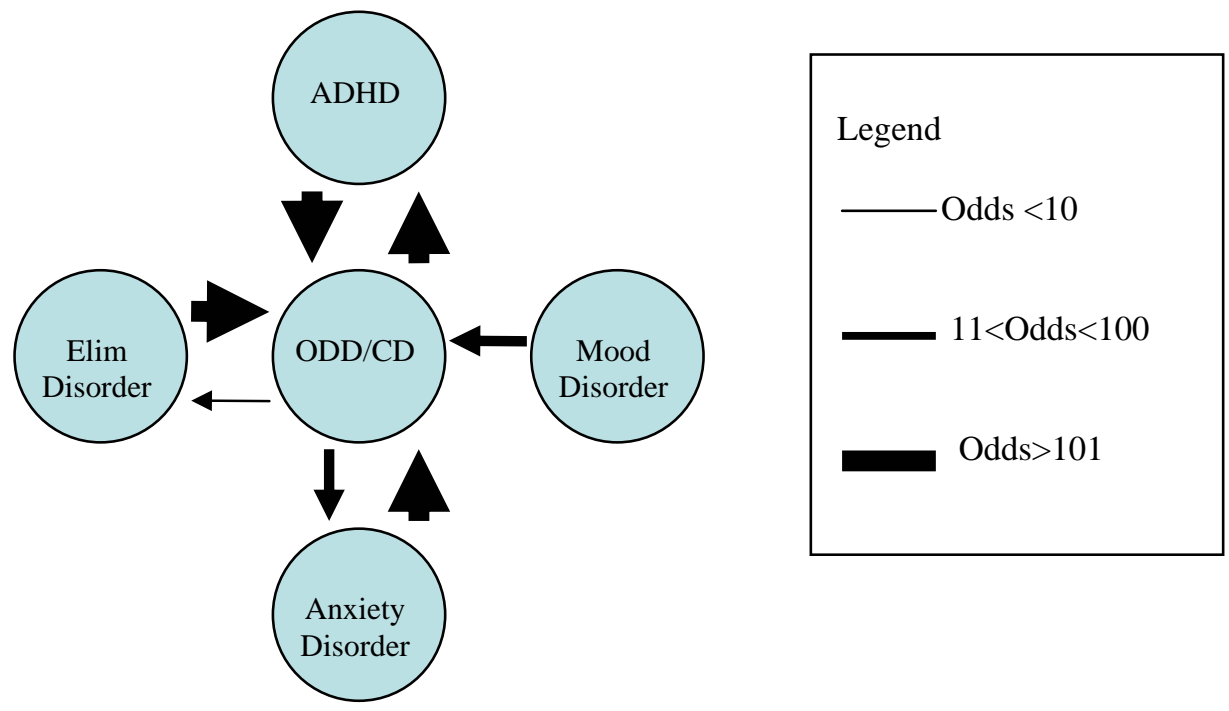


The sociodemographic risk factors were then introduced into the multivariate logistic model in a stepwise manner and showed no influence on the overall comorbidity patterns. Due to missing data, the analysis was performed on a weighted sample of 1859 individuals. No significant variables could be added to the model for ADHD, MD and ED. For the ODD/CD model, an age trend with a risk raise of 3.7 (95\% CI 1.3-10.1) per year of age was found and the absence of family intactness (OR 10.4, 95\% CI 1.4-79.5) had a negative influence. In contrast, the absence of family intactness was a borderline significant protective factor for $\mathrm{AD}$, and children of broken families had 4.8 (95\% CI 1.02-22.2) times fewer anxiety symptoms.

\section{Discussion}

\section{Prevalence of Childhood Psychiatric Disorders}

This paper has reported on the estimated prevalence and comorbidity rates of a number of common DSM-III-R (IV) disorders in a population of six to eight year old children. An earlier report on the SAM study (Kroes et al., 2001) showed that the prevalence rates in the clinical group were very similar to prevalence rates in the entire population. We found a weighted general prevalence of $55.7 \%$, which is at the higher end of the range reported by other studies(Canino et al., 2004; Costello et al., 1996; Ford et al., 2003; Verhulst et al., 1997). This can most likely be explained by our inclusion of elimination disorder and simple phobia. Age seven is a critical age for these disorders and it is therefore difficult to make distinctions between developmentally healthy levels of anxiety, delay of development, and true psychopathology.

We used the need for mental health care support as a global measure to determine the proportion of children with a disorder who could considered to be clinical cases. When this impact criteria is added for these three diagnoses, only one out of ten diagnoses remain in children of this age range.

In the clinical population, our study demonstrated a prevalence rate of 5\%. When comparing our results to other studies in young children, including those with stringent impact criteria or mental health criteria, our finding was at the lower end of the $4.4 \%$ to $12.5 \%$ prevalence which has been previously reported (Costello et al., 1996; Fleitlich-Bilyk and Goodman, 2004; Fombonne, 1994; Ford et al., 2003; Gillberg et al., 2004; Gomez-Beneyto et al., 1994; Jensen et al., 1995; McArdle et al., 2004; Shaffer et al., 1996). However, it is important to note that comparing our findings to other prevalence studies is complex because of variations in sampling, methods, and diagnostic criteria. Additionally, differences in age range tend to make the process of comparison even more complex. Costello et al. (1993) estimated 
Table 3. Comorbidity Analysis with Odds Ratios and C.I. among the 6-8 Year Old Children

\begin{tabular}{|c|c|c|c|c|c|c|}
\hline & \multicolumn{2}{|c|}{$\begin{array}{l}\text { Without "need for mental health } \\
\text { support" criteria }\end{array}$} & \multicolumn{2}{|c|}{$\begin{array}{l}\text { With "need for mental health } \\
\text { support" criteria }\end{array}$} & \multicolumn{2}{|c|}{$\begin{array}{l}\text { With "need for mental health support' } \\
\text { criteria and adjusted for other disor- } \\
\text { ders }\end{array}$} \\
\hline & OR & $(95 \% \mathrm{CI})$ & OR & $(95 \% \mathrm{CI})$ & OR & $(95 \% \mathrm{CI})$ \\
\hline ADHD - ODD/CD & 26 & $(14.1-48)$ & 557 & (168->999) & 265 & $(31->999)$ \\
\hline ADHD - DEP & 5.4 & $(2.7-10.9)$ & 144 & $(45-457)$ & n.s & \\
\hline $\mathrm{ADHD}$ - AD & 2.7 & $(1.6-4.7)$ & 54 & (21-139) & n.s & \\
\hline ADHD - Elim & n.s & & 102 & $(24-450)$ & n.s & \\
\hline ODD/CD - ADHD & 26 & $(14.1-48)$ & 557 & (168->999) & 159 & $(25->999)$ \\
\hline $\mathrm{ODD} / \mathrm{CD}$ - DEP & 3.3 & $(1.8-6.2)$ & $226 a$ & $(31->999)$ & n.s & \\
\hline $\mathrm{ODD} / \mathrm{CD}-\mathrm{AD}$ & 3.2 & $(2.0-5.2)$ & 122 & $(43-346)$ & 86 & $(20-362)$ \\
\hline ODD/CD - Elim & 1.8 & $(1.1-3.1)$ & 212 & (51->999) & 7.4 & $(1.04-54)$ \\
\hline DEP - ADHD & 5.4 & $(2.7-10.9)$ & 144 & $(45-457)$ & n.s & \\
\hline $\mathrm{DEP}-\mathrm{ODD} / \mathrm{CD}$ & 3.3 & $(1.8-6.2)$ & $226 a$ & $(31->999)$ & 68 & $(3.2->999)$ \\
\hline $\mathrm{DEP}-\mathrm{AD}$ & 2.3 & $(1.1-4.5)$ & 30 & $(10.4-85)$ & n.s & \\
\hline DEP - Elim & 2.4 & $(1.1-5.4)$ & 51 & $(13-193)$ & n.s & \\
\hline $\mathrm{AD}-\mathrm{ADHD}$ & 2.7 & $(1.6-4.7)$ & 54 & $(21-139)$ & n.s & \\
\hline $\mathrm{AD}-\mathrm{ODD} / \mathrm{CD}$ & 3.2 & $(2.0-5.2)$ & 122 & $(43-346)$ & 121 & $(26-555)$ \\
\hline $\mathrm{AD}$ - DEP & 2.3 & $(1.1-4.5)$ & 30 & $(10.4-85)$ & n.s & \\
\hline AD - Elim & 1.8 & $(1.1-2.9)$ & 31 & $(7.6-127)$ & n.s & \\
\hline Elim - ADHD & n.s. & & 102 & $(24-450)$ & n.s & \\
\hline Elim - ODD/CD & 1.8 & $(1.1-3.1)$ & 212 & (51->999) & 106 & $(6.6->999)$ \\
\hline Elim - DEP & 2.4 & $(1.1-5.4)$ & 51 & $(13-193)$ & n.s & \\
\hline Elim - AD & 1.8 & $(1.1-2.9)$ & 31 & $(7.6-127)$ & n.s & \\
\hline
\end{tabular}


that the relationship between diagnosis and contact with services for one in ten children does correspond very closely with the prevalence rates found in the general versus clinical population.

\section{Comorbidity}

In our study, we found more than one diagnosis in $23 \%$ of the children in the general population, and in $3.5 \%$ of the children in the clinical population. Including only the children with at least one diagnosis, comorbidity was present in $41 \%$ of the general population and in $75 \%$ of the clinical population. Again, it is important to note that comparing our findings with those of other prevalence studies is complex due to the earlier mentioned variations in research. Despite this complexity, our results do correspond with recent epidemiological studies that have reported findings of 25-89\% comorbidity (Costello et al., 1996; FleitlichBilyk and Goodman, 2004; Ford et al., 2003; Goodman et al., 1998; Simonoff et al., 1997). Additionally, other studies have shown that comorbidity is negatively associated with the level of impact and with male gender (Bird et al., 1993; Costello et al., 1996; Simonoff et al., 1997). The high percent of comorbidity for each disorder and the high OR in the general population demonstrate that comorbidity does not occur by chance, nor is it the result of Berkon's or clinical referral bias.

Our data show that classification models such as the DSM and ICD systems, which are characterised by discrete and mutually exclusive categories with few or no intermediate cases, are applicable primarily to children without a need for mental health support. Additionally, our data strengthens the concept that patterns of psychopathology exist as a continuous variation along a series of scales. These scales are based on a dimensional model as a representation of the structure of a disorder in which no strict natural boundaries exist between normal and abnormal. The arbitrary nature of clinical threshold based on social and cultural constructions about deviance and impairment may have to be acknowledged (Sonuga-Barke, 1998).

As previously mentioned, the comparison of our findings with other two-by-two comorbidity studies is complex because of a number of variations. However, a meta-analysis conducted by Angold et al. (1999) has provided clear guidelines for the general population. Although the ADHD-ODD/CD comorbidity reported by our study is higher than the median OR of the meta-analysis, both confidence intervals fall within each other's range. The other comorbidities investigated are also very comparative to the results of the meta-analysis. Nonetheless, lower ORs were found for MD-AD (2.3 vs. 8.2) and ODD/CD-MD (3.3 vs. 6.6). In our study, the comorbidity of $\mathrm{ODD} / \mathrm{CD}$ and $\mathrm{AD}$ in $\mathrm{MD}$ was within the same range while the comorbidity rate of MD in ODD/CD and $\mathrm{AD}$ was much lower than in the meta- 
analysis. For the age group in question, it may be possible that the presence of another disorder makes it difficult to distinguish MD (Birmaher et al., 1998). However, it is also possible that comorbidity patterns are age dependent. Several authors have reported an increasing time trend for the prevalence of MD (Cohen et al., 1993; Feehan et al., 1994; Ford et al., 2003; Simonoff et al., 1997) while the onset age of AD in subjects with MD has been found to be significantly earlier (Biederman et al., 1995a; Breslau et al., 1995; Cole et al., 1998; Lewinsohn et al., 1995; Reinherz et al., 1993; Rohde et al., 1991).

By adjusting for the presence of other disorders, we found that the high correlation between ADHD-ODD/CD was robust at both the general and the clinical level, with the highest significance and OR for each model. It is important to determine whether we are dealing with different disorders. Further separate analyses for the ADHD subtypes, ODD, and CD therefore need to be performed. However, their different comorbidity patterns in the multivariate analysis suggest so. Long term outcome studies on antisocial personality disorder have further demonstrated the independent associations of conduct disorder and hyperactivity in the early adult period (Simonoff et al., 2004).

Despite the high comorbidity rates and the significant ORs generated by the two-by-two analysis, no associations between the internalising disorders were found in the multivariate analysis. This could be a methodological artefact. As discussed earlier, the diagnostic criteria of the interview could have led to an overestimation of anxiety disorder which, in turn, may have hidden the relationship between MD and AD. If this was the case, different patterns in both populations can be expected. However, different patterns were not found. Additionally, the AD group consisted of several different anxiety disorders and may not have been a homogenous group. Although this goes beyond the aims of the present study reported here, the finding that some anxiety symptoms are part of depression, whereas separation anxiety, fears, and compulsions constitute a separate anxiety dimension (Lahey et al., 2004) supports the idea that sub-analyses for the different AD are necessary. This same finding also suggests that the comorbidity pattern could be age-related, as it was reported that AD preceded MD as a primary disorder. Other studies, such as the Oregon study (Rohde et al., 1991) and the Biederman study (1995) have demonstrated that the temporal relationship for disorders that are comorbid with depression may not be limited to AD alone. Also, disruptive disorders tend to precede MD and, as such, the relationship between MD and AD may be less specific than generally thought. Furthermore, recent data has indicated that the more the diagnostic threshold is reached, the more depression and anxiety differentiate into separate constructs (Gurley et al., 1996). Our results support this hypothesis. This is further supported by genetic family studies in which a high clustering for both childhood onset MD and AD were demonstrated (Last et al., 1991; Weissman et al., 1997) but a unique genetic component for MD was found. The genetic factors of anxiety symptoms were entirely explained by the common genetic factors with MD (Thapar and McGuffin, 1997). Others have 
proposed models of common genetic/biological predispositions in which timing of environmental factors determine the type of disorder manifested (Cole et al., 1998). This too supports a heterotypic comorbidity process. Overall, our results indicate that MD and AD at a young age are related but separate entities. More longitudinal follow-up data may be able to clarify whether the comorbidity between MD and AD should be seen as a primary vs. secondary disorder or as a heterotypic comorbidity process, in which clinical manifestations take different forms over time.

When looking at the relationship between internalising versus externalising disorders, a robust relationship between ODD/CD and AD presented in our study. This relationship is well-known (Keiley et al., 2003; Lilienfeld, 2003) and is considered an important predictor of later substance abuse (Costello et al., 2003). The relationship between MD and externalising disorders was found to be less clear and may be more dependent on the population. The arguments discussed earlier for the MD-AD relationship may also apply to these relationships.

This study is one of the few population based studies that have investigated the comorbidity pattern of elimination disorders. Comorbidity analyses in the general population have shown that the correlation between ED and any psychopathology was non-specific and only related to male gender. A strong but, again, non-specific correlation was found at the clinical level. This may explain why no physiological markers differentiating between psychologically disturbed and non-disturbed children have been found (Mikkelsen, 2001). Controlling for the presence of other psychopathology revealed a relationship only with ODD/CD and not with ADHD. Arguments for epiphenomenal comorbidity include the fact that the relationship between enuresis and ADHD reported in clinical studies (Biederman et al., 1995b) is caused by the link with ODD/CD. Further support for this epiphenomenal comorbidity has been provided by a genetic study in which the patterns of transmission indicated independent transmission of ED and ADHD (Bailey et al., 1999).

\section{Limitations}

A major limitation of this study was the lack of multiple informants. This may have led to either the over representation or under representation of some disorders (Ezpeleta et al., 1997b; Fergusson et al., 1993). Although the data did not suggest selective attrition, the low response rate (56.2\%) must still be considered a limitation of the study. The prevalence of ADIKA diagnoses in the general population group showed similar prevalence rates (Kroes et al., 2001), thereby providing some support to generalize our results to an entire population. 
One notable aspect of our study, especially for the clinical population, is the wide confidence intervals around the adjusted ORs. This was due to the mathematical properties (exponential function) of the ORs and the rarity of the disorders. Unfortunately, this decreased the reliability of our findings. Unfortunately, in our survey, some important disorders such as autism spectrum disorders or tic disorders were not investigated.

\section{Clinical implications}

To our knowledge, this article is the first to report comorbidity rates and patterns in a school based population of six to eight year old children. The high percentages of comorbidity demonstrated that psychopathology was clustered within individuals. Understanding the cooccurrence of psychiatric conditions is highly informative for the nosology of psychopathology. Identifying anxiety at a young age could be highly beneficial given that the comorbidity of mood disorders through the pathway of heterotypic or secondary comorbidity could be avoided and the evolution towards anti-social personality disorder when comorbid ODD/CD is present could be influenced. Additionally, the low and non-specific correlation between ED and any psychopathology in the general population may serve to caution primary health care workers against drawing conclusions regarding psychopathological conditions too quickly.

\section{Conclusion}

In a two stage design, the SAM study screened 2,466 eligible children with the Child Behavior Checklist (CBCL), of which 789 were further assessed using a semi-structured diagnostic interview. The generalised prevalence rates demonstrated the presence of symptoms in $55.7 \%$ of the clinical group. When an impact criterion was included, only $5 \%$ of the children were considered to have one or more psychiatric disorders. Comorbidity was present in $41 \%$ of the general population and in $75 \%$ of the clinical population. Comorbidity was also associated with the impact level and male gender. Further, the results showed that comorbidity between ADHD-ODD/CD and ODD/CD-anxiety disorder were the most stable. Mood and anxiety disorders were found to be related but separate entities. Elimination disorder was generally not predicted by any psychopathology. However, in clinical cases, an association with ODD/CD was found. We recommend that evidenced-based diagnostic and treatment protocols focus more on the co-occurrence of psychiatric disorders. 


\section{References}

Achenbach T ed. (1991), Manual for the Child Behavior Checklist 4-18 and 1991 Profile. Burlington: University of Vermont Department of Psychiatry

Anderson JC, Williams S, McGee R, Silva PA (1987), DSM-III disorders in preadolescent children. Prevalence in a large sample from the general population. Archives Of General Psychiatry 44: 6976

Angold A, Costello EJ, Erkanli A (1999), Comorbidity. Journal of Child Psychology and Psychiatry and Allied Disciplines 40: 57-87

August G-J, Braswell L, Thuras P (1998), Diagnostic stability of ADHD in a community sample of school-age children screened for disruptive behavior. Journal of Abnormal Child Psychology 26: 345-356

Bailey JN, Ornitz EM, Gehricke JG, Gabikian P, Russell AT, Smalley SL (1999), Transmission of primary nocturnal enuresis and attention deficit hyperactivity disorder. Acta Paediatrica 88: 1364-1368

Biederman J, Faraone S, Mick E, Lelon E (1995a), Psychiatric Comorbidity among Referred Juveniles with Major Depression - Fact or Artifact. Journal of the American Academy of Child and Adolescent Psychiatry 34: 579-590

Biederman J, Santangelo SL, Faraone SV, Kiely K, Guite J, Mick E, Reed ED, Kraus I, Jellinek M, Perrin J (1995b), Clinical correlates of enuresis in ADHD and non-ADHD children. Journal of Child Psychology and Psychiatry and Allied Disciplines 36: 865-77

Bird HR, Gould MS, Staghezza BM (1993), Patterns of diagnostic comorbidity in a community sample of children aged 9 through 16 years. Journal of the American Academy of Child and Adolescent Psychiatry 32: 361-8

Birmaher B, Brent DA, Benson RS (1998), Summary of the practice parameters for the assessment and treatment of children and adolescents with depressive disorders. Journal of the American Academy of Child and Adolescent Psychiatry 37: 1234-1238

Boyle MH, Offord DR, Racine Y, Sanford M, Szatmari P, Fleming JE, Price-Munn N (1993), Evaluation of the Diagnostic Interview for Children and Adolescents for use in general population samples. Journal of Abnormal Child Psychology 21: 663-81

Breslau N, Schultz L, Peterson E (1995), Sex-Differences in Depression - a Role for Preexisting Anxiety. Psychiatry Research 58: 1-12

Canino G, Shrout PE, Rubio-Stipec M, Bird HR, Bravo M, Ramirez R, Chavez L, Alegria M, Bauermeister JJ, Hohmann A, Ribera J, Garcia P, Martinez-Taboas A (2004), The DSM-IV rates of child and adolescent disorders in Puerto Rico - Prevalence, correlates, service use, and the effects of impairment. Archives of General Psychiatry 61: 85-93

Cohen P, Cohen J, Kasen S, Velez CN, Hartmark C, Johnson J, Rojas M, Brook J, Streuning EL (1993), An Epidemiologic-Study of Disorders in Late Childhood and Adolescence .1. AgeSpecific and Gender-Specific Prevalence. Journal of Child Psychology and Psychiatry and Allied Disciplines 34: 851-867

Cole DA, Peeke LG, Martin JM, Truglio R, Seroczynski AD (1998), A longitudinal look at the relation between depression and anxiety in children and adolescents. Journal of Consulting and Clinical Psychology 66: 451-460

Costello EJ, Angold A, Burns BJ, Stangl DK, Tweed DL, Erkanli A, Worthman CM (1996), The Great Smoky Mountains Study of Youth. Goals, design, methods, and the prevalence of DSM-III-R disorders. Archives Of General Psychiatry 53: 1129-36

Costello EJ, Mustillo S, Erkanli A, Keeler G, Angold A (2003), Prevalence and development of psychiatric disorders in childhood and adolescence. Archives Of General Psychiatry 60: 837-844

de la Osa N, Ezpeleta L, Domenech JM, Navarro JB, Losilla JM (1997), Convergent and Discriminant Validity of the Structured Diagnostic Interview for Children and Adolescents (DICA-R). Psychology in Spain 1: 37-44

Ezpeleta L, de la Osa N, Domenech JM, Navarro JB, Losilla JM (1997a), Test-retest reliability of the Spanish adaptation of the Diagnostic Interview of Children and Adolescents. Psicothema 9: 529539 
Ezpeleta L, de la Osa N, Domenech JM, Navarro JB, Losilla JM, Judez J (1997b), Diagnostic agreement between clinicians and the Diagnostic Interview for Children and Adolescents--DICA-R--in an outpatient sample. Journal of Child Psychology and Psychiatry and Allied Disciplines 38: 43140

Feehan M, McGee R, Raja SN, Williams SM (1994), Dsm-III-R Disorders in New-Zealand 18-YearOlds. Australian and New Zealand Journal of Psychiatry 28: 87-99

Fergusson D-M, Horwood L-J, Lynskey M-T (1993), Prevalence and comorbidity of DSM-III-R diagnoses in a birth cohort of 15 year olds. Journal of the American Academy of Child and Adolescent Psychiatry 32: 1127-34

Fleitlich-Bilyk B, Goodman R (2004), Prevalence of child and adolescent psychiatric disorders in southeast Brazil. Journal of the American Academy of Child and Adolescent Psychiatry 43: 727 34

Fombonne E (1994), The Chartres Study: I. Prevalence of psychiatric disorders among French schoolage children. British Journal of Psychiatry 164: 69-79

Ford T, Goodman R, Meltzer H (2003), The British Child and Adolescent Mental Health Survey 1999: the prevalence of DSM-IV disorders. Journal of the American Academy of Child and Adolescent Psychiatry 42: 1203-11

Gillberg C, Gillberg IC, Rasmussen P, Kadesjo B, Soderstrom H, Rastam M, Johnson M, Rothenberger A, Niklasson L (2004), Co-existing disorders in ADHD - implications for diagnosis and intervention. European Child \& Adolescent Psychiatry 13: I80-I92

Gomez-Beneyto M, Bonet A, Catala MA, Puche E, Vila V (1994), Prevalence of mental disorders among children in Valencia, Spain. Acta Psychiatr Scand 89: 352-7

Goodman SH, Hoven CW, Narrow WE, Cohen P, Fielding B, Alegria M, Leaf PJ, Kandel D, Horwitz SM, Bravo M, Moore R, Dulcan MK (1998), Measurement of risk for mental disorders and competence in a psychiatric epidemiologic community survey: the National Institute of Mental Health Methods for the Epidemiology of Child and Adolescent Mental Disorders (MECA) Study. Soc Psychiatry Psychiatr Epidemiol 33: 162-73

Gurley D, Cohen P, Pine DS, Brook J (1996), Discriminating depression and anxiety in youth: a role for diagnostic criteria. Journal of Affective Disorders 39: 191-200

Hurks PPM, Hendriksen JGM, Vles JSH, Kalff AC, Feron FJM, Kroes M, van Zeben T, Steyaert J, Jolles J (2004), Verbal fluency over time as a measure of automatic and controlled processing in children with ADHD. Brain and Cognition 55: 535-544

Hurks PPM, Vles JSH, Hendriksen JGM, Kalff AC, Feron FJM, Kroes M, Van Zeben T, Steyaert J, Jolles J (2006), Semantic category fluency versus initial letter fluency over 60 seconds as a measure of automatic and controlled processing in healthy school-aged children. Journal of Clinical and Experimental Neuropsychology 28: 684-695

Jensen PS (2003), Comorbidity and child psychopathology: recommendations for the next decade. Journal of Abnormal Child Psychology 31: 293-300

Jensen PS, Watanabe HK, Richters JE, Cortes R, Roper M, Liu S (1995), Prevalence of mental disorder in military children and adolescents: findings from a two-stage community survey. Journal of the American Academy of Child and Adolescent Psychiatry 34: 1514-24

Kalff AC, de Sonneville LMJ, Hurks PPM, Hendriksen JGM, Kroes M, Feron FJM, Steyaert J, van Zeben T, Vles JSH, Jolles J (2003), Low- and high-level controlled processing in executive motor control tasks in 5-6-year-old children at risk of ADHD. Journal of Child Psychology and Psychiatry and Allied Disciplines 44: 1049-1057

Kalff AC, De Sonneville LMJ, Hurks PPM, Hendriksen JGM, Kroes M, Feron FJM, Steyaert J, Van Zeben T, Vles JSH, Jolles J (2005), Speed, speed variability, and accuracy of information processing in 5 to 6-year-old children at risk of ADHD. Journal of the International Neuropsychological Society 11: 173-183

Kalff AC, Hendriksen JG, Kroes M, Vles JS, Steyaert J, Feron FJ, van Zeben TM, Jolles J (2002), Neurocognitive performance of 5- and 6-year-old children who met criteria for attention deficit/hyperactivity disorder at 18 months follow-up: results from a prospective population study. Journal of Abnormal Child Psychology 30: 589-98

Kalff AC, Kroes M, Vles JS, Bosma H, Feron FJ, Hendriksen JG, Steyaert J, van Zeben TM, Crolla IF, Jolles J (2001), Factors affecting the relation between parental education as well as occupation and problem behaviour in Dutch 5- to 6-year-old children. Social Psychiatry and Psychiatric Epidemiology 36: 324-31 
Keiley MK, Lofthouse N, Bates JE, Dodge KA, Pettit GS (2003), Differential risks of covarying and pure components in mother and teacher reports of externalizing and internalizing Behavior across ages. Journal of Abnormal Child Psychology 31: 267-283

Kortenbout vn der Sluijs M, Levita D, Manen R, Defares P (1993), In: ADIKA, Amsterdams Diagnostisch Interview voor Kinderen en Adolescenten Lisse: Swetz and Zeitlinger

Kroes M, Kalff AC, Kessels AGH, Steyaert J, Feron FJM, van Someren A, Hurks PPM, Hendriksen JGM, van Zeben T, Rozendaal N, Crolla I, Troost J, Jolles J, Vles JSH (2001), Child psychiatric diagnoses in a population of Dutch schoolchildren aged 6 to 8 years. Journal Of The American Academy Of Child And Adolescent Psychiatry 40: 1401-1409

Kroes M, Kessels AG, Kalff AC, Feron FJ, Vissers YL, Jolles J, Vles JS (2002), Quality of movement as predictor of ADHD: results from a prospective population study in 5- and 6-year-old children. Developmental Medicine and Child Neurology 44: 753-60

Lahey BB, Applegate B, Waldman ID, Loft JD, Hankin BL, Rick J (2004), The structure of child and adolescent psychopathology: Generating new hypotheses. Journal Of Abnormal Psychology 113: 358-385

Last C-G, Hersen M, Kazdin A, Orvaschel H, et al. (1991), Anxiety disorders in children and their families. Archives of General Psychiatry 48: 928-934

Lewinsohn PM, Gotlib IH, Seeley JR (1995), Adolescent Psychopathology .4. Specificity of Psychosocial Risk-Factors for Depression and Substance-Abuse in Older Adolescents. Journal of the American Academy of Child and Adolescent Psychiatry 34: 1221-1229

Lilienfeld SO (2003), Comorbidity between and within childhood externalizing and internalizing disorders: reflections and directions. Journal of Abnormal Child Psychology 31: 285-91

McArdle P, Prosser J, Kolvin I (2004), Prevalence of psychiatric disorder: with and without psychosocial impairment. European Child \& Adolescent Psychiatry 13: 347-353

Meehl PE (2001), Comorbidity and taxometrics. Clinical Psychology-Science and Practice 8: 507-519

Mikkelsen EJ (2001), Enuresis and encopresis: ten years of progress. Journal of the American Academy of Child and Adolescent Psychiatry 40: 1146-58

Neale MC, Kendler KS (1995), Models of Comorbidity for Multifactorial Disorders. American Journal of Human Genetics 57: 935-953

Reich W (2000), Diagnostic Interview for Children and Adolescents (DICA). Journal of the American Academy of Child and Adolescent Psychiatry 39: 59-66

Reich W, Shayla JJ, Taibleson C (1992), The Diagnostic Interview for Children and Adolescents Revised (DICA-R) (structured psychiatric interview). St Louis, MO: Washington University.

Reinherz HZ, Giaconia RM, Pakiz B, Silverman AB, Frost AK, Lefkowitz ES (1993), Psychosocial Risks for Major Depression in Late Adolescence - a Longitudinal Community Study. Journal of the American Academy of Child and Adolescent Psychiatry 32: 1155-1163

Rhee SH, Hewitt JK, Corley RP, Stallings MC (2003), The validity of analyses testing the etiology of comorbidity between two disorders: a review of family studies. Journal Of Child Psychology And Psychiatry And Allied Disciplines 44: 612-636

Rohde P, Lewinsohn PM, Seeley JR (1991), Comorbidity of Unipolar Depression .2. Comorbidity with Other Mental-Disorders in Adolescents and Adults. Journal of Abnormal Psychology 100: 214222

Rozendaal N (1998), In: Handleiding Computer Algoritme Amsterdams Diagnostisch Interview voor Kinderen en Adolescenten. Maastricht: Vakgroep Psychiatrie en Neuropsychologie, Universiteit Maastricht.

Rutter M, Sroufe LA (2000), Developmental psychopathology: concepts and challenges. Dev Psychopathol 12: 265-96

Shaffer D, Fisher P, Dulcan MK, Davies M, Piacentini J, SchwabStone ME, Lahey BB, Bourdon K, Jensen PS, Bird HR, Canino G, Regier DA (1996), The NIMH Diagnostic Interview Schedule for Children Version 2.3 (DISC-2.3): Description, acceptability, prevalence rates, and performance in the MECA study. Journal of the American Academy of Child and Adolescent Psychiatry 35: 865877

Simonoff E, Elander J, Holmshaw J, Pickles A, Murray R, Rutter M (2004), Predictors of antisocial personality. Continuities from childhood to adult life. British Journal of Psychiatry 184: 118-27

Simonoff E, Pickles A, Meyer JM, Silberg JL, Maes HH, Loeber R, Rutter M, Hewitt JK, Eaves LJ (1997), The Virginia Twin Study of Adolescent Behavioral Development. Influences of age, sex, and impairment on rates of disorder. Archives Of General Psychiatry 54: 801-8 
Sonuga-Barke EJS (1998), Categorical models of childhood disorder: A conceptual and empirical analysis. Journal Of Child Psychology And Psychiatry 39: 115-133

Teagle S (2002), Parental problem recognition and child mental health service use. Ment Health Serv Res 4: 257-266

Thapar A, McGuffin P (1997), Anxiety and depressive symptoms in childhood - A genetic study of comorbidity. Journal of Child Psychology and Psychiatry and Allied Disciplines 38: 651-656

van den Brandt P-A, Goldbohm R-A, van 't Veer P, Volovics A, Hermus R-J, Sturmans F (1990), A large-scale prospective cohort study on diet and cancer in The Netherlands. Journal of ClinicalEepidemiology 43: 285-95

Van Grimbergen I, Célestin-Westreich, S \& Ponjaert-Kristofferson, I (1999), Validering van ADIKAIV(deel externaliserend gedrag) bij een klinische populatie kinderen tussen 6 en 18 jaar. In: De kinderschoenen ontgroeid? Tweede Vlaams Congres Kinder- en jeugdpsychiatrie en psychotherapie., Garant ed. Leuven, pp p.76

Verhulst F-C, van-der-Ende J, Ferdinand R-F, Kasius M-C (1997), The prevalence of DSM-III-R diagnoses in a national sample of Dutch adolescents. Archives of General Psychiatry 54: 329-36

Verhulst F, Koot H, Van der Ende J (1996), Handleiding voor de CBCL / 4-18. Rotterdam: Erasmus University

Weissman MM, Warner V, Wickramaratne P, Moreau D, Olfson M (1997), Offspring of depressed parents - 10 years later. Archives of General Psychiatry 54: 932-940

Wels PMA, Robbroeckx LMH (1996), Manual of Nijmeegse Questionnaire for Educational Situation Lisse: Swets and Zeitlinger BV

Woodruff RS (1971), A simple method for approximating the variance of a complicated estimate. Journal of the American Statistical Association 66: 411-414 
Chapter 5

\title{
Diagnostic Continuity of ADHD in a Community
}

\section{Sample of Primary School Children: a Three Year}

\author{
Follow-up Study ${ }^{1}$
}

1 Sabine Tremmery, Jan K. Buitelaar, Jean Steyaert, Geert Molenberghs, Frans J.M. Feron, Ariane C. Kalff, Petra P.M. Hurks, Jos G.M. Hendriksen, Johan S.H. Vles, Jelle Jolles. Submitted for publication 


\begin{abstract}
Background: Few studies have examined the diagnostic continuity of Attention Deficit and Hyperactivity Disorder (ADHD) in community samples between the ages of six and nine, an age range in which ADHD prevalence rates peak.
\end{abstract}

Objective: To examine the diagnostic continuity of ADHD and its determinants in a community sample of seven to nine year old children (initial $\mathrm{N}=1317$ ).

Methods: Scores on the Child Behavior Checklist (CBCL) at age six served to select a high risk externalizing $(\mathrm{N}=173)$, a high risk internalizing $(\mathrm{N}=59)$, and normal risk $(\mathrm{N}=220)$ group. Follow-up assessments at age seven and nine included a structured psychiatric interview (DICA-R) and a Teacher Report Form (TRF) along with a CGAS score and an IQ estimate.

Results: Externalizing behaviors at age six strongly predicted an ADHD diagnosis at ages seven and nine. Of the 21 children that were diagnosed with ADHD at age seven, 15 still had ADHD at age nine (71\%). Male gender, the existence of pervasive symptoms and the presence of symptoms that require mental health care were predictive factors for the continuity of ADHD. Of the 40 children that had ADHD at age nine, 25 were newly diagnosed cases (62\%). Upon comparing the two groups, the following was found: Newly diagnosed children displayed only subthreshold ADHD symptoms at age seven. Additionally, the newly diagnosed group had lower total TRF scores, less comorbidity with Oppositional Defiant Disorder (ODD) or Conduct Disorder (CD), and less need for mental health services. The newly diagnosed ADHD cases also displayed less hyperactive/impulsive symptoms and had lower impairment scores.

Conclusions: The findings indicate that children who are diagnosed with ADHD at age nine often display subthreshold ADHD symptoms at age seven. Additionally, the results support the notion of high ADHD symptom persistence in school age children in the community. 


\section{Introduction}

In recent decades, numerous studies have shown that ADHD is marked by a chronic course that proceeds from childhood into adulthood. This is especially the case for those who are clinically referred. The persistence, alternatively termed the diagnostic continuity, of ADHD from early childhood into adolescence is estimated to be between $72 \%$ and $85 \%$ in clinically referred populations (Barkley et al., 1990; Biederman et al., 1996; Hart et al., 1995; Lahey et al., 2004). Evidently, ADHD is transient for only a small group of children. Transient ADHD may occur when normally developing children experience increased levels of stress with concomitant atypically high levels of inattention and hyperactivity. This often "normalizes” sometime after referral (Hart et al., 1995).

Persistence of ADHD over time is related to a poor long-term outcome in adolescence or adulthood. Children with persistent ADHD, thus children who continue to meet diagnostic criteria over a longer period of time, are characterized by one or more of the following: a young age of onset, greater severity of hyperactivity and inattention symptoms, a positive family history of ADHD, high levels of psychosocial adversity, greater functional impairment, and comorbidity with a conduct disorder, bipolar disorder or multiple anxiety disorders (August et al., 1998; Barkley et al., 1990; Biederman et al., 1996; Hart et al., 1995; Lavigne et al., 1998; Mannuzza et al., 1997).

Data on the stability of ADHD generated by community-based research are sparse and results are often dependent on the diagnostic criteria used. However, a study by Cohen and colleagues (Cohen et al., 1993b) demonstrated that, in a sample of 734 children, $42 \%$ of those diagnosed with DSM-III-R-defined ADHD at a mean age of 13.7 still exhibited symptoms 2.5 years later. For severe ADHD, this figure increased to $73 \%$. Significant sex and age differences with respect to the persistence of ADHD were not found. Additionally, in another study (August et al., 1998), the diagnostic stability of DSM-III-R-defined ADHD was examined in a school-based sample of nine year old children. In this study, $38 \%$ of the children that had been diagnosed at nine years of age continued to meet diagnostic criteria at two later points in time, namely three and four years following the initial diagnosis while $31 \%$ of those initially diagnosed with ADHD met diagnostic criteria at only one of the follow-up measurements. Evidently, these community studies have mapped the development of ADHD during late childhood and adolescence. In yet another study (Lavigne et al., 1998), the stability of a more broadly defined group of externalizing disorders (ADHD, ODD or both) was investigated in 510 preschoolers aged two to five. A moderate level of stability was found four years later. What these studies show is that ADHD is less stable in a community based sample than in clinical samples. 
ADHD has a developmental etiology (Krain and Castellanos, 2006). Between the ages of 4 and 18, prevalence rates are highest between the ages of 6 and 11 (Pineda et al., 1999; Szatmari et al., 1989). No research has been done on the stability of ADHD in community samples of children entering elementary school, an age at which peak-prevalence is found. We have shown, in an earlier paper, that problem behavior in six year old children predicted psychopathology one year later (Kroes et al., 2002). However, the extent to which behavioral problems in preschool children contribute to a diagnosis of ADHD at a later stage remains unclear. We know even less about how children with DSM-IV-defined ADHD in primary school develop and change. Children who are already at risk for ADHD in the early years of elementary education may experience significant difficulties with the acquisition of scholastic skills and may be less able to comply with demands to perform in task-related contexts.

The study presented here was part of a large research program entitled "Study of Attention Disorders in Maastricht” (SAM). SAM is a school-based prospective and longitudinal study on the precursors of ADHD in young children (Kalff et al., 2001b; Kroes et al., 2001). Children aged five to six (kindergarten age) were monitored for approximately three years and were, during that time period, assessed twice (at approximately age seven and age nine). In this study, we endeavored to do the following: First and foremost, we attempted to investigate the extent to which behavior problems of six year old children in a large community sample predict a diagnosis of ADHD at ages seven and nine. Secondly, we sought to explore the diagnostic stability of DSM-IV-defined ADHD in primary school children between the ages of seven and nine. Thirdly, we examined possible predictors of persistent versus remittent ADHD for the age group seven to nine years of age. Lastly, we investigated the differential correlates of a) persistent ADHD between ages seven and nine; and b) the newly diagnosed ADHD cases at age nine.

\section{Method}

\section{Subjects and Procedure}

\section{Phase 1: Children enrolled at approximately six years of age}

The methodology for this phase has been reported in detail elsewhere (Kalff et al., 2001a). This study was approved by the Ethics Committee at Maastricht University. All parents of a school-based population of 2290 children were approached to participate. All children were enrolled in the kindergarten $(\mathrm{N}=65)$ in the city of Maastricht, the Netherlands or in the surrounding area. The parents of 1317 (57.5\%) children (669 boys and 618 girls, age mean \pm SD $5.87 \pm 0.41$ year) agreed to participate and written informed consent was obtained for 
phases 1 and 2. No significant differences in terms of age, sex, and demographic factors were observed between the 1317 participating children and the 973 children who did not participate (Kroes et al., 2001). In the first phase, the parents of all 1317 children completed the Child Behavior Checklist (CBCL) (Achenbach, 1991a; Verhulst et al., 1996) and a questionnaire on socio-demographic characteristics.

\section{Phase 2: First follow-up at seven years of age.}

On the basis of CBCL scores in phase 1, three groups of children (in total $\mathrm{N}=452$ ) were selected for follow-up. The first group was an externalizing high risk group that consisted of 173 children with scores on the CBCL broadband externalizing scale above the $90^{\text {th }}$ percentile $(\mathrm{T}>63)$ and/or scores on the CBCL inattention scale above the $95^{\text {th }}$ percentile $(\mathrm{T}>67)$. Of the 173 children, 153 were selected based on the externalizing scale criteria and 20 children were selected based on the inattention scale criteria. The CBCL attention problems subscale was included because it contributed to other research questions in the SAM project that focused on the precursors of attention deficits. The second group was an internalizing high risk group consisting of 59 children with scores on the CBCL broadband internalizing scale

Figure 1. Sampling Design for the first Cohort "Study of Attention Disorders in Maastricht”

CBCL Selection

At about 6 Years $\mathrm{N}=452$

Follow-up At about 7 Years $\mathrm{N}=403$

Follow-up At about 9 Years $\mathrm{N}=283$

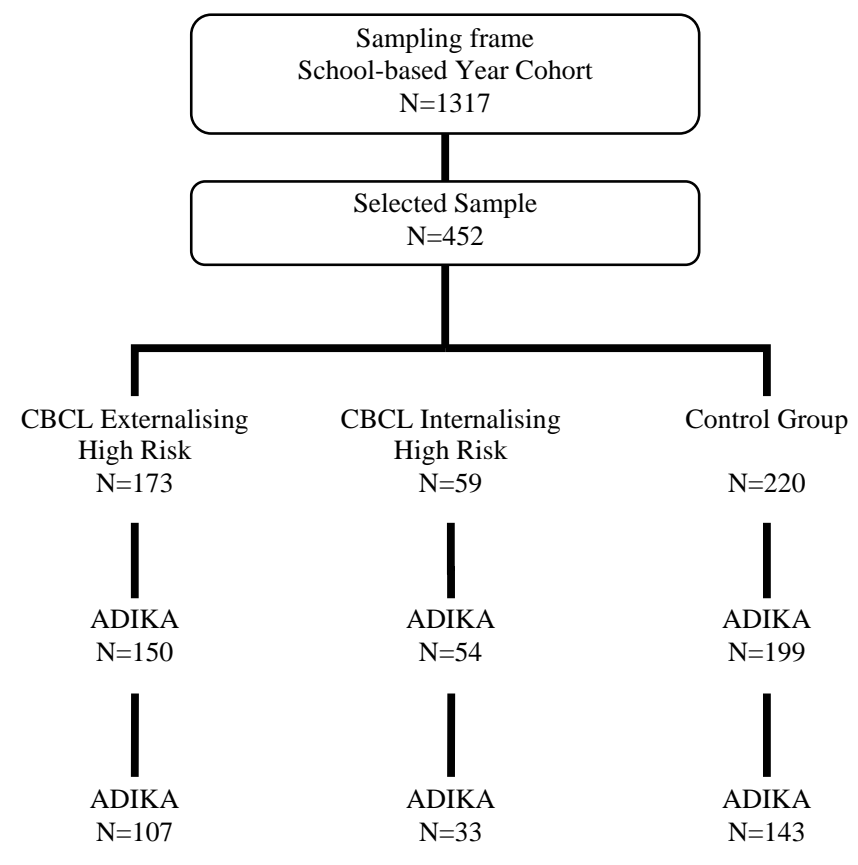


above the $90^{\text {th }}$ percentile $(\mathrm{T}>63$ ). Children who also met the criteria for the externalizing high risk group were excluded from this group. The chosen cut-off points reflect the clinical cut-off scores for the CBCL broadband and inattention scales determined in earlier epidemiological studies in the Netherlands (Verhulst et al., 1996). Lastly, a control group was selected. The control group consisted of 220 children who had CBCL total scores below the $90^{\text {th }}$ percentile who also did not meet selection criteria for the two high risk groups mentioned above. These children were matched in terms of age, sex, and geographic area (urban versus rural) with the children in the two high risk groups.

The parents of all children were invited to participate in structured psychiatric interviews (see below). Of the total 452 children that were categorized in one of the three groups mentioned above, the parents of the 403 children (89\%) agreed to participate (233 boys and 170 girls, age $7.1 \pm 0.42$ year). Consent was given for 150 (87\%) of the 173 children initially included in group one, 54 (91\%) of the 59 children initially placed in group two and 199 (90\%) of the 220 children originally assigned to the control group (see Figure 1). A teacher report form (TRF) was completed by the homeroom teacher of all participating children. The participating and non-participating children did not differ in terms of CBCL scores, sex, or demographic characteristics.

\section{Phase 3: Second follow-up at nine years of age.}

When the participating children reached the age of nine, the parents of the three groups were contacted and asked to provide written consent for continued participation in the study. This part of the study included a structured psychiatric interview, an evaluation of overall functioning using the Children's Global Assessment Scale (CGAS), an estimate of the cognitive functioning of the child and a TRF.

The parents of 283 (63\%) of the 452 children for whom we sought consent in the second phase agreed to participate in this third phase (163 boys and 120 girls, age $9.2 \pm 0.4$ year). Consent was provided for 107 (62\%) of the 173 children in group one, 33 (56\%) of the 59 children in group two and 143 (65\%) of the 220 in the control group (see Figure 1). Because some teachers refused to participate, TRF forms were collected for only 91 children in the first group, 24 in the second and 124 in the control group. The 169 (36\%) non-participating children did not differ from the participating children in terms of age, sex, demographic factors and psychiatric diagnosis at age seven.

\section{Measures}

The Child Behavior Checklist (CBCL) was completed by parents when the participating child was six years of age. The Teacher Report Forms (TRF) (Achenbach, 1991b) were 
completed by teachers when the children were seven (TRF) and nine years of age (TRF). The CBCL and TRF were scored by computer, using appropriate age and sex norms for the Dutch population (De Groot et al., 1996; Verhulst et al., 1996).

Demographic information was also compiled. Parental level of occupation was scored on a seven point scale when the children were six years of age. The scale ranged from labor requiring minimal skills to a scientific occupation requiring high levels of education. For the purposes of this study, all results on this scale were categorized in one of three occupational categories, namely low (1,2, and 3), moderate (4 and 5), and high (6 and 7) (van den Brandt et al., 1990). In addition to parental occupation, we collect demographic information on the parents' country of birth, household structure ( one or two parent household), number of siblings, and area of residence (urban or rural).

The instrument used in the structured psychiatric assessments of the children at seven and nine was the Dutch version of the Diagnostic Interview for Children and Adolescents (DICA-R) (Reich et al., 1992) (Amsterdam Diagnostisch Interview voor Kinderen - ADIKA) (Kortenbout van der Sluijs et al., 1993). The DICA-R is based on DSM-III-R criteria and has since been adapted to the ADHD diagnostic criteria described in the DSM-IV (Van Grimbergen, 1999). The reliability and validity of the ADHD criteria for the DSM-IV criteria are good-to-average.

Although no reliability studies have been performed with the ADIKA, the DICA-R has been described as a useful measure for generating reliable psychiatric information on children in both research and clinical settings (Reich, 2000). Parents were the most stable informant in reporting disorders in a six to nine year old population (Boyle et al., 1993). The test-retest reliability of DICA-R in a sample of 251 subjects (Boyle et al., 1993) and in a sample of 110 subjects (Ezpeleta et al., 1997)) was good to very good (ADHD 0.51 - 0.86; ODD 0.61 0.92; CD 0.66 - 0.87; MD 0.31 - 0.35; dysthymia 0.49 - 0.51; anxiety disorder 0.62 - 0.69 ; separation anxiety disorder 0.62 ; enuresis 0.73 ; encopresis 0.74 ). Agreement between trained lay interviewers and child psychiatrists was generally high (any diagnosis 0.781.0)(August et al., 1998; Boyle et al., 1993). The convergent validity using the CBCL as a criterion to discriminate between psychiatric $(\mathrm{N}=196)$ and control $(\mathrm{N}=130)$ groups demonstrated that the ADIKA is a valid assessment instrument for measuring the most common child psychiatric disorders (de la Osa et al., 1997).

When the children were seven years of age, the DICA-R was administered to the parents by one of the three different interviewers, namely a medical doctor, a psychologist and a health care worker. At age nine, the instrument was administered by one of the two interviewers namely a child-psychiatry trainee and a psychologist. The interviewers had all been trained by an experienced child psychiatrist. To reach consensus and improve the reliability and 
validity of our diagnosis, the interviewers' results were discussed weekly during an intensive supervision session with the supervisor (third author: J.S.). Discrepancies in scoring were resolved by consensus. When questions arose, parents were contacted and reassessed for further clarification.

All interviewers were blind to the results of prior assessments. The DICA-R assesses symptoms of axis-I psychiatric disorders, such as disruptive, emotional, anxiety, and elimination disorders. The DICA-R also gathers information on the duration of the disorder(s), impairment, and previous consultations with health care professionals. Diagnoses were generated by a computer algorithm that ignores the hierarchical DSM structure. This means that Oppositional Defiant Disorder (ODD) and Conduct Disorder (CD) could be diagnosed in the same patient.

The ADHD module of the Dutch DICA-R contains 10 items that measure inattention and 11 items that measure hyperactivity and impulsivity. Positive answers were used to compute the number of inattention symptoms (range 0-10) and the number of hyperactivity and impulsivity symptoms (range 0-11). The DICA-R includes four binary items on impairment. These items measure problems at home, problems at school, social problems, and overall performance impairment. Using these items, a total impairment score was derived (range 04). An ADHD diagnosis was generated when the DSM-IV criteria for ADHD were present with at least six hyperactivity and impulsivity symptoms and/or inattention symptoms, two positive scores on impairment and onset prior to seven years of age. If an ADHD diagnosis was made, the ADHD subtype was based on threshold score (minimum 6) for the two symptom groups.

Intelligence at age nine was estimated using the Vocabulary and Block Design subtests of the Revised Wechsler Intelligence Scale for Children (WISC-R) (Sattler, 1992). The children were tested at school by three well-trained psychology students and a child neuropsychologist.

The Children's Global Assessment Scale (CGAS), a measure of overall functioning, is an adaptation of the Global Assessment Scale for adults (Shaffer et al., 1983). In this study, the CGAS was applied at age nine at the end of a non-structured interview in which information was gathered on how the child was functioning at home, at school, with friends and during leisure time. To optimize the reliability of the scores, the interviewers' results were discussed weekly during an intensive supervision session with the child psychiatrist (J.S.).

Information on treatment or the provision of services was gathered using the DICA-R, which contains, for each positively scored diagnosis, an item on the use of services and medication. Additionally information was provided by the regional Youth Health Care 
(YHC) Division of the Regional Public Health Institute of Maastricht. This organization is responsible for performing a periodic systematic health examination of all children in the region. This health examination is performed by school physicians and boasts a response rate of $98 \%$. By law, the medical information gathered from the health examinations can be used for epidemiological research purposes as long as anonymity is maintained. The information obtained during the interview was, in all cases, similar to the data in the YHC files. For the children that did not reach a threshold diagnosis, only YHC information was available.

\section{Statistical procedures}

Explorative analyses were performed for all variables using bivariate and multivariate tests. For nominal variables, the Pearson $\chi^{2}$ test $\left(\chi^{2}\right)$ and the Fisher exact two-sided test (FE) were used. For continuous variables that were not normally distributed, the Wilcoxon rank sum test (W) and Kruskal-Wallis test (KW) were employed. Logistic regression was conducted to obtain odds ratios with the Wald confidence limits (OR 95\% C.I.). Because the analyses were exploratory rather than hypotheses-driven, no corrections for multiple testing were done. A threshold of.05 was applied to determine statistical significance.

\section{Results}

\section{Descriptive results of ADHD prevalence and ADHD subtype prevalence at age seven and nine}

Of the initial 452 children, 269 (60\%) completed DICA-R at both longitudinal assessment points. At age seven, $7.8 \%(n=21)$ of this group met the criteria for ADHD. The prevalence of ADHD among respondents was generalized to the entire cohort (Kroes et al., 2001) and estimated at 3.8\%. Of the children that met the criteria for ADHD at age seven, $47.6 \%$ were diagnosed with a combined ADHD subtype (ADHD:C), 28.6\% with the inattentive subtype (ADHD:IN), and 23.8\% with the hyperactive/impulsive subtype (ADHD:HI). Two years later, the rate of ADHD in the study population was $14.9 \%(n=40)$. Assuming that attrition occurred randomly, a general prevalence rate of $7.2 \%$ was estimated. At age nine, $62.5 \%$ of the ADHD diagnoses were ADHD:C, 30.0\% were ADHD:IN, and 7.5\% were ADHD:HI. 
Table 1.ADHD status at age seven and nine according to high risk status at age six

\begin{tabular}{ccccccccccc}
\hline & $\begin{array}{c}\text { High-Risk } \\
(\mathrm{n}=101)\end{array}$ & \multicolumn{2}{c}{$\begin{array}{c}\text { High-Risk INT } \\
(\mathrm{n}=31)\end{array}$} & \multicolumn{2}{c}{$\begin{array}{c}\text { Control } \\
(\mathrm{n}=137)\end{array}$} & \multicolumn{2}{c}{$\begin{array}{c}\text { High-Risk } \\
\text { vs. Control }\end{array}$} & \multicolumn{2}{c}{$\begin{array}{c}\text { High-Risk EXT } \\
\text { vs. INT }\end{array}$} \\
\cline { 2 - 12 } & $\mathrm{n}$ & $\%$ & $\mathrm{n}$ & $\%$ & $\mathrm{n}$ & $\%$ & OR & (C.I.) & OR & (C.I.) \\
\hline $\begin{array}{c}\text { ADHD:C } \\
\text { age 7 }\end{array}$ & 10 & $(9.9)$ & 0 & & 0 & & - & & - & \\
age 9 & 24 & $(22)$ & 1 & $(3.7)$ & 0 & & - & & 10.4 & $(1.9-193)$ \\
ADHD:IN & & & & & & & & & & \\
age 7 & 5 & $(5)$ & 1 & $(3.2)$ & 0 & & - & & 1.3 & $(.1-12)$ \\
age 9 & 7 & $(6.9)$ & 3 & $(9.7)$ & 2 & $(1.5)$ & 4.7 & $(.9-23)$ & .1 & $(.01-.7)$ \\
ADHD:HI & & & & & & & & & & \\
age 7 & 4 & $(3.7)$ & 0 & & 1 & $(.7)$ & 6.7 & $(.7-63)$ & - & \\
age 9 & 2 & $(2)$ & 0 & & 1 & $(.7)$ & 2.5 & $(.2-29)$ & - & \\
ADHD - Overall & & & & & & & & & & \\
age 7 & 19 & $(18.8)$ & 1 & $(3.2)$ & 1 & $(.7)$ & 33.9 & $(4-262)$ & 8.4 & $(1.6-156)$ \\
age 9 & 33 & $(32.7)$ & 4 & $(12.9)$ & 3 & $(2.2)$ & 20.3 & $(6-69)$ & 3.1 & $(1.0-10)$
\end{tabular}

\section{ADHD status at seven and nine years of age according to high risk clas- sification at age six}

Table 1 displays the DSM-IV ADHD status of the children at age seven and nine according to the high risk classification at age six. For the externalizing high risk group, the odds of have any ADHD subtype at age seven was, after controlling for age and sex, 33.9 (95\% C.I. 4-262) times higher that the odds for the control group. When compared to the internalizing high risk group, the odds were 8.4 (95\% C.I. 1.6-156) times higher. Similar results were found two years later. For the externalizing high risk group, the odds of having any subtype of ADHD at age nine was 20.3 (95\% C.I. 6-69) times higher than the odds for the control group and 3.1 (95\% C.I. 1.0-10) times higher than the internalizing high risk group.

\section{Stability of ADHD between seven and nine years of age}

At age seven, 21 children met the full criteria for any subtype of ADHD. Two years later, 15 (71.4\%) continued to meet the full criteria (persistent $A D H D)$ and 6 (28.6\%) no longer met criteria (remittent ADHD). At age nine, 40 children met the full criteria for ADHD. Of these 
40 children, 25 (62.5\%) were 'newly diagnosed' (newly diagnosed ADHD). The remaining 63 children classified in the externalizing high risk group were not diagnosed with ADHD (high risk-non $A D H D$ ).

\section{Predictors of persistent ADHD, newly diagnosed ADHD and remittent ADHD}

We compared the sociodemographic predictors (table 2), referral and treatment status (table 3 and 4) of children with persistent ADHD to that of children with newly diagnosed ADHD and children with remittent ADHD.

At age seven, children with persistent ADHD had significantly higher needs for mental health support than children with newly diagnosed ADHD. This difference was not found for children age nine (Fisher exact, $\mathrm{p}<.001$ ). In our study population, children with persistent ADHD were, when compared to children with remittent ADHD, 14 times (C.I. 1.1-185) more likely to be boys. No significant differences were found between children with persistent ADHD, children with newly diagnosed ADHD and children with remittent ADHD with

\section{Table 2. Descriptives at age six according to ADHD persistence status}

\begin{tabular}{|c|c|c|c|c|c|c|c|c|c|}
\hline \multirow[b]{3}{*}{ Gender boys } & \multicolumn{2}{|c|}{$\begin{array}{l}\text { Persisters } \\
\qquad(\mathrm{n}=15)\end{array}$} & \multicolumn{2}{|c|}{$\begin{array}{l}\text { Newly diagnosed } \\
\qquad(\mathrm{n}=25)\end{array}$} & \multicolumn{2}{|c|}{$\begin{array}{c}\text { Remitters } \\
\qquad(\mathrm{n}=6)\end{array}$} & \multicolumn{2}{|c|}{$\begin{array}{c}\text { High risk } \\
\text { non ADHD } \\
(\mathrm{n}=63)\end{array}$} & \multirow{3}{*}{$\begin{array}{l}\text { Chi-square } \\
\mathrm{dF}=3 ; \mathrm{p}=.01\end{array}$} \\
\hline & $\mathrm{N}$ & $\%$ & $\mathrm{n}$ & $\%$ & $\mathrm{n}$ & $\%$ & $\mathrm{n}$ & $\%$ & \\
\hline & 14 & (93) & 19 & (76) & $3^{\mathrm{ab}}$ & (50) & $35^{\mathrm{ab}}$ & (55) & \\
\hline Education parents & & & & & & & & & $\mathrm{dF}=6 ; \mathrm{p}=.3$ \\
\hline Low & 8 & (53) & 15 & $(60)$ & 5 & (83) & 27 & (46) & \\
\hline Average & 4 & (27) & 8 & (32) & 0 & & 15 & (25) & \\
\hline \multirow[t]{2}{*}{ High } & 3 & (20) & 2 & (8) & 1 & (17) & 17 & (29) & \\
\hline & mean & s.d. & mean & s.d. & mean & s.d. & mean & s.d. & $\begin{array}{c}\text { Kruskal- } \\
\text { Wallis }\end{array}$ \\
\hline Age & 5.9 & 0.3 & 6.2 & 0.6 & 6.1 & 0.3 & 5.9 & 0.4 & $\mathrm{dF}=3 ; \mathrm{p}=.2$ \\
\hline \multicolumn{10}{|l|}{ CBCL at 6 years } \\
\hline Total T-score & 68.1 & 4.2 & 65.3 & 9.0 & 69.0 & 7.3 & 65.0 & 5.7 & $\mathrm{dF}=3 ; \mathrm{p}=.1$ \\
\hline Internalizing T-score & 57.9 & 9.7 & 59.9 & 9.8 & 66.5 & 12.1 & 58.4 & 9.1 & $\mathrm{dF}=3 ; \mathrm{p}=.3$ \\
\hline Externalizing T-score & 69.7 & 7.2 & 63.2 & 12.4 & 68.8 & 6.9 & 67.5 & 6.2 & $\mathrm{dF}=3 ; \mathrm{p}=.2$ \\
\hline
\end{tabular}

a significantly different at 0.05 from the group with persistent ADHD with Wilcoxon 2-sided test

b significantly different at 0.05 from the group with remittent ADHD with Wilcoxon 2-sided test 
respect to the other sociodemographic variables, namely parents' country of birth, household structure (one or two parent household), number of siblings, and area of residence (urban or rural). Additionally, age, IQ, and CBCL score at six years of age did vary significantly between the three groups.

\section{Newly Diagnosed versus Persistent ADHD: the Role of ADHD Criteria, Treatment Status and Comorbidity}

At seven years of age, the newly diagnosed group differed significantly from the persistent group on number of inattention symptoms, the TRF total problem score, ODD/CD comorbidity and need for mental health support (Table 3). This newly diagnosed group could be considered a subtreshold ADHD group with insufficient symptoms and low levels impairment at age seven. Nonetheless, the levels of agreement between parent and teacher scores did illustrate the pervasiveness of the subtreshold ADHD symptoms. At nine years of age, the children with newly diagnosed ADHD had less hyperactive and impulsive symptoms than those with persistent ADHD (Wilcoxon, $\mathrm{p}=.047$ ) but did not differ from one another with respect to the number of inattention symptoms. Children with newly diagnosed ADHD also had significantly lower impairment scores than the persistent group (Wilcoxon, $\mathrm{p}=.005$ ). Over time, both groups showed an increase in symptoms and impairment. Among the children with persistent ADHD, the number of inattention symptoms (Wilcoxon, $p=.04$ ) and the degree of impairment (Wilcoxon, $\mathrm{p}=.0005$ ) increased between the ages of seven and nine. The age of onset remained unchanged, which indicates that recall bias was not present. ODD/CD comorbidity differences between the groups with newly diagnosed ADHD and the group with persistent ADHD disappeared. Additionally, no differences were found with respect to the need for mental health support, clinical referral or use of methylphenidate.

\section{Remittent ADHD}

Given that the group of children with remittent ADHD was reasonably small, all results and conclusions must be considered explorative. At seven years of age, this group did not differ from the persistent group regarding diagnostic criteria. Information from teachers revealed that the total problem scores for the group with remittent ADHD were significantly lower than the scores for the group with persistent ADHD. Over time, the need for mental health support among children with remittent ADHD remained low (33\% at seven years of age and $16.7 \%$ at nine years of age). This is in contract to the persistent ADHD group who reported a high need for mental health support (73.3\% at seven years of age and $60 \%$ at nine years of age). 
Table 3. ADHD characteristics at age seven according to ADHD persistence status

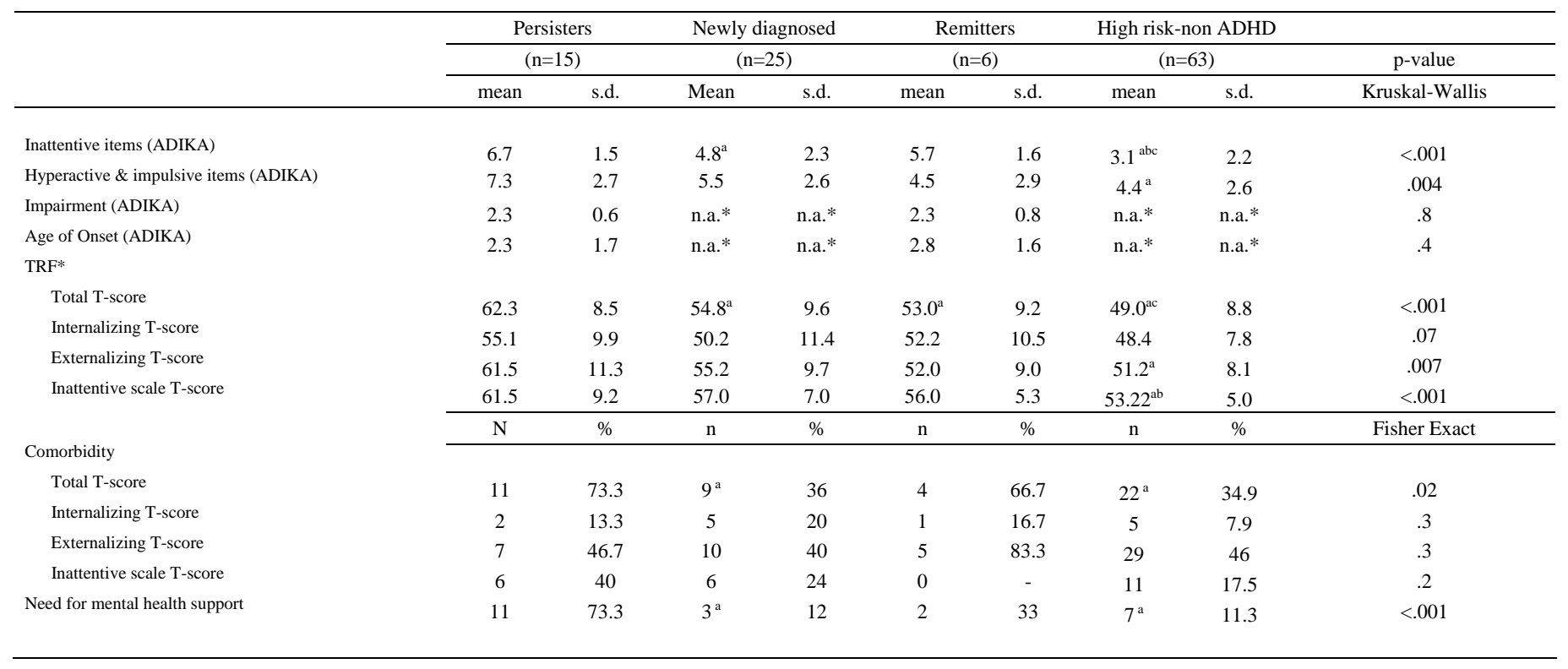

*n.a. = not assessed: according to the interview algorithm, impairment and age of onset was only explored when the threshold was met.

ODD/CD: Oppositional Defiant Disorder / Conduct Disorder

a significantly different at 0.05 from the group with persistent ADHD with Fisher Exact test (discrete variable) or Wilcoxon 2-sided test (continuous variable)

b significantly different at 0.05 from the group with remittent ADHD with Fisher Exact test (discrete variable) or Wilcoxon 2-sided test (continuous variable)

c significantly different at 0.05 from the group with remittent ADHD with Fisher Exact test (discrete variable) or Wilcoxon 2-sided test (continuous variable) 
Table 4: ADHD characteristics at age nine according to ADHD persistence status

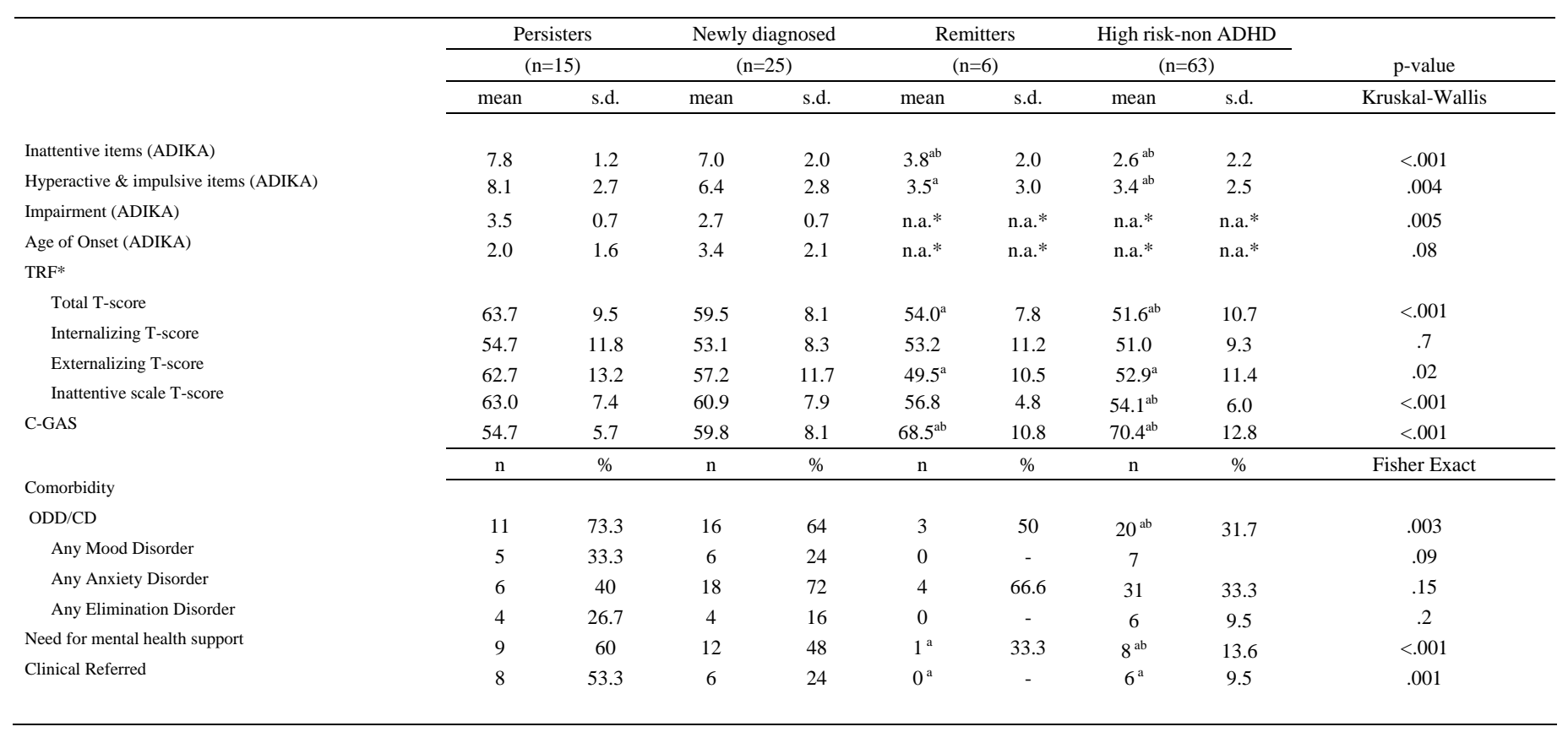

* smaller sample size for Persisters n=12, Newly Diagnosed n=21 and High risk-non ADHD n=52 ; ODD/CD: Oppositional Defiant Disorder / Conduct Disorder

a significantly different at 0.05 from the group with persistent ADHD with Fisher Exact test (discrete variable) or Wilcoxon 2-sided test (continuous variable)

b significantly different at 0.05 from the newly diagnosed group with Fisher Exact test (discrete variable) or Wilcoxon 2-sided test (continuous variable) 


\section{Discussion}

The primary aim of the present study was to examine the extent to which behavior problems at age six could predict a diagnosis of ADHD at ages seven and nine. Using a three year follow-up study, we were able to establish that externalizing behavior problems at six were indeed strong predictors of an ADHD diagnosis ages seven and nine. This corresponds with earlier studies in which the findings show that behavior problems among preschool children have high within-subject stability (Achenbach et al., 1995; Pianta and Caldwell, 1990; Verhulst and van-der-Ende, 1992). In this study, we found that ADHD:C to be the most prevalent subtype found in seven and nine year old children. Our subtype ratios for ADHD:IN were also comparable to those seen in earlier clinic-referred field trials (Lahey et al., 1994). However, we found an unexpectedly high ADHD:HI ratio in nine year old children.

In addition to examining the extent to which behavior problems can predict an ADHD diagnosis, we also sought to explore the diagnostic stability of DSM-IV-defined ADHD in primary school children aged seven to nine. The ADHD diagnosis included an impairment criterion and, as such, only severe cases were assigned a positive score. The diagnostic stability of all types of ADHD between seven and nine years of age was $71 \%$. This rate corresponds with the overall persistence rate of $64 \%$ to $69 \%$ found in earlier communitybased studies (August et al., 1998). It is also comparable with the $75 \%$ to $85 \%$ rate reported in clinically referred samples of older children (Barkley et al., 1990; Biederman et al., 1996; Hart et al., 1995). It is important to note that, while the above mentioned studies examined the diagnostic stability in late childhood to adolescence, our study demonstrated that, at the threshold age of seven years, the ADHD diagnosis has similar validity. However, this finding on the stability of ADHD requires further exploration since almost one child in four failed to meet the diagnostic threshold two years later. Because the group of children with remittent ADHD was quite small, no definitive conclusions can be drawn. However, some trends can be described. When we reanalyzed the raw DICA-R data, the parent-related information led to a valid ADHD diagnosis with threshold levels of symptoms and impairment in different situations. But the low TRF scores demonstrate a possible important role of the pervasive criteria on the stability of the AD/HD diagnosis over time.

In accordance with earlier findings in a study with non-referred older subjects (Cohen et al., 1993a), our study demonstrated that children who continue to fulfill the diagnostic criteria for ADHD at a young age are more likely to be boys. Although our results may have been influenced by certain methodological restrictions, such as the absence of girl-specific ADHD research instruments (Waschbusch and King, 2006) and low statistical power, the finding does correspond with other recently published findings. An Australian epidemiol- 
ogical study (Graetz et al., 2005) found that gender patterns vary across ADHD subtype on impairment measures of social problems, schoolwork difficulties, and self-esteem, with boys displaying more impairment in the combined and hyperactive-impulsive groups. These risk factors are all highly related to persistence. Additionally, brain studies have found that boys are more likely to meet criteria for ADHD because of gender differences in the brain structure (Krain and Castellanos, 2006). Because the extensive overproduction of dopamine receptors in the striatum and substantia nigra during prepuberal development occurs in males but not in females, it is possible that dopaminergic increases in these regions produce hyperactivity and stereotypes. Evidently, this may help to explain why males are more often afflicted with ADHD. After puberty, an extensive pruning of dopamine receptors in the striatum occurs but the pattern by which this occurs varies according to gender (Andersen and Teicher, 2000). The finding of a prepuberal increasing but postpuberal decreasing effect of the dopaminergic metabolism is reflected in the age-related ADHD prevalence differences. It would be interesting to further investigate the relationships between gender, persistence and age with respect to the dopamine metabolism.

An important finding in our study was the high rate (62.5\%) of newly diagnosed ADHD at age nine. Although one could argue that this finding is potentially an artefact due to missed diagnosis at the seven years of age or imprecision in the DICA, we contend that this is not the case. The same diagnostic procedures were used at both age seven and nine and additional care was taken to ensure that the diagnostic procedures were optimal. Furthermore, the TRF total problem scores and externalizing scores at ages seven and nine support this finding. Age is an important variable that can modify the prevalence of ADHD. An earlier study found a higher prevalence of ADHD between 6 and 11 than between the ages of 4 and 5 or between the ages of 12 and 18 (Pineda et al., 1999). Another study found a peak ADHD prevalence between six and nine years of age (Szatmari et al., 1989).

Another issue that has come to light in this study that should be subject to further investigation is related to whether children with newly diagnosed ADHD suffer from pervasive or more transient ADHD. In our study, children with newly diagnosed ADHD at age seven had fewer inattention symptoms than seven year old children with persistent ADHD. Interestingly, these two groups did not differ with respect to the number of hyperactive and impulsive symptoms. It is possible that children with newly diagnosed ADHD did not meet the criteria for ADHD at a younger age because their symptoms only became obvious at a later point in time when greater demands were made on their ability to sustain attention and control behavior. The high symptom scores of the seven year old newly diagnosed group may indicate that this group can be placed at the milder end of the ADHD spectrum. This group may thus fluctuate around the diagnostic threshold. Nonetheless, it is important that this group be recognized given that they possess the same two important outcome indicators, namely demographic characteristics and comorbidity pattern, as the persistent group. 


\section{Limitations}

Although the children were recruited from a large elementary school population $(\mathrm{N}=1317)$, the number of ADHD diagnoses was relatively small (at seven years $\mathrm{N}=21$, at nine years $\mathrm{N}=40$ ). This means that, although the data did not suggest selective attrition and the dropout rate was similar to that of a comparable study (August et al., 1998), estimating the extent to which these results can be generalized is difficult. Additionally, because the interview interval was approximately two years, it is possible that the interview results were biased by a potentially low re-test reliability of the diagnostic interview. However, we contend that this bias was minimal. The test-retest reliability of DICA-R is good to very good and the data from other instruments and informants such as CBCL and TRF support our conclusions. A final potential limitation of this study was our decision not to correct for multiple testing. This choice was made because our analyses were exploratory rather than hypotheses-driven. Nonetheless, we recommend replicating the result in a larger sample.

\section{Conclusion}

This study has demonstrated that a high rate of externalizing behavior or inattention problems in six-year-old children is an important risk factor for the development of ADHD. ADHD also appears to be a stable diagnosis for children diagnosed at young age. In particularly, male gender, symptom pervasiveness and the need for mental health support are related to strong persistence over time. Few children with ADHD showed fewer symptoms two years following the first diagnoses. The data thus challenge the idea that behavioral problems will diminish or resolve as the child grows older.

A large group of children who were not diagnosed with ADHD at age seven were then diagnosed at age nine. We contend that these children's inattention problems only became obvious when greater demands were made on their ability to sustain attention and control behavior. These findings therefore suggest that public health professionals, parents, and teachers need to pay attention to the potential development of ADHD in young hyperactive children. 


\section{References}

Achenbach T-M, Howell C-T, McConaughy S-H, Stanger C (1995), Six-year predictors of problems in a national sample of children and youth: I. Cross-informant syndromes. Journal of the American Academy of Child and Adolescent Psychiatry 34: 336-47

Achenbach T ed. (1991a), Manual for the Child Behavior Checklist 4-18 and 1991 Profile. Burlington: University of Vermont Department of Psychiatry

Achenbach T ed. (1991b), Manual for the Teacher's Report Form and 1991 Profile. Burlington: University of Vermont Department of Psychiatry

Andersen SL, Teicher MH (2000), Sex differences in dopamine receptors and their relevance to ADHD. Neuroscience and Biobehavioral Reviews 24: 137-141

August G-J, Braswell L, Thuras P (1998), Diagnostic stability of ADHD in a community sample of school-age children screened for disruptive behavior. Journal of Abnormal Child Psychology 26: 345-356

Barkley RA, Fischer M, Edelbrock CS, Smallish L (1990), The adolescent outcome of hyperactive children diagnosed by research criteria: I. An 8-year prospective follow-up study. Journal of the American Academy of Child and Adolescent Psychiatry 29: 546-57.

Biederman J, Faraone S, Milberger S, Curtis S, Chen L, Marrs A, Ouellette C, Moore P, Spencer T (1996), Predictors of persistence and remission of ADHD into adolescence: results from a fouryear prospective follow-up study. Journal of the American Academy of Child and Adolescent Psychiatry 35: 343-51

Boyle MH, Offord DR, Racine Y, Sanford M, Szatmari P, Fleming JE, Price-Munn N (1993), Evaluation of the Diagnostic Interview for Children and Adolescents for use in general population samples. Journal of Abnormal Child Psychology 21: 663-81

Cohen P, Cohen J, Brook J (1993a), An epidemiological study of disorders in late childhood and adolescence- -II. Persistence of disorders. Journal of Child Psychology and Psychiatry and Allied Disciplines 34: 869-77.

Cohen P, Cohen J, Kasen S, Velez CN, Hartmark C, Johnson J, Rojas M, Brook J, Streuning EL (1993b), An epidemiological study of disorders in late childhood and adolescence- -I. Age- and gender-specific prevalence. Journal of Child Psychology and Psychiatry and Allied Disciplines 34: 851-67.

De Groot A, Koot H, Verhulst F (1996), Cross-cultural generalizability of the Youth Self-Report and Teacher's Report Form cross informant syndromes. Journal of Abnormal Child Psychology 24: 651-664

de la Osa N, Ezpeleta L, Domenech JM, Navarro JB, Losilla JM (1997), Convergent and Discriminant Validity of the Structured Diagnostic Interview for Children and Adolescents (DICA-R). Psychology in Spain 1: 37-44

Ezpeleta L, de la Osa N, Domenech JM, Navarro JB, Losilla JM (1997), Test-retest reliability of the Spanish adaptation of the Diagnostic Interview of Children and Adolescents. Psicothema 9: 529539

Graetz BW, Sawyer MG, Baghurst P (2005), Gender differences among children with DSM-IV ADHD in Australia. Journal of the American Academy of Child and Adolescent Psychiatry 44: 159-68

Hart EL, Lahey BB, Loeber R, Applegate B, Frick PJ (1995), Developmental change in attentiondeficit hyperactivity disorder in boys: a four-year longitudinal study. Journal of Abnormal Child Psychology 23: 729-49.

Kalff AC, Kroes M, Vles JS, Bosma H, Feron FJ, Hendriksen JG, Steyaert J, van Zeben TM, Crolla IF, Jolles J (2001a), Factors affecting the relation between parental education as well as occupation and problem behavior in Dutch 5- to 6-year-old children. Social Psychiatry and Psychiatric Epidemiology 36: 324-31

Kalff AC, Kroes M, Vles JS, Hendriksen JG, Feron FJ, Steyaert J, van Zeben TM, Jolles J, van Os J (2001b), Neighbourhood level and individual level SES effects on child problem behavior: a multilevel analysis. Journal of Epidemiological Community Health 55: 246-50

Kortenbout van der Sluijs M, Levita D, Manen R, Defares P (1993), In: ADIKA, Amsterdams Diagnostisch Interview voor Kinderen en Adolescenten Lisse: Swetz and Zeitlinger 
Krain AL, Castellanos FX (2006), Brain development and ADHD. Clinical Psychology Review 8: 8

Kroes M, Kalff AC, Kessels AG, Steyaert J, Feron FJ, van Someren AJ, Hurks PP, Hendriksen JG, van Zeben TM, Rozendaal N, Crolla IF, Troost J, Jolles J, Vles JS (2001), Child psychiatric diagnoses in a population of Dutch schoolchildren aged 6 to 8 years. Journal of the American Academy of Child and Adolescent Psychiatry 40: 1401-9

Kroes M, Kalff AC, Steyaert J, Kessels AG, Feron FJ, Hendriksen JG, van Zeben TM, Troost J, Jolles J, Vles JS (2002), A longitudinal community study: do psychosocial risk factors and child behavior checklist scores at 5 years of age predict psychiatric diagnoses at a later age? Journal of the American Academy of Child and Adolescent Psychiatry 41: 955-63

Lahey B-B, Applegate B, McBurnett K, Biederman J, Greenhill L, Hynd G-W, Barkley R-A, Newcorn J, Jensen P, Richters J, et al. (1994), DSM-IV field trials for attention deficit hyperactivity disorder in children and adolescents. American Journal of Psychiatry 151: 1673-85

Lahey BB, Pelham WE, Loney J, Kipp H, Ehrhardt A, Lee SS, Willcutt EG, Hartung CM, Chronis A, Massetti G (2004), Three-year predictive validity of DSM-IV attention deficit hyperactivity disorder in children diagnosed at 4-6 years of age. American Journal of Psychiatry 161: 2014-2020

Lavigne JV, Arend R, Rosenbaum D, Binns HJ, Christoffel KK, Gibbons RD (1998), Psychiatric disorders with onset in the preschool years: I. Stability of diagnoses. Journal of the American Academy of Child and Adolescent Psychiatry 37: 1246-54.

Mannuzza S, Klein R-G, Bessler A, Malloy P, Hynes M-E (1997), Educational and occupational outcome of hyperactive boys grown up. Journal of the American Academy of Child and Adolescent Psychiatry 36: 1222-1227

Pianta R-C, Caldwell C-B (1990), Stability of externalizing symptoms from kindergarten to first grade and factors related to instability. Development and Psychopathology 2: 247-258

Pineda D-A, Ardila A, Rosselli M, Arias B-E, Henao G-C, Gomez L-F, Mejia S-E, Miranda M-L (1999), Prevalence of attention-deficit/hyperactivity disorder symptoms in 4- to 17-year-old children in the general population. Journal of Abnormal Child Psychology 27: 455-462

Reich W (2000), Diagnostic Interview for Children and Adolescents (DICA). Journal of the American Academy of Child and Adolescent Psychiatry 39: 59-66

Reich W, Shayla JJ, Taibleson C (1992), The Diagnostic Interview for Children and Adolescents Revised (DICA-R) (structured psychiatric interview). St Louis, MO: Washington University.

Sattler JM (1992), Assessment of Children: WISC-III and WPPSI-R supplement San Diego, CA: Jerome M. Sattler

Shaffer D, Gould M-S, Brasic J, Ambrosini P, Fisher P, Bird H, Aluwahlia S (1983), A children's global assessment scale (CGAS). Archives of General Psychiatry 40: 1228-31

Szatmari P, Offord D-R, Boyle M-H (1989), Ontario Child Health Study: Prevalence of attention deficit disorder with hyperactivity. Journal of Child Psychology and Psychiatry and Allied Disciplines 30: 219-230

van den Brandt P-A, Goldbohm R-A, van 't Veer P, Volovics A, Hermus R-J, Sturmans F (1990), A large-scale prospective cohort study on diet and cancer in The Netherlands. Journal of Clinical Epidemiology 43: 285-95

Van Grimbergen I, Célestin-Westreich, S \& Ponjaert-Kristofferson, I (1999), Validering van ADIKAIV(deel externaliserend gedrag) bij een klinische populatie kinderen tussen 6 en 18 jaar. In: De kinderschoenen ontgroeid? Tweede Vlaams Congres Kinder- en jeugdpsychiatrie en psychotherapie., Garant ed. Leuven, pp p.76

Verhulst F-C, van-der-Ende J (1992), Six-year developmental course of internalizing and externalizing problem behaviors. Journal of the American Academy of Child and Adolescent Psychiatry 31: 924-31

Verhulst F, Van der Ende J, Koot H (1996), In: Handleiding voor de CBCL Rotterdam: Erasmus University/ Departement of Child and Adolescent Psychiatry, Sophia Children's Hospital

Waschbusch DA, King S (2006), Should sex-specific norms be used to assess attentiondeficit/hyperactivity disorder or oppositional defiant disorder? Journal of Consulting and Clinical Psychology 74: 179-185 
Chapter 6

\section{The Use of Health Care Services and Psychotropic}

Medication in a Community Sample of 9-Year-Old Schoolchildren with ADHD ${ }^{1}$

${ }^{1}$ Tremmery S., Jan K. Buitelaar, Jean Steyaert, Geert Molenberghs, Frans J.M. Feron, Ariane C. Kalff, Petra P.M. Hurks, Jos G.M.Hendriksen, Johan S.H. Vles, Jelle Jolles. European Child and Adolescent Psychiatry, Aug 2007;16(5):327-336 


\section{Abstract}

Objective: To examine the prevalence of the use of health care services and psychotropic medication within a community sample $(\mathrm{N}=283)$ of 9-year-old school children and, more specifically, to evaluate the use of prescribed stimulants.

Methods: Data from the second follow-up phase of the "Study of Attention Deficit Maastricht" (SAM) were analyzed. Assessments at age 9 included a structured psychiatric interview with parents, behavior and family situation questionnaire, IQ estimate and global assessment scale. Use of health care services and medication was obtained by the DICA-R and from the Youth Health Care records.

Results: 190 children of the selected sample had at least one child psychiatric diagnosis, 26 (14\%) of them were clinically referred and $12(6 \%)$ received stimulants. Of the children with ADHD (N=45), 10/45 (22\%) received stimulants. Conversely, 2 out of 12 children who were treated with stimulants did not meet full DSM-IV diagnostic criteria, but were subthreshold ADHD cases. The treatment status was highly dependent on being clinically referred.

Conclusion: The major finding of our survey is a lack of referral to child mental health services, and associated underdiagnosis and undertreatment, particularly in children with ADHD. There is a critical need to translate and implement the diagnostic and treatment guidelines to clinical practice. 


\section{Introduction}

Attention Deficit Hyperactivity Disorder (ADHD) is a neuropsychiatric condition, characterized by enduring and pervasive symptoms of inattention, hyperactivity and impulsivity (Taylor et al., 2004). Stimulant medication (particularly methylphenidate) is a common and accepted form of treatment for ADHD. Methylphenidate has also proved to be very safe and generally well tolerated, and professional guidelines are available for determining optimal dosage levels and avoiding side effects (Goldman et al., 1998; Greenhill et al., 1999; Taylor et al., 2004). However, the use of stimulant medication for the treatment of ADHD has not been without controversy. Concerns have been raised about overprescription of medication and potential abuse of stimulant medication (Jensen et al., 1999; Wolraich, 1999).

The prescription of stimulant medication for children with ADHD has significantly increased in the last decade (Safer et al., 1996). This increase is probably due to a number of factors, including an increase in public and clinical awareness and acceptance of ADHD as a disorder, a broadening of the diagnostic criteria for ADHD and an increase in the availability of ADHD-specific services, particularly pediatric and child psychiatric services (Hoagwood et al., 2000). Sceptics however, argue that the increase indicates an inappropriate use of stimulants. In the United States, the number of children who receive stimulants increased approximately 2.5-fold in the first half of the 1990s (Safer et al., 1996). The scarce research literature available outside the United States confirms this trend. A drug utilization study based on computerized pharmacy dispensing records was conducted from 1995 to 1999 for children aged 0 to 19 years in the north of the Netherlands also found a 2.5-fold increase (Schirm et al., 2001). In Australia, about 5300 children (age 0-17 years) started on stimulants for the first time in 2000 and this was 5 times the number in 1990 (Salmelainen, 2002). A German study showed that during the 1998 - 2000 period the number of methylphenidate prescriptions increased two and a half times (von Ferber et al., 2003). These surveys were database driven and do not permit validation of the correctness of the diagnosis, thus precluding inferences about the appropriateness of the use of medication.

Three studies have examined ADHD in an unbiased community-based design. In an American population of youth aged from 9 to 17 only 1 in 8 children with ADHD received stimulant treatment, but $50 \%$ of the children who were prescribed a stimulant did not meet diagnostic criteria for ADHD (Jensen et al., 1999). A similar result was found in an Australian population (aged 6-17) where $12.6 \%$ of the ADHD children received stimulants treatment and $23 \%$ of the children used stimulants without meeting the criteria for ADHD (Sawyer et al., 2002). In the Great Smoky Mountains Study (Angold et al., 2000) 52.9\% of the ADHD or ADHD-NOS children (9-16 years old) received stimulant treatment, but 51.2 
$\%$ of the children who were prescribed a stimulant did not have any ADHD symptoms. These studies suggest a trend in the United States and Australia from the perspective of "evidence-based medicine" towards inappropriate use of stimulants, with undertreatment of children diagnosed with ADHD and overprescribing of stimulant medication in the group of children without ADHD. In Europe, no studies exist that examine the relationship between diagnostic correctness and the use of stimulants. A German study based on health insurance data gives little evidence for overtreatment because about two-thirds of the ADHD children did not receive drug therapy. (Schubert et al., 2003).

In this article we want to investigate the use of health care services and psychotropic medication in a community sample of 9-year-old schoolchildren, and, more specifically, the treatment status of ADHD children in a non-clinical Dutch population. This study is part of a large research program entitled "Study of Attention Disorders in Maastricht (SAM)". In a school-based prospective study the precursors of ADHD were investigated in children aged 5 to 6 (Kalff et al., 2001b; Kroes et al., 2001). A multi-phase, screening-stratified sampling design was used (Shrout et al., 1986) and the follow-up phase at age 9 was examined.

\section{Method}

\section{Subjects and Procedure}

\section{Phase 1: Children enrolled at about 6 years of age}

The methodology has been reported in detail elsewhere (Kalff et al., 2001a). This study was approved by the Ethics Committee of the Maastricht University. All parents of a schoolbased population of 2290 children were approached with regard to participation. All the children were enrolled in the kindergarten $(\mathrm{N}=65)$ (year before the first grade of elementary school) in the Maastricht area, in the southern Netherlands. The parents of 1317 (57.5\%) children (669 boys and 618 girls, age mean \pm SD $5.87 \pm 0.41$ year) agreed to participate and written informed consent was obtained for phases 1 and 2. Parents did not have to explain why they refused participation. No significant differences were observed between the 1317 children who participated and the 973 children who did not in terms of age, gender and demographic factors (Kroes et al., 2001). Kroes et al. (1999) generalized the estimated prevalences of psychiatric disorders to an entire population and found no substantial differences. In the first stage the parents of all 1317 children completed the Child Behavior Checklist (CBCL) (Achenbach, 1991a; Verhulst et al., 1996) and a questionnaire on sociodemographic characteristics. 


\section{Phase 2: First follow-up at 7 years of age.}

On the basis of CBCL scores in phase 1, three groups of children (in total $\mathrm{N}=452$ ) were selected for follow-up. The first, an externalizing high-risk group, consisted of 173 children with scores on the CBCL broadband externalizing scale above the $90^{\text {th }}$ percentile $(\mathrm{T}>63)$ and/or scores on the inattention scale of the CBCL above the $95^{\text {th }}$ percentile $(\mathrm{T}>67)$. The second, an internalizing high-risk group, consisted of 59 children with scores on the broadband internalizing scale of the CBCL above the $90^{\text {th }}$ percentile $(\mathrm{T}>63)$ and who did not meet the selection criteria for the externalizing high-risk group. The cut-off points chosen represent the clinical cut-off scores for the CBCL broadband and inattention scales determined in earlier Dutch epidemiological studies (Verhulst et al., 1996). Finally, a control group of 220 children with CBCL total scores below the $90^{\text {th }}$ percentile who did not meet selection criteria for the two high-risk groups was selected. These children were matched with the children of the two high-risk groups in terms of age, gender and geographic area (urban versus rural).

The parents of all children were invited to participate in structured psychiatric interviews (see below). Parents of 403 (89\%) children (233 boys and 170 girls, age $7.1 \pm 0.42$ year)

Figure 1. Sampling Design for the first Cohort "Study of Attention Disorders in Maastricht"

CBCL Selection At about 6 Years $\mathrm{N}=452$

Follow-up At about 7 Years $\mathrm{N}=403$

Follow-up At about 9 Years $\mathrm{N}=283$

Sampling frame

School-based Year Cohort

CBCL Externalising High Risk $\mathrm{N}=173$

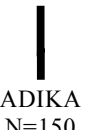

$\mathrm{N}=150$

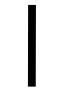

ADIKA

$\mathrm{N}=107$
Selected Sample $\mathrm{N}=452$

\section{N=1317}

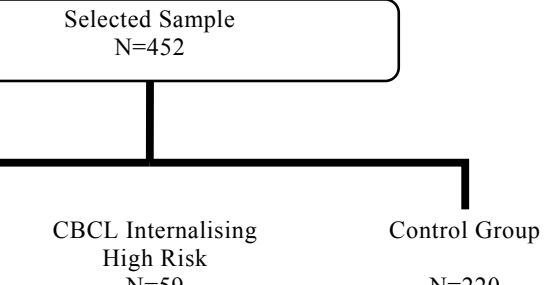
$\mathrm{N}=59$

$\mathrm{N}=220$

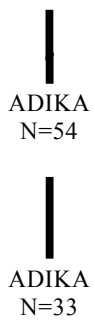

$\mathrm{N}=199$

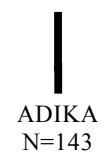


agreed to participate. Among these were 150 (87\% from initial group) from the first group, 54 (91\% from initial group) from the second and 199 (90\% from initial group) from the third group of control children. A teacher report form (TRF) was completed by the teachers of all children. The participating and non-participating children did not differ in terms of CBCL scores, gender or demographic characteristics.

\section{Phase 3: Second follow-up at 9 years of age.}

When the children were 9 the parents of the three groups of children were asked for written consent to continue participation, which included a structured psychiatric interview and an overall functioning evaluation using the Children's Global Assessment Scale (CGAS) and a cognitive functioning estimation of the child.

In total 283 (63\% of the selected sample) parents and children (163 boys and 120 girls, age $9.2 \pm 0.4$ year) took part. Among these were 107 (62\% from initial group) from the first group, 33 (56\% from initial group) from the second and 143 (65\% from initial group) controls. The 169 (36\%) non-participating children did not differ from the participating children in terms of psychiatric diagnosis at age 7, age, gender and demographic factors.

\section{Measures}

The Child Behavior Checklist (CBCL) and the Teacher Report Form (TRF) (Achenbach, 1991b) were completed by parents and teachers when the children were 6 (CBCL), 7 (TRF) and 9 (TRF) years old respectively. The CBCL and TRF were computer scored, using appropriate age and gender norms for the Dutch population (De Groot et al., 1996; Verhulst et al., 1996).

Demographic information. When the children were 6, the level of parental occupation was scored on a 7-point scale, ranging from unskilled to graduate / professional, and was divided into three levels for the present study: low (1, 2 and 3), middle (4 and 5) and high (6 and 7) (van den Brandt et al., 1990). Other demographic information included the parents' country of birth, family intactness (child living with one versus two parents), number of siblings and residential area (urban area of Maastricht versus surrounding villages).

The Diagnostic Interview for Children and Adolescents (DICA-R) (Reich et al., 1992) in its Dutch version (Amsterdam Diagnostisch Interview voor Kinderen - ADIKA) (Kortenbout van der Sluijs et al., 1993) was used for structured psychiatric assessment of the children at 7 and 9 years of age. The DICA-R is based on the criteria of DSM-III-R (APA, 1987) and was adapted to the criteria of DSM-IV (APA, 1994) for diagnosing ADHD (Van Grimbergen, 1999). Although no reliability studies have been performed with the ADIKA, 
the DICA-R has been described recently as a useful measure in both research and clinical settings for providing reliable psychiatric information about children (van den Brandt et al., 1990).

The DICA-R was administered to the parents of 7-year-old children by three (a medical doctor, a psychologist and a health care worker) and of 9-year-old children by two (a child psychiatry trainee and a psychologist) different interviewers, who had received prior training. We chose to optimize reliability by intensive supervision of the interviewers by the child psychiatrist. To reach consensus and improve the reliability and validity of our diagnosis, the results were discussed weekly during an intensive supervision session of the interviewers by the research child psychiatrist (J.S.). Discrepancy in scoring was resolved by consensus. When questions arose, parents were reassessed for further clarification.

All interviewers were blind to the results of prior assessments. The DICA-R assesses symptoms of axis-I psychiatric disorders, such as disruptive, emotional, anxiety and elimination disorders, and their duration, impairment and possible consultation with health professionals. Diagnoses were generated by a computer algorithm that ignores the hierarchical DSM structure. For example, Oppositional Defiant Disorder (ODD) and Conduct Disorder (CD) could be diagnosed in the same patient.

The ADHD module of the Dutch DICA-R contains 10 questions about inattention and 11 about hyperactivity and impulsivity. Positive answers were used to compute the number of inattention symptoms (range $0-10$ ) and the number of hyperactivity and impulsivity symptoms (range 0-11). The Dutch DICA-R includes 4 binary items on impairment: problems at home, problems at school, social problems and overall performance. An impairment sum score was derived (range 0-4) from these items. An ADHD diagnosis was generated when the DSM-IV criteria for ADHD were present with at least 6 hyperactive and impulsive symptoms and / or inattention symptoms, 2 positive scores on impairment and an age of onset before the age of 7 . When an ADHD diagnosis was reached, the ADHD subtype was based on a threshold score (min. 6) for the 2 symptom groups

Intelligence at age 9 was estimated with the Vocabulary and Block Design subtests of the WISC-R (Lezak, 1995). The children were tested at school by three psychology students and a child psychologist. They had been extensively trained in the assessment.

The Children's Global Assessment Scale (CGAS), a measure of overall severity of disturbance, is an adaptation of the Global Assessment Scale for adults (Shaffer et al., 1983). The CGAS was completed at age 9 at the end of the interview by the interviewer. Information obtained during the interview was accomplished with a non-structured interview about the functioning of the child at home, at school, with friends and during 
spare time. To optimize the reliability of the scoring, the results were discussed weekly during an intensive supervision session of the interviewers by the child psychiatrist (J.S.).

Information on the treatment or services was collected in two different ways. First the DICA-R contains a question about services used and medication taken for each positively scored diagnosis. Secondly, information was collected by the Youth Health Care (YHC) Service. This national organization is responsible for performing a periodic systematic health examination for all children in the region. The response rate is $98 \%$. School doctors perform this examination and they are allowed, by law, to use the medical information gained anonymously for epidemiological research purposes. The information obtained by the interview was in all cases similar to the YHC files. Only YHC information was available for the children not reaching a threshold diagnosis.

Subjective Family Burden and Assessment of Educational Situation was measured by a Dutch questionnaire, the Nijmegen Family Situation Questionnaire (NVOS). The reliability and validity are good to excellent (Wels and Robbroeckx, 1996). The Subjective Family Burden exists of 46 items resulting in 8 categories: acceptance of the educational situation, coping capacity, having problems with the child, wanting a different educational situation, child is burden, being on one's own in the educational situation, enjoying education and having good contact with the child. Each item is scored from 1 to 5, with a low score indicating a positive response and a high score indicating a problematic situation. The score for each category is the average of the corresponding items. The norm score for a clinically referred population varies between 2.13 and $2.68(2.4+/-.3)$ for the different categories and for a control group between 1.4 and $2.01(1.7+/-.3)$. As regards the educational situation, parents can make a choice out of 8 descriptions of the current educational situation, with the highest score indicating that there are no problems and no need for educational support, and the lowest score indicating that there are severe problems, parents are desperate and urgent help is necessary. The norm score for a clinically referred population is 4.07 and for a control group 2.07 .

\section{Statistical procedures}

Explorative analysis was performed for all variables using bivariate and multivariate tests. The Pearson $\chi^{2}$ test $\left(\chi^{2}\right)$ and the Fisher exact two-sided test (FE) were used for the nominal variables. The Wilcoxon rank sum test (W) and Kruskal-Wallis test (KW) were used for continuous variables that were not normally distributed. Logistic regression was used to obtain odds ratios with the Wald confidence limits (OR 95\% CI). Because analyses were exploratory rather than hypothesis-driven we did not correct for multiple testing. We used .05 as threshold of statistical significance. 


\section{Results}

\section{Child and Family Demographic characteristics at age 9 as a function of the DICA-R diagnostic status}

In table 1 we present the child and family demographic characteristics for the 283 participating children at age 9 as a function of the DICA-R diagnostic status: ADHD $(n=45)$, other diagnosis $(n=145)$ and no diagnosis $(n=93)$. The other diagnosis includes other disruptive behavior disorders, mood disorder, elimination disorder and pervasive developmental disorder. The criteria for simple phobia are not age specific and result in an overestimation of anxiety disorder at this age (Kroes et al., 2001), so more than two anxiety disorders had to be present. Of the children interviewed, $14.9 \%$ were regarded as having DSM-IV ADHD. As we used a design that oversampled children with ADHD because of selection based upon CBCL externalizing group, this percentage is not representative for the general population. At age 7 Kroes et al. (2001) found an ADHD prevalence of $3.8 \%$ for the

Table 1. Child and Family Demographic Characteristics according to the ADIKA diagnostic Status

\begin{tabular}{|c|c|c|c|c|c|c|c|}
\hline & \multicolumn{2}{|c|}{$\begin{array}{l}\text { ADHD } \\
(n=45) \\
\end{array}$} & \multicolumn{2}{|c|}{$\begin{array}{c}\text { Other Diagnosis } \\
(n=145)\end{array}$} & \multicolumn{2}{|c|}{$\begin{array}{c}\text { No Diagnosis } \\
(n=93) \\
\end{array}$} & \multirow[b]{2}{*}{$\begin{array}{c}\text { Kruskal- } \\
\text { Wallis }\end{array}$} \\
\hline & mean & s.d. & mean & s.d. & mean & s.d. & \\
\hline Age at baseline & 6.1 & $(.5)$ & $5.9^{\mathrm{a}}$ & $(.4)$ & $5.8^{\mathrm{a}}$ & $(.4)$ & .03 \\
\hline CBCL at 6 years & & & & & & & \\
\hline Total & 66.4 & $(9.4)$ & $56.5^{\mathrm{a}}$ & $(11.7)$ & $48.6^{\mathrm{ab}}$ & $(11.5)$ & $<.0001$ \\
\hline Internalizing & 59.1 & $(9.4)$ & $55.7^{\mathrm{a}}$ & (11.3) & $48.1^{\mathrm{ab}}$ & $(10.1)$ & $<.0001$ \\
\hline Externalizing & 65.4 & $(10.9)$ & $56.4^{\mathrm{a}}$ & (11.7) & $49.9^{\mathrm{ab}}$ & $(11.0)$ & $<.0001$ \\
\hline \multirow[t]{2}{*}{ Inattention Scale } & 65.5 & $(9.4)$ & $56.1^{\mathrm{a}}$ & $(6.9)$ & $53.2^{\mathrm{ab}}$ & $(5.3)$ & $<.0001$ \\
\hline & $\mathrm{n}$ & $\%$ & $\mathrm{n}$ & $\%$ & $\mathrm{n}$ & $\%$ & Chi-square \\
\hline Gender boys & 35 & $(77.8)$ & $48^{\mathrm{a}}$ & $(57.9)$ & $45^{\mathrm{a}}$ & $(48.4)$ & .005 \\
\hline Urban & 31 & $(68.9)$ & 98 & $(67.6)$ & 52 & $(55.9)$ & .14 \\
\hline Intact Family & 36 & $(80)$ & 114 & $(78.6)$ & $87^{\mathrm{ab}}$ & $(93.5)$ & .007 \\
\hline Immigrant parents & 4 & $(9.3)$ & 18 & (12.6) & 11 & $(12.1)$ & .84 \\
\hline Education parents $\$$ & & & & & & & .005 \\
\hline Low & 27 & $(60)$ & 64 & $(45.4)$ & $28^{\mathrm{a}}$ & $(30.1)$ & \\
\hline Average & 12 & $(26.7)$ & 34 & (24.1) & $27^{\mathrm{a}}$ & $(29.0)$ & \\
\hline High & 6 & (13.3) & 43 & $(30.5)$ & $38^{\mathrm{a}}$ & (40.9) & \\
\hline
\end{tabular}

\footnotetext{
$\$ 4$ missing in the No Diagnosis Group

${ }^{a}$ significantly different at .05 from high risk externalizing

${ }^{b}$ significantly different at .05 from high risk internalizing
} 
entire $(\mathrm{N}=2290)$ population. The age at baseline was about 6 , with the ADHD group containing slightly older children than the 2 other groups ( $\mathrm{KW} 7.0 \mathrm{df}=2, \mathrm{p}=.03$ ). Boys were over represented in the ADHD group (77.8\% versus $57.9 \%$ in the other diagnosis group and versus $48.4 \%$ in the no diagnosis group, $\left.\chi^{2} 10.7 \mathrm{df}=2, \mathrm{p}=.005\right)$. Two family demographic characteristics distinguish the different groups. The first, intactness of the family was overrepresented in the no diagnosis group $(93.5 \%$ versus $80 \%$ in the ADHD group and $78.6 \%$ in the no other diagnosis group, $\chi^{2}=9.8 \mathrm{df}=2, \mathrm{p}=.007$ ). Secondly, parents of the no diagnosis group tend to be more highly qualified than parents of the other groups $(\mathrm{KW}=14.7$ $\mathrm{df}=4, \mathrm{p}=.005$ ). The other sociodemographic variables did not distinguish between the three groups.

\section{Use of services}

In table 2 we present data on the major types of services provided for the 283 participating children at age 9 as a function of the DICA-R diagnostic status: ADHD, other diagnosis and no diagnosis. Only $30 / 283(10.6 \%)$ of the study population had ever been clinically referred for psychosocial or behavioral problems. This referral could be to a paediatrician $(n=1)$, child neurologist $(n=8)$, or a child psychiatrist $(n=22)$. Some children were referred to more than one medical doctor. Children were 7.1 (95\% CI 2.9 - 17.1) times more likely to be referred for ADHD behavior ( $\mathrm{n}=16$ or $5.6 \%$ ) than for other psychopathology $(\mathrm{n}=10$ or $3.5 \%)$ (FE, $\mathrm{p}=0.03$ ). This trend was not present for other types of services such as school services or psychosocial treatment. In the ADHD group 5 children versus 10 in the other psychopathology group received school services (FE, $\mathrm{p}=0.15)$ and 6 children versus 8 (FE, $\mathrm{p}=0.06$ ) received psychosocial treatment.

Table 2. Numbers of Children receiving Types of Services by ADIKA diagnostic Status

\begin{tabular}{lcccccccc}
\hline & \multicolumn{2}{c}{$\begin{array}{c}\text { ADHD } \\
(\mathrm{n}=45)\end{array}$} & \multicolumn{2}{c}{$\begin{array}{c}\text { Other Diagnosis } \\
(\mathrm{n}=145)\end{array}$} & \multicolumn{2}{c}{$\begin{array}{c}\text { No Diagnosis } \\
(\mathrm{n}=93)\end{array}$} & \multicolumn{2}{c}{$\begin{array}{c}\text { Total } \\
(\mathrm{n}=283)\end{array}$} \\
\hline & $\mathrm{n}$ & $\%$ & $\mathrm{n}$ & $\%$ & $\mathrm{n}$ & $\%$ & $\mathrm{n}$ & $\%$ \\
\cline { 2 - 9 } Clinically Referred & 16 & $(35.6)$ & 10 & $(6.9)$ & 4 & $(4.3)$ & 30 & $(10.6)$ \\
Stimulants & 10 & $(22.2)$ & 1 & $(.7)$ & 1 & $(1.1)$ & 12 & $(4.2)$ \\
Other medication & 0 & $(0)$ & 1 & $(.7)$ & 0 & $(0)$ & 1 & $(.3)$ \\
School services & 5 & $(11.1)$ & 10 & $(6.9)$ & 6 & $(6.4)$ & 21 & $(7.4)$ \\
Psychosocial treatment & 6 & $(13.3)$ & 8 & $(5.5)$ & 2 & $(2.1)$ & 16 & $(5.6)$ \\
& & & & & & & & \\
\hline
\end{tabular}




\section{Use of medication}

Methylphenidate was the only prescribed stimulant treatment in this cohort. At age 7, none of the children received stimulant medication. At age 9, 12 children or $4.2 \%$ of the followup study population receive stimulant medication. Medication was initiated in 11 children after clinical referral, and only one child received medication after contacting the general practitioner (GP). Ten children had a DICA-R diagnosis of ADHD, 1 child with an emotional disorder and one child with no diagnosis at all. Two children with a positive ADHD diagnosis received both therapies (medication and psychosocial treatment).

Thus, 2 out of $12(16.6 \%)$ of the children on stimulants did not meet full diagnostic criteria for ADHD. This group is too small to draw strong conclusions, but some individual descriptions can be made. Both children have subthreshold or borderline ADHD. They have threshold ADHD symptom scores but low impairment scores. They have poor results on the WISC-R but were going to a normal school, had average to highly educated parents, and the teacher scored average to high on the TRF.

Table 3. Characteristics among Children with/without Stimulant Treatment

\begin{tabular}{|c|c|c|c|c|c|}
\hline & \multicolumn{2}{|c|}{$\begin{array}{c}\text { ADHD + } \\
\text { Stimulant }+ \\
(\mathrm{n}=10)\end{array}$} & \multicolumn{2}{|c|}{$\begin{array}{c}\text { ADHD + } \\
\text { Stimulant - } \\
(\mathrm{n}=35)\end{array}$} & \multirow[b]{2}{*}{ Fisher Exact } \\
\hline & $\mathrm{n}$ & $\%$ & $\mathrm{n}$ & $\%$ & \\
\hline Gender boys & 10 & $(100)$ & 25 & $(71.4)$ & .08 \\
\hline Clinically Referred & 9 & $(90)$ & 7 & (20) & .001 \\
\hline \multicolumn{6}{|l|}{ Comorbidity } \\
\hline ODD & 2 & (20) & 21 & $(60)$ & .03 \\
\hline $\mathrm{CD}$ & 4 & (40) & 4 & (11.4) & .06 \\
\hline Mood disorder & 5 & (50) & 24 & $(68.6)$ & .4 \\
\hline Anxiety disorder $>2$ & 4 & (40) & 11 & $(31.4)$ & .7 \\
\hline \multirow[t]{2}{*}{ Enuresis } & 3 & (30) & 8 & (22.9) & .7 \\
\hline & mean & s.d. & mean & s.d. & Wilcoxon \\
\hline \multicolumn{6}{|l|}{ TRF at age 7} \\
\hline Total & 62.0 & (12.6) & 56.2 & (8.4) & .03 \\
\hline Externalizing & 63.0 & (11.6) & 55.7 & (9.9) & .08 \\
\hline Internalizing & 55.8 & (12.7) & 50.8 & (10.4) & .3 \\
\hline Inattention Scale & 63.7 & $(10.1)$ & 57.0 & $(6.6)$ & .09 \\
\hline \multicolumn{6}{|l|}{ ADHD Criteria } \\
\hline Inattentive items & 8.2 & (1.1) & 7.1 & (1.8) & .05 \\
\hline Hyperactive \& impulsive items & 8.5 & (2.7) & 6.8 & (3.1) & .09 \\
\hline Impairment & 3 & $(.8)$ & 2.9 & (.8) & .8 \\
\hline Age of onset & 3.1 & (2.2) & 2.8 & (2.0) & .9 \\
\hline CGAS & 56.2 & $(6.5)$ & 58.1 & (7.6) & .7 \\
\hline
\end{tabular}


Within the ADHD group 30 or $66.7 \%$ of the children did not receive any kind of therapy, 10 $(22.2 \%)$ received monotherapy and $5(11.1 \%)$ received combined therapy. Looking at the different kinds of therapy, $10(22.2 \%)$ received stimulant medication, 5 (11.1\%) special school services and $6(13.3 \%)$ psychosocial treatment. Only one child, diagnosed with autism, received a non-stimulant medication (pipamperone). The average dose of methylphenidate was about $22.5+/-8.6 \mathrm{mg} /$ day and there was no dependence on the ADHD diagnostic status. To evaluate the rationale for stimulation treatment, two different subgroups were formed. The first group included the children with ADHD who were treated with stimulants $(n=10)$, the second group the children with ADHD without stimulant treatment $(n=35)$.

\section{Influence of Demographics, ADHD Characteristics, Comorbidity and Educational Situation on Stimulant Treatment Status}

As expected, the main difference between these two groups was the percentage of children clinically referred $(90 \%$ versus $20 \%$, FE, $\mathrm{p}<.001)$ (table 3$)$.

Furthermore, the ADHD children on stimulants, compared with those without stimulant use, had higher total scores on the TRF at age 7, (mean \pm SD $62.0 \pm 12.6$, versus $56.2 \pm 8.4, \mathrm{~W}$, $\mathrm{p}=.3)$, had more inattentive symptoms of ADHD as obtained by DICA-R $(8.2 \pm 1.1$ versus $7.1 \pm 1.8, \mathrm{~W}, \mathrm{p}=.05)$, had more frequent comorbid conduct disorder $(40 \%$ versus $11.4 \%$, Fisher exact test, $\mathrm{p}=.06)$ and had less frequent comorbid oppositional defiant disorder $(20 \%$ versus $60 \%, \mathrm{~F}, \mathrm{p}=.03$ ). No differences between the two groups were found in regard to gender, residential area, family intactness, parental education, prorated scores of the WISC, CBCL scores at age 6, CGAS, the distribution of ADHD subtypes, the ADHD impairment score and comorbidity with anxiety and mood disorders.

We also explored whether ADHD children treated with stimulants differed from those without stimulants in terms of subjective family burden, educational situation and need for health care services. Both ADHD groups had high scores for subjective family burden, which were consistent with the norm scores for clinically referred populations (between 1.6 $+/-.4$ and $3.2+/-.8$ for the different categories). Similar results were obtained for the educational situation, where both ADHD groups scored within the clinical range $(3.7+/-1.2$ vs. $3.6+/-1.8)$. However, the subjective family burden and assessment of the educational situation did not differ between ADHD children with or without stimulant treatment. 


\section{Discussion}

To the best of our knowledge, this survey is the first European study examining the relationship between ADHD status and the clinical referral and treatment status including the use of psychotropic medication in a non-clinical sample of ADHD children.

Since the start of the discussion about the question of over versus undertreatment of ADHD (Jensen et al., 1999), sceptics have argued that only community-based epidemiological surveys within a well-defined sampling frame and rigorous diagnostic procedures can yield meaningful estimates of treated and untreated prevalence rates of ADHD. These diagnostic procedures must include the information of different informants so that the presence of the ADHD symptoms can be evaluated in more than one setting. In this project, we have tried to achieve this by using a semi-structured interview of the parent with specific questions about the onset of the symptoms and the impairment in different settings such as home, school, friends and overall functioning. The $\mathrm{CBCL}$ and TRF behavior questionnaires were completed by the parents and teachers at different ages, together with specific child and family characteristics such as IQ, CGAS, subjective family burden and assessment of the educational situation. As such, we were able to validate the DICA-R based diagnoses at subgroup level by questionnaire data completed by parents and teachers. Despite the methodological limitation in respect of generalizing our results to an entire population, the relation between ADHD status and mental health support generates some interesting hypotheses, which we will discuss further in this section.

We conducted our survey in a cohort of schoolchildren all of the same age. At the time of the data collection (1999-2000) the children were about 9-10 years old, when ADHD is most prevalent (Pineda et al., 1999; Szatmari et al., 1989). Another important issue is the short study's sampling period ( 8 months) and the fact that information on the prescription of medication was attached to the period of 12 months just before the interview. Since we did not want to rely just on the parents for the information about prescribing psychotropic medication, information was also collected by Youth Health Care (YHC) Service. In this way additional information was collected with exact start and end dates of medication, together with the doses and the prescriber.

Our study shows a discrepancy between DICA-R diagnosis and the use of medical health care services. Only $13.7 \%$ of the children with an eventual child psychiatric diagnosis had been clinically referred in the 12 months before the interview. This figure was higher (35.6\%) for the ADHD group. It would be interesting to investigate the factors influencing the referral and treatment status. Several studies have been done to investigate the concordance between the psychological diagnosis by a general practitioner (GP) and parent reports of psychological problems. A London study (Sayal and Taylor, 2004) showed that 
only a third of parents of 5 to 11 year olds who had concerns expressed them during the consultation. In a general population sample of 2,449 Dutch children and adolescents (4-17 years old) (Zwaanswijk et al., 2005) the concordance between psychological diagnoses by the GP and parent, teacher and adolescent reports of psychological problems was limited. Strong recommendations were made to increase GP identification of child psychological problems and enhance access to care for those in need. Our results support these recommendations, but the study design limits the generalization.

At the time of the data collection (1999-2000) the dramatic increase in prescribing methylphenidate in the Netherlands had occurred (Schirm et al., 2001), but the use of psychotropic medication within an at-risk population still remains low. Only $4.2 \%$ of our follow-up study population used stimulants - all methylphenidate - and only one child $(0.3 \%)$ used other psychotropic medication. Of the children with an ADHD diagnosis, only $22.2 \%$ received stimulants.

Because of the different design of epidemiological studies on the use of stimulants, it is difficult to compare our results with other studies. Important differences are the age of the child under study, the use of DSM IV, the short study's sampling period and the time of collecting the data (1999-2000). Nevertheless, our results are congruent with the findings of Jensen (1999) in an American population and Saywer (2002) in an Australian population with about 1 in 8 children with ADHD receiving medication. In our study, we found few arguments for the group with stimulant treatment being less impaired than the group without stimulant treatment. Parents of both groups have a serious need for health care services. Both impairment and CGAS scores indicated serious impairment in all the ADHD children. Possible protective factors such as sociodemographic or educational characteristics or absence of comorbidity were found unable to explain thetreatment versus non treatment status of the ADHD children. They support the idea that undertreatment of ADHD is the predominant problem.

A next and related issue is whether the treatment offered is adequate. The average dose of methylphenidate in our study was about $22.5+/-8.6 \mathrm{mg} /$ day. This dose is comparable to the average dose at baseline in the community part (23 mg daily) of the MTA study (Pelham, 1999). The MTA study showed that the titration protocol for optimal treatment effect of methylphenidate resulted in higher doses (Vitiello et al., 2001). We have no information on the effect of the medication in our sample, but it could be interesting to evaluate the effect of the protocol in this population. Extrapolating from the MTA study, our data suggest that the prescribed dosages of methylphenidate were suboptimal.

Factors influencing the medication status in the present study were the number of inattentive symptoms and the absence of comorbidity with ODD. The groups were too small 
to investigate the distribution of subtypes of ADHD. The subjective family burden and the educational situation seemed to have no influence on this result, but the recognition of the problems by the teacher was highly significant. The treated and untreated ADHD group experienced the same burden and both achieved the norm score for a clinical population, indicating that medication was necessary and undertreatment was present also for the untreated ADHD group. Questions arise as to whether the subjective family burden and the educational situation are good measures for the need for psychopharmacological treatment. One study examined ADHD and parental psychological distress with respect to the medication status of children with ADHD (Harrison and Sofronoff, 2002). The introduction of medication status in the multiple regression analyses did not significantly influence parental stress. This suggests that subjective family burden may be associated more with "learned helplessness" than with the child's behavior (Harrison and Sofronoff, 2002).

The most important factor influencing the medication status was being clinically referred. Almost all the children with stimulant treatment were referred compared with only $20 \%$ of the ADHD children without stimulant treatment. This correlation could be expected because referral is necessary to obtain medication. ADHD behavior was more related to clinical referral than other psychopathology, but other patterns determining the referral status remain unclear. Further work is needed on parental and child behavior characteristics before any conclusion can be drawn. We will focus on this in a future report.

Two of the 12 children receiving stimulants (i.e. 16.6\%) did not meet the full diagnostic criteria for ADHD. They had threshold ADHD symptoms on at least one symptom cluster but without impairment. Of these, one child was diagnosed with an emotional disorder and one child had no diagnosis at all. We have reason to believe that the use of stimulants in these cases is not totally inappropriate. Another consideration is the effect of treatment resulting in the disappearance of the symptoms and underscoring on the DICA. Angold (2000) however investigated this topic and concluded that low symptom score cannot be accounted for by the curative effect.

The methods in this study design were well worked out and a 2-stage screening design was used. Two-stage designs frequently result in wide confidence intervals, so that results have to be interpreted prudently. The data did not suggest selective attrition and the drop-out rate was about similar to that of a comparable study (August et al., 1998). Nonetheless, because of the 2-stage screening design it is difficult to estimate to what extent these results can be generalized to an entire population. The drop-out rate could be influenced by the treatment status and biases the results in both ways. Furthermore, although the children were recruited from a large primary school population $(\mathrm{N}=1317)$, it should be acknowledged that the prevalence of ADHD diagnoses would have been larger if children from special schools for 
primary education had been included. These results should therefore be replicated in other samples.

The recent findings of the MTA study and the European Clinical Guidelines for hyperkinetic disorder indicate that for pervasive and severe disabling ADHD stimulant medication is more powerful than behavior treatment alone. With respect to this recommendation, the availability of medication for ADHD children whose problems are severe should be a major concern. Based on our survey, we have few reasons to conclude that overtreatment with stimulants is a major problem in this region of the Netherlands. Undertreatment and low rates of clinical referral to child mental health services of children who are impaired by their ADHD symptoms seems to be one of the major findings of our survey. Research is needed to elucidate the most common pathways leading to children's referral, diagnosis and treatment and to evaluate the impact on this process by variables such as parental perception of impairment, social and academic expectations, schools' attitudes, clinician characteristics, health insurance and availability of alternative services. 
Health Care Services and Psychotropic Medication | 123

\section{References}

Achenbach T ed. (1991a), Manual for the Child Behavior Checklist 4-18 and 1991 Profile. Burlington: University of Vermont Department of Psychiatry

Achenbach T ed. (1991b), Manual for the Teacher's Report Form and 1991 Profile. Burlington: University of Vermont Department of Psychiatry

Angold A, Erkanli A, Egger H-L, Costello E-J (2000), Stimulant treatment for children: A community perspective. Journal of the American Academy of Child and Adolescent Psychiatry 39: 975-984

August G-J, Braswell L, Thuras P (1998), Diagnostic stability of ADHD in a community sample of school-age children screened for disruptive behavior. Journal of Abnormal Child Psychology 26: 345-356

De Groot A, Koot H, Verhulst F (1996), Cross-cultural generalizability of the Youth Self-Report and Teacher's Report Form cross informant syndromes. Journal of Abnormal Child Psychology 24: 651-664

Goldman L-S, Genel M, Bezman R-J, Slanetz P-J (1998), Diagnosis and treatment of attentiondeficit/hyperactivity disorder in children and adolescents. Journal of the American Medical Association 279: 1100-1107

Greenhill L-L, Halperin J-M, Abikof H (1999), Stimulant medications. Journal of the American Academy of Child and Adolescent Psychiatry 38: 503-512

Harrison C, Sofronoff K (2002), ADHD and parental psychological distress: role of demographics, child behavioral characteristics, and parental cognitions. Journal of the American Academy of Child and Adolescent Psychiatry 41: 703-11

Hoagwood K, Kelleher KJ, Feil M, Comer DM (2000), Treatment services for children with ADHD: a national perspective. Journal of the American Academy of Child and Adolescent Psychiatry 39: 198-206

Jensen PS, Kettle L, Roper MT, Sloan MT, Dulcan MK, Hoven C, Bird HR, Bauermeister JJ, Payne JD (1999), Are stimulants overprescribed? Treatment of ADHD in four U.S. communities. Journal of the American Academy of Child and Adolescent Psychiatry 38: 797-804

Kalff AC, Kroes M, Vles JS, Bosma H, Feron FJ, Hendriksen JG, Steyaert J, van Zeben TM, Crolla IF, Jolles J (2001a), Factors affecting the relation between parental education as well as occupation and problem behavior in Dutch 5- to 6-year-old children. Social Psychiatry and Psychiatric Epidemiology 36: 324-31

Kalff AC, Kroes M, Vles JS, Hendriksen JG, Feron FJ, Steyaert J, van Zeben TM, Jolles J, van Os J (2001b), Neighbourhood level and individual level SES effects on child problem behavior: a multilevel analysis. Journal of Epidemiological Community Health 55: 246-50

Kortenbout van der Sluijs M, Levita D, Manen R, Defares P (1993), In: ADIKA, Amsterdams Diagnostisch Interview voor Kinderen en Adolescenten Lisse: Swetz and Zeitlinger

Kroes M, Kalff AC, Kessels AG, Steyaert J, Feron FJ, van Someren AJ, Hurks PP, Hendriksen JG, van Zeben TM, Rozendaal N, Crolla IF, Troost J, Jolles J, Vles JS (2001), Child psychiatric diagnoses in a population of Dutch schoolchildren aged 6 to 8 years. Journal of the American Academy of Child and Adolescent Psychiatry 40: 1401-9

Lezak MD (1995), Neuropsychological Assessment. 3 edition Oxford: Oxford University Press

Pelham W-E, Jr. (1999), The NIMH Multimodal Treatment Study for attention-deficit hyperactivity disorder: Just say yes to drugs alone? Canadian Journal of Psychiatry 44: 981-990

Pineda D-A, Ardila A, Rosselli M, Arias B-E, Henao G-C, Gomez L-F, Mejia S-E, Miranda M-L (1999), Prevalence of attention-deficit/hyperactivity disorder symptoms in 4- to 17-year-old children in the general population. Journal of Abnormal Child Psychology 27: 455-462

Reich W, Shayla JJ, Taibleson C (1992), The Diagnostic Interview for Children and Adolescents Revised (DICA-R) (structured psychiatric interview). St Louis, MO: Washington University.

Safer DJ, Zito JM, Fine EM (1996), Increased methylphenidate usage for attention deficit disorder in the 1990s. Pediatrics 98: 1084-8

Salmelainen P (2002), Trends in the prescribing of stimulant medication for the treatment of attention deficit hyperactivity disorder in children and adolescents in New South Wales. New South Wales Public Health Bull 13 Suppl S-1: 1-65 
Sawyer MG, Rey JM, Graetz BW, Clark JJ, Baghurst PA (2002), Use of medication by young people with attention-deficit/hyperactivity disorder. Medical Journal of Australia 177: 21-5

Sayal K, Taylor E (2004), Detection of child mental health disorders by general practitioners. Br J Gen Pract 54: 348-52

Schirm E, Tobi H, Zito JM, de Jong-van den Berg LT (2001), Psychotropic medication in children: a study from the Netherlands. Pediatrics 108: E25

Schubert I, Köster I, Adam C, Ihle P, Döpfner M, Lehmkuhl G (2003), Psychotropic Drugs for Children with the Claims Diagnosis "Attention Deficit/Hyperkinetic Disorder". A Drug Utilisation Study of Outpatient Care with Person-Related Data of the Statutory Health Insurance (Versichertenstichprobe AOK Hessen/ KV Hessen, 1998-2001) Zeitschrift für Gesundheitswissenschaften 11: 306-324

Shaffer D, Gould M-S, Brasic J, Ambrosini P, Fisher P, Bird H, Aluwahlia S (1983), A children's global assessment scale (CGAS). Archives of General Psychiatry 40: 1228-31

Shrout P, Skodol A, Dohrenwend B (1986), A two-stage approach for case identification and diagnosis: first-stage instruments, Mental Disorders in the Community ne ed. New York: Guildford Press

Szatmari P, Offord D-R, Boyle M-H (1989), Ontario Child Health Study: Prevalence of attention deficit disorder with hyperactivity. Journal of Child Psychology and Psychiatry and Allied Disciplines 30: 219-230

Taylor E, Dopfner M, Sergeant J, Asherson P, Banaschewski T, Buitelaar J, Coghill D, Danckaerts M, Rothenberger A, Sonuga-Barke E, Steinhausen HC, Zuddas A (2004), European clinical guidelines for hyperkinetic disorder -- first upgrade. European Child \& Adolescent Psychiatry 13: I7-30

van den Brandt P-A, Goldbohm R-A, van 't Veer P, Volovics A, Hermus R-J, Sturmans F (1990), A large-scale prospective cohort study on diet and cancer in The Netherlands. Journal of Clinical Epidemiology 43: 285-95

Van Grimbergen I, Célestin-Westreich, S \& Ponjaert-Kristofferson, I (1999), Validering van ADIKAIV (deel externaliserend gedrag) bij een klinische populatie kinderen tussen 6 en 18 jaar. In: De kinderschoenen ontgroeid? Tweede Vlaams Congres Kinder- en jeugdpsychiatrie en psychotherapie., Garant ed. Leuven, pp p.76

Verhulst F, Van der Ende J, Koot H (1996), In: Handleiding voor de CBCL Rotterdam: Erasmus University/ Departement of Child and Adolescent Psychiatry, Sophia Children's Hospital

Vitiello B, Severe JB, Greenhill LL, Arnold LE, Abikoff HB, Bukstein OG, Elliott GR, Hechtman L, Jensen PS, Hinshaw SP, March JS, Newcorn JH, Swanson JM, Cantwell DP, Davies M, Clevenger W, Wu M, Conners CK, Hoza B, Kraemer HC, Wells K, Wigal T, Elliott G, Newcorn J, Pelham WE (2001), Methylphenidate dosage for children with ADHD over time under controlled conditions: lessons from the MTA. Journal of the American Academy of Child and Adolescent Psychiatry 40: 188-96

von Ferber L, Lehmkuhl G, Köster I, Döpfner M, Schubert I, Frölich J, Ihle P (2003), Methylphenidate Usage in Germany. Deutsches Ärzteblatt 100: A41-A46

Wels PMA, Robbroeckx LMH (1996), Manual of Nijmeegse Questionnaire for Educational Situation Lisse: Swets and Zeitlinger BV

Wolraich M-L (1999), Attention deficit hyperactivity disorder: The most studied and yet most controversial diagnosis. Mental Retardation and Developmental Disabilities Research Reviews 5: 163-168

Zwaanswijk M, Verhaak PF, van der Ende J, Bensing JM, Verhulst FC (2005), Consultation for and identification of child and adolescent psychological problems in Dutch general practice. Family Practice 17: 17 
Chapter 7

Concluding remarks 


\section{Introduction}

This thesis focuses on various aspects of Attention deficit/Hyperactive Disorder AD/HD at population level. Within a large school-based population of 6-7 years old children we first focused on the distribution of the AD/HD symptoms and the validity of the DSM-IV ADHD algorithm (chapter 3). In addition, the frequency of occurrence and the diagnostic stability of ADHD at a young age (chapter 4) and the presence of comorbid conditions (chapter 5) were studied. Finally, the use of health care services and psychotropic medication (chapter 6) within a school population was investigated.

The studies presented are part of the Study of Attention Disorders in Maastricht (SAM), a large longitudinal research program on ADHD in young children. SAM consists of several related projects of which the present thesis is one.

Briefly the design of SAM can be summarised as follow. Out of two school cohorts, children were selected by their CBCL scores (Verhulst et al., 1996) and divided in two subsamples: an at risk school population and a healthy population. Children enrolled at about 6 years of age and were follow up at 7 and 9 years. At the different stages information on socio-demographic characteristics, motoric performance, neuropsychological functioning, medical and psychiatric diagnoses were collected.

In the current chapter we provide an overview of the main results of the thesis, with their implications for research and the possible applications in clinical practice.

\section{The Symptomatology of ADHD within a broader perspective}

ADHD has been firmly established as a psychiatric disorder that meets the criteria for the validation of psychiatric diagnoses as outlined by Robins and Guze (Faraone, 2005; Robins and Guze, 1970). Since the release of the DSM-IV it is conceptualised as a discrete disorder of 18 symptoms clustered into 3 subtypes: the predominantly inattentive subtype (ADHD:IA), the predominantly hyperactive/impulsive subtype (ADHD:HI) and the combined subtype (ADHD:C).

Historically, the terminology of the ADHD concept has changed over the years and emphasis shifted from an organic aetiology with hyperactivity as the most characteristic symptom to a broader syndrome characterized by a number of symptoms with attention problems as the core deficit. Syndromes of ADHD-like symptoms were labelled in the past as 'Postencephalitic Behavior Disorder', followed by 'Organic Driveness', 'Brain-Injured 
Child Syndrome', 'Minimal Brain Damage Syndrome' and 'Minimal Brain Dysfunction' (Baeyens et al., 2006). After a long period in which descriptions were aetiologically based, a shift occurred towards a more symptom-based description in which characterisations were used such as 'Restlessness Syndrome', 'Hyperkinetic Impulse Disorder', 'Hyperkinetic Behavior Syndrome' and 'Hyperactive Child Syndrome'. This nomenclature indicated that 'hyperactivity' was regarded as the core problem of this condition. The introduction of child psychiatric disorders in the Diagnostic and Statistical Manual of Mental Disorders (DSM), Second Edition (DSM II, 1968) and third edition (DSM III, 1980) was the start of a process which led to the description of the disorder in the way we currently know and which is multidimensional in nature. A dysfunction in attention processes is still perceived nowadays as one of the core deficits of ADHD.

This historical evolution of the ADHD concept supports the notion of a complex disorder and recent research emphasizes its multi-factorl aetiology and multiple pathways (Faraone, 2005; Sonuga-Barke, 2005). A number of causal models have been proposed based on genetic, neuroanatomic, neurophysiological and neuropsychological findings (Castellanos and Tannock, 2002; Coghill et al., 2005). Yet, it is still not possible to describe a full causal model of ADHD, in which also its component symptom dimensions are described in sufficient detail. Accordingly, we found in the present thesis that the distribution of the total number of Inattentive (IA) and Hyperactive \& Impulsive (HI) symptoms does not lead to a well distinguished 'ADHD' group. There is more evidence for a heterogeneous distribution that does not support the notion that there is a simple relation between IA and HI symptoms. This finding is important for the concept of ADHD. The current concept of the DSM-IV ADHD put both symptom clusters at the same level, contributing equally to an ADHD outcome but as such a large scale of ADHD syndromes is reached.

In an attempt to find causal pathways to ADHD a shift from phenotypic to endophenotypic research has taken place. Endophenotypes are regarded as the underlying vulnerability traits that heighten the risk for further development of the disorder. These latent traits, assumed to carry genetic loading and measured at a neurocognitive, neurophysiological, or morphological level, are related indirectly to the classic behavioral symptoms which are defined in DSM-IV or ICD-10 (Leboyer et al., 1998; Skuse, 2001). They are promising tools for multilevel investigations of etiological pathways and potential predictors of clinical treatment response.. Based on this concept, high response variability/ inconsistency in performance, deficit in response inhibition, and impairment of working memory have been proposed as candidate endophenotypes of ADHD.

Our distribution of the total number of IA and HI symptoms shows that, most likely, a heterogenic relation between IA and HI is present, which is probably mediated by one or more (unknown) factors. In addition, the polygenic genetic underpinning of ADHD is 
complex, and the multiple environmental influences make a detailed description of the relation between IA and HI impossible. A full causal model will need to predict a ballet choreographed interactively among genotype, environment, and epigenetic factors. As such a large variety of phenotypes is reached. Future research of the endophenotypes of ADHD needs to take this complex distribution into account.

It could be interesting for the ADHD concept and the study of ADHD endophenotypes, to analyse the influences of known risk factors on the relation between IA and HI by multivariate techniques in order to understand the nature of this relation. As such, specific endophenotypes based on clustering techniques will have to be formulated.

\section{ADHD Symptom Specificity and the ADHD Subtypes in a General Population}

Multiple field trials, mostly based on clinically referred children within a wide age range of 7-18 years have been performed to define and evaluate the DSM-IV criteria of ADHD (Burns et al., 2003; Faraone et al., 2000; Graetz et al., 2001; Hartman et al., 2001; Lahey and Applegate, 2001; Lahey et al., 1994; McBurnett et al., 1999; Morgan et al., 1996; Muris and Meesters, 2003; Rohde et al., 2001; Woo and Rey, 2005). Despite the extensive DSMIV field trials for children and adolescents in clinical cases, little is known about the frequency of the symptoms and the influence of the other diagnostic criteria in a general population. Even less is known about these factors at a young age. Within this framework, and in the light of the ongoing process which will eventually lead to the DSM-V, we have investigated the symptom specificity and diagnostic criteria in the present thesis in a large population of 6-8 year old children.

The frequency of the different ADHD symptoms appears to vary widely from $5 \%$ to $48 \%$ in our sample of children who had been drawn from the general population. About 25\% (4/18) of the ADHD symptoms were rare, even at a young age and appear in less than $10 \%$ of the children. This contradicts the prevailing opinion that all ADHD symptoms are common in a normal general population. But, even stronger, it emphasises that the variousADHD symptoms have different predictive power to the ADHD outcome. We were able to confirm the research of Barkley and colleagues (2007 in press) in adults who found that a small set of 3 attention and 3 hyperactive-impulsive items were best able to distinguish the ADHD from the non-ADHD group with 3 symptoms overlapping in both models. These findings question the notion that the DSM-IV symptom list comprises the best possible list of symptoms for identifying ADHD. Our results imply that the list of DSM-IV symptoms is redundant. This is of importance for the discussion as to the optimal list of symptoms to be included into DSM-V. Therefore, and before these results can be made operational in the 
DSM algorithm it is important that more elaborate research is performed on the age specificity and the stability of DSM-IV-defined ADHD symptoms. ADHD has a developmental aetiology (Krain and Castellanos, 2006) and the prevalence rates are highest between the ages of 6 and 11 (Pineda et al., 1999; Szatmari et al., 1989). In our studies (notably those described in chapter 5), a high ADHD symptom persistence was found but it remains unclear how the frequency of the different ADHD symptoms evolves over time and whether particular subsets of symptoms are more related to persistent ADHD than others.

A factor-analytic study by Lahey and colleagues (Lahey et al., 1988) revealed that clinician ratings of ADHD-diagnosed children yielded a three-factor solution (HI factor, IAdisorganization factor, and a sluggish (cognitive) tempo factor (SCT)). Several researchers openly question whether ADHD-HI, ADHD-IA and ADHD-C are distinct and unrelated disorders and whether they should be considered separately (Barkley, 2001; Hinshaw, 2001; Lahey, 2001; Milich et al., 2001; Pelham, 2001). In his review, Baeyens (2006) concluded that the more fundamental the measurement level, the less evidence is unambiguous found for subtype differences. Only on the clinical psychiatric diagnostic level, do more or less clear-cut differences in cognitive, social, academic, and behavioral functioning emerge. Our graph of the distribution of the number of ADHD symptoms shows no arguments for clear, separated subtypes of ADHD. As mentioned earlier, the heterogeneous distribution indicates a complex multi-causal aetiology of ADHD and as such supports the need to model multipathway processes in a dynamic fashion.

\section{The DSM-IV taxonomy: Splitting or Lumping?}

The DSM-IV is conceptualized as a categorical diagnostic manual to classify psychopathology. Its clear definition of psychopathology should lead to single diagnosis. This is in sharp contrast with clinical and epidemiological research. Epidemiological data show that the co-occurrence or comorbidity of two or more supposedly separate child psychiatric conditions far exceeds that expected by chance. Many reviews have detailed the importance of taking comorbidity into account when endeavouring to understand the aetiology, classification, course, and treatment of psychiatric disorders (Angold et al., 1999; Jensen, 2003; Lilienfeld, 2003; Rutter and Sroufe, 2000).

Within our large sample, comorbidity was frequent and we investigated the comorbidity patterns using univariate and multivariate logistic regression. Comorbidities between ADHD-ODD/CD and ODD/CD-anxiety disorder remained in all statistical models supporting some causality. Mood and anxiety disorders were related but separate entities. Elimination disorder was generally not predicted by any psychiatric disorder, but was associated with ODD/CD in clinical cases. It shows that child psychiatric disorders cannot 
be described by separate diagnostic categories. Allthough the majority of health care workers can be expected to be aware of the concept of comorbidity there are strong indications that this knowledge is not reflected in diagnostic and treatment protocols or in clinical practice. More fundamental research into the causal factors of a disorder including children with highly comorbid conditions is needed to extend our knowledge on the course and treatment of comorbid conditions.

\section{Referral and treatment of ADHD children.}

One of the diagnostic criteria for ADHD states that the problems must manifest themselves for at least six months before the age of seven and that certain symptoms (pervasively) impede the child's functioning in various environments. ADHD must have an impact on the way the child functions as an individual, the way he functions in his family and interacts with his peers, and on his performance at school. Such a measurement of symptom severity is introduced to make a distinction between ADHD and children who can be considered 'very active but part of the normal spectrum'. Still it remains unclear how this impairment criteria is related to the need for mental health services. One could expect that all the children who need mental health services suffer from impairment, while the converse is not true. We found that the two criteria generate different groups. Research on clinically referred research groups is commonly described as the Berkson bias population but in this thesis we shed light on the question as to how a clinical population differs on symptom level from a general population. The 3 symptoms which are best predictive to distinguish both groups reflect a certain interactive aspect of the child-parent relation (does not listen; runs/climbs; interrupts or intrudes) and are different from the best predictive symptoms for the ADHD outcome. We believe that this is an important finding for further clinical research.

The recent findings of the MTA study and the European Clinical Guidelines for hyperkinetic disorder indicate that for pervasive and severely disabling ADHD stimulant medication is more powerful than behavior treatment alone. Because of this recommendation, the availability of medication for ADHD children whose problems are severe should be a major concern. Based on our survey, we have few reasons to conclude that overtreatment with stimulants is a major problem in the region of the Netherlands which provided the sampling frame for subject recruitment. Major findings of our study are the fact that there is undertreatment and, in addition, low rates of clinical referral to child mental health services of children who are impaired by their ADHD symptoms. Further research is needed to elucidate the most common pathways leading to children's referral, diagnosis and treatment and to evaluate the impact on this process by variables such as parental perception of 
impairment, social and academic expectations, schools' attitudes, clinician characteristics, health insurance and availability of alternative services.

\section{SAM Study - Further Research}

The strengths of the SAM study include the large number of subjects within one age range, the young age of the children and the extended amount of information collected. Not only were diagnostic interviews performed by clinicians supervised by a child psychiatrist for the assessment of a wide range of disorders including elimination disorder, but also a large amount of socio-demographic and medical data were collected together with a motor and neuropsychological evaluation. 'Intention to treat' biostatistical analysis taking the properties of the design into account made it possible to generalize the results of the research population to the entire participant population. Although the data did not suggest selective attrition, the rather low response rate of $58 \%$ must still be considered a limitation of the study. Nevertheless, the prevalence of ADIKA diagnoses in the general population group showed similar prevalence rates (Kroes et al., 2001), thereby providing some support to generalize our results in an entire population. A limitation of this study was the lack of multiple informants. This may have led to either the over or under representation of some disorders (Ezpeleta et al., 1997; Fergusson et al., 1993).

One of the major findings through all the different chapters of this thesis is the epidemiological reconfirmation that within psychiatric diagnostics no clear boundaries exist. We documented how a heterogenic distribution between IA and HI exists, how symptoms have different predictive value to a positive diagnosis and vary over time and how high comorbidity between disorders is present. This implies that psychiatric diagnostics can only be as good as the diagnostic criteria. It is important that in the future established diagnostic concepts are re-evaluated in the light of new findings. By integrating the concepts of molecular genetics, neurobiology, and cognitive psychology, the psychiatric neurosciences can make remarkable progress in the understanding of the relationship between neurodevelopment, neural function, and behavior related to ADHD. More studies should focus on the interaction and integration of the different risk factors of (the long-term course of ) ADHD. Knowledge is particularly lacking on the question as to how these diverse fragments of knowledge are connected, not only phenomenologically but also mechanically. These studies are hard to manage as large samples are necessary and expensive and invasive techniques such as blood sampling (for genetic and biological analyses) and advanced technical diagnostics (e.g. functional MRI techniques) would be necessary. In this context probably also animal models such as mouse models may contribute important insights. This type of research will allow a better understanding of both the molecular and cellular foundation of ADHD and the relevance of genetic variation 
for disease-related behavior such as hyperactivity, attentional and cognitive deficits, emotional dysregulation, and drug abuse.

Until then, clinicians should be aware that the 'unique' ADHD child does not exist. Psychiatric diagnostics should not only focus on the criteria of a disorder, but also on concepts such as impairment, pervasiveness, strength and weakness analysis. The recent findings of the MTA study and the European Clinical Guidelines for hyperkinetic disorder indicate that for pervasive and severe disabling ADHD stimulant medication is more powerful than behavior treatment. It could be of importance to combine the use of pharmacological treatment with treatments based upon cognitive (neuro)psychological insights. With respect to this recommendation, the availability of medication for ADHD children whose problems are severe should be a major concern. Research is needed to elucidate the most common pathways leading to children's referral, diagnosis and treatment and to evaluate the impact on this process by variables such as parental perception of impairment, social and academic expectations, schools' attitudes, clinician characteristics, health insurance and availability of alternative services. 


\section{References}

Angold A, Costello EJ, Erkanli A (1999), Comorbidity. Journal of Child Psychology and Psychiatry 40: $57-87$

Baeyens D, Roeyers H, Walle JV (2006), Subtypes of Attention-Deficit/Hyperactivity disorder (ADHD): Distinct or related disorders across measurement levels? Child Psychiatry \& Human Development 36: 403-417

Barkley RA (2001), The inattentive type of ADHD as a distinct disorder: what remains to be done. Clinical Psychology Science and Practice 8: 489-493

Burns GL, Walsh JA, Gomez R (2003), Convergent and discriminant validity of trait and source effects in ADHD-inattention and hyperactivity/impulsivity measures across a 3-month interval. Journal of Abnormal Child Psychology 31: 529-541

Castellanos FX, Tannock R (2002), Neuroscience of attention-deficit/hyperactivity disorder: the search for endophenotypes. Nature Reviews Neuroscience 3: 617-28

Coghill D, Nigg J, Rothenberger A, Sonuga-Barke E, Tannock R (2005), Whither causal models in the neuroscience of ADHD? Developmental Science 8: 105-114

Ezpeleta L, de la Osa N, Domenech JM, Navarro JB, Losilla JM (1997), Test-retest reliability of the Spanish adaptation of the Diagnostic Interview of Children and Adolescents. Psicothema 9: 529-539

Faraone SV (2005), The scientific foundation for understanding attention-deficit/hyperactivity disorder as a valid psychiatric disorder. European Child \& Adolescent Psychiatry 14: 1-10

Faraone SV, Biederman J, Friedman D (2000), Validity of DSM-IV subtypes of attentiondeficit/hyperactivity disorder: a family study perspective. Journal of the American Academy of Child and Adolescent Psychiatry 39: 300-7

Fergusson D-M, Horwood L-J, Lynskey M-T (1993), Prevalence and comorbidity of DSM-III-R diagnoses in a birth cohort of 15 year olds. Journal of the American Academy of Child and Adolescent Psychiatry 32: 1127-34

Graetz BW, Sawyer MG, Hazell PL, Arney F, Baghurst P (2001), Validity of DSM-IVADHD subtypes in a nationally representative sample of Australian children and adolescents. Journal of the American Academy of Child and Adolescent Psychiatry 40: 1410-7

Hartman CA, Hox J, Mellenbergh GJ, Boyle MH, Offord DR, Racine Y, McNamee J, Gadow KD, Sprafkin J, Kelly KL, Nolan EE, Tannock R, Schachar R, Schut H, Postma I, Drost R, Sergeant JA (2001), DSM-IV internal construct validity: when a taxonomy meets data. Journal of Child Psychology and Psychiatry 42: 817-36

Hinshaw SP (2001), Is the inattentive type of ADHD a separate disorder? Clinical Psychology Science and Practice 8: 498-501

Jensen PS (2003), Comorbidity and child psychopathology: recommendations for the next decade. Journal of Abnormal Child Psychology 31: 293-300

Krain AL, Castellanos FX (2006), Brain development and ADHD. Clin Psychol Rev 8: 8

Kroes M, Kalff AC, Kessels AG, Steyaert J, Feron FJ, van Someren AJ, Hurks PP, Hendriksen JG, van Zeben TM, Rozendaal N, Crolla IF, Troost J, Jolles J, Vles JS (2001), Child psychiatric diagnoses in a population of Dutch schoolchildren aged 6 to 8 years. Journal of the American Academy of Child and Adolescent Psychiatry 40: 1401-9

Lahey BB (2001), Should the combined and predominantly inattentive types of ADHD be considered distinct and unrelated disorders? Not now, at least. Clinical Psychology Science and Practice 8: 494-497

Lahey BB, Applegate B (2001), Validity of DSM-IV ADHD. Journal of the American Academy of Child and Adolescent Psychiatry 40: 502-503

Lahey BB, Applegate B, McBurnett K, Biederman J, Greenhill L, Hynd GW, Barkley RA, Newcorn J, Jensen P, Richters J, et al. (1994), DSM-IV field trials for attention deficit hyperactivity disorder in children and adolescents. American Journal of Psychiatry 151: 1673-85

Lahey BB, Pelham WE, Atkins MS, Murphy HA, Hynd GW, Russo M, Hartdagen S, Lorys-Vernon A (1988), Dimensions and types of attention deficit disorder. Journal of the American Academy of Child and Adolescent Psychiatry 27: 330-335 
Lilienfeld SO (2003), Comorbidity between and within childhood externalizing and internalizing disorders: reflections and directions. Journal of Abnormal Child Psychology 31: 285-91

McBurnett K, Pfiffner LJ, Willcutt E, Tamm L, Lerner M, Ottolini YL, Furman MB (1999), Experimental cross-validation of DSM-IV types of attention-deficit/hyperactivity disorder. Journal of the American Academy of Child and Adolescent Psychiatry 38: 17-24

Milich R, Balentine AC, Lynam DR (2001), ADHD combined type and ADHD predominantly inattentive type are distinct and unrelated disorders. Clinical Psychology-Science and Practice 8: 463-488

Morgan AE, Hynd GW, Riccio CA, Hall J (1996), Validity of DSM-IV ADHD predominantly inattentive and combined types: relationship to previous DSM diagnoses/subtype differences. Journal of the American Academy of Child and Adolescent Psychiatry 35: 32533

Muris P, Meesters C (2003), The validity of attention deficit hyperactivity and hyperkinetic disorder symptom domains in nonclinical Dutch children. Journal of Clinical Child and Adolescent Psychology 32: 460-6

Pelham WE (2001), Are ADHD/I and ADHD/C the same or different. Doest it matter? Clinical Psychology Science and Practice 8: 502-506

Pineda D-A, Ardila A, Rosselli M, Arias B-E, Henao G-C, Gomez L-F, Mejia S-E, Miranda M-L (1999), Prevalence of attention-deficit/hyperactivity disorder symptoms in 4- to 17-year-old children in the general population. Journal of Abnormal Child Psychology 27: 455-462

Robins E, Guze SB (1970), Establishment of diagnostic validity in psychiatric illness: its application to schizophrenia. American Journal of Psychiatry 126: 983-987

Rohde LA, Barbosa G, Polanczyk G, Eizirik M, Rasmussen ER, Neuman RJ, Todd RD (2001), Factor and latent class analysis of DSM-IV ADHD symptoms in a school sample of Brazilian adolescents. Journal of the American Academy of Child and Adolescent Psychiatry 40: 711718

Rutter M, Sroufe LA (2000), Developmental psychopathology: concepts and challenges. Development and Psychopathology 12: 265-96

Sonuga-Barke EJS (2005), Causal models of attention-deficit/hyperactivity disorder: From common simple deficits to multiple developmental pathways. Biological Psychiatry 57: 1231-1238

Szatmari P, Offord D-R, Boyle M-H (1989), Ontario Child Health Study: Prevalence of attention deficit disorder with hyperactivity. Journal of Child Psychology and Psychiatry and Allied Disciplines 30: 219-230

Verhulst F, Van der Ende J, Koot H (1996), In: Handleiding voor de CBCL Rotterdam: Erasmus University/ Departement of Child and Adolescent Psychiatry, Sophia Children's Hospital

Woo BSC, Rey JM (2005), The validity of the DSM-IV subtypes of attention-deficit/hyperactivity disorder. Australian and New Zealand Journal of Psychiatry 39: 344-353 
Chapter 8

Summary 
The overall aim of this thesis was to improve our understanding of $\mathrm{AD} / \mathrm{HD}$ in a large school-based population of children aged 6-7 years. The studies in this thesis focused on the earlier mentioned aims of the study such as the distribution of the $\mathrm{AD} / \mathrm{HD}$ symptoms, the frequency of occurrence at young age, the presence of comorbid conditions and the diagnostic stability and the prevalence of treatment.

Chapter 1 started with a brief description of the concept of ADHD. Some methodological issues in studying $\mathrm{AD} / \mathrm{HD}$ were given. Next, an introduction was given to the four major aims of the study i.e. the distribution of the $\mathrm{AD} / \mathrm{HD}$ symptoms, the frequency of occurrence at young age, the presence of comorbid conditions, the diagnostic stability and the prevalence of treatment of ADHD. This chapter ended with an elaboration on the design of the large research program, which is entitled 'Study of Attention disorders Maastricht' (SAM) and a short overview of the following chapters is given.

Chapter 2 gived an extended review of the current views on the concept of ADHD and its symptomatology, diagnosis and treatment.

Chapter 3 described the symptom distribution and examines the validity of the DSM-IV algorithm of ADHD in a large school-based sample of about 7 year old Dutch children. In a 2 stage design, 2466 eligible children were screened with the Child Behavior Checklist (CBCL). Of these, 789 were further assessed using the Dutch Diagnostic Interview for Children and Adolescents (DICA-R, DSM-IIIR/ IV). The symptom distribution and diagnostic determinants are weighteded to the responder group $(\mathrm{N}=2466)$. We found that 4 out of the 18 ADHD symptoms such as difficulty sustained attention, difficulty organizing tasks, avoidance of sustained attention, and difficulty playing quietly, are rare at age 7 . They appear in less than $10 \%$ of the children. A model including only 6 of the 18 ADHD symptoms appeared to be sufficient to separate cases from non-cases. No gender specific symptoms could be found. The distribution of the total number of Inattentive (IA) and Hyperactive \& Impulsive (HI) Symptoms did not lead to well distinguished subtypes of ADHD and supported a heterogeneous distribution. The need for mental health support within the ADHD cases was predicted by a 3- symptom pattern including 'doesn't seem to listen', 'runs/climbs' and 'interrupts or intrudes'. Thus, there is clear redundancy in the18 item set of DSM-IV symptoms of ADHD. Clinical ADHD samples differ from population based research samples in symptom level. These results may be useful in developing an algorithm for ADHD in DSM-V.

Chapter 4 examined the diagnostic continuity of ADHD. Few studies have examined the diagnostic continuity of Attention Deficit and Hyperactivity Disorder (ADHD) in community samples between the ages of six and nine, an age range in which ADHD prevalence rates peak. The diagnostic continuity of ADHD and its determinants was examined in a 
community sample of seven to nine year old children (initial $\mathrm{N}=1317$ ). Scores on the Child Behavior Checklist (CBCL) at age six served to select a high risk externalizing $(\mathrm{N}=173)$, a high risk internalizing ( $\mathrm{N}=59)$, and normal risk ( $\mathrm{N}=220)$ group. Follow-up assessments at age seven and nine included a structured psychiatric interview (DICA-R) and a Teacher Report Form (TRF) along with a CGAS score and an IQ estimate. We found that externalizing behaviors at age six strongly predicted an ADHD diagnosis at ages seven and nine. Of the 21 children that were diagnosed with ADHD at age seven, 15 still had ADHD at age nine (71\%). Male gender, the existence of pervasive symptoms and the presence of symptoms that require mental health care were factors that were predictive for the continuity of ADHD. Of the 40 children that had ADHD at age nine, 25 were newly diagnosed cases (62\%). Based upon a comparison between the two groups, the following was found: Newly diagnosed children displayed only subthreshold ADHD symptoms at age seven. Additionally, the newly diagnosed group had lower total TRF scores, less comorbidity with Oppositional Defiant Disorder (ODD) or Conduct Disorder (CD), and less need for mental health services. The newly diagnosed ADHD cases also displayed less hyperactive/impulsive symptoms and had lower impairment scores.

The findings indicate that children who are diagnosed with ADHD at age nine often display subthreshold ADHD symptoms at age seven. Additionally, the results support the notion of high ADHD symptom persistence in school age children in the community.

Chapter 5 focused on the comorbidity patterns in a large population. There is limited information on the prevalence and comorbidity of psychiatric disorders at age seven. This report described the prevalence of psychiatric disorders and comorbidity patterns in a large schoolbased sample of Dutch children in this age group. In a two stage design, 2,466 eligible children were screened using the Child Behavior Checklist (CBCL); 789 children were further assessed using the Amsterdam Diagnostic Interview for Children and Adolescents (ADIKA, DSM-IIIR / IV). Prevalence rates were generalised to the study population $(\mathrm{N}=2,466)$ and comorbidity patterns were examined using univariate and multivariate logistic regression. We found that ADIKA diagnosis, including enuresis and simple phobia, were present in $55.7 \%$ of the respondents. When the need for mental health support was used as an impairment criterion, the prevalence rate decreased to 5\%. Comorbidity rates ranged between $41 \%$ and $75 \%$. Comorbidity was associated with higher impairment and the male gender. Only comorbidities between ADHD-ODD/CD and ODD/CD-anxiety disorder remained in the multivariate logistic models supporting some causality. Mood and anxiety disorders were related but separate entities. Elimination disorder was generally not predicted by any psychiatric disorder, but was associated with ODD/CD in clinical cases. 
We concluded that child psychiatric disorders cannot be described well by separate diagnostic categories. Evidence-based diagnostic and treatment protocols should focus more on comorbidity among psychiatric disorders.

In Chapter 6 we examined the prevalence of the use of health care services and psychotropic medication in a community sample $(\mathrm{N}=283)$ of 9-year-old school children and, more specifically, evaluated the use of prescribed stimulants. Data from the second follow-up phase of the "Study of Attention Deficit Maastricht" (SAM) were analyzed. Assessments at age 9 included a structured psychiatric interview with parents, behavior and family situation questionnaire, IQ estimate and global assessment scale. Use of health care services and medication was obtained by the DICA-R and from the Youth Health Care records.

In our selected sample 190 children had at least one child psychiatric diagnosis, 26 (14\%) of them were clinically referred and $12(6 \%)$ received stimulants. Of the children with ADHD ( $\mathrm{N}=45), 10 / 45$ (22\%) received stimulants. Conversely, 2 out of 12 children who were treated with stimulants did not meet full DSM-IV diagnostic criteria, but were subthreshold ADHD cases. The treatment status was highly dependent on being clinically referred.

The major finding of our survey was that the referral to child mental health services is less than needed. Consequently, there is underdiagnosis and undertreatment, particularly in children with ADHD. Thus, there is a critical need to translate and implement the diagnostic and treatment guidelines into clinical practice.

Chapter 7 provided some concluding remarks on issues which are discussed in the context of the theme of the present dissertation and the recent scientific literature. Overall, the present dissertation is the first to provide more insight into the epidemiology of ADHD in a large school-based population of 6-7 years old children. We first focused on the distribution of the $\mathrm{AD} / \mathrm{HD}$ symptoms and the validity of the DSM-IV ADHD algorithm and found a possibility to reduce the ADHD symptoms. Clinical ADHD samples differ from population based research samples in symptom level. These results may be useful in the development of an algorithm for ADHD in DSM-V. In addition, the frequency of occurrence and the diagnostic stability of ADHD at young age revealed a large group of children who are diagnosed with ADHD at age nine but often display sub-threshold ADHD symptoms at age seven. The results support the notion of high ADHD symptom persistence in school age children in the community. Next, we concluded that child psychiatric disorders cannot be described well by separate diagnostic categories and that comorbidity is highly present. Comorbidities between ADHD-ODD/CD and ODD/CD-anxiety disorder remained in the multivariate logistic models indicating possible causality, all other significant comorbid relation of the univariate analysis disappeared. Finally, the use of health care services and psychotropic medication within a school population was investigated. The major finding of 
this survey is a lack of referral to child mental health services, and associated underdiagnosis and undertreatment, particularly in children with ADHD. There is a critical need to translate and implement the diagnostic and treatment guidelines to clinical practice. More studies should focus on the interaction and integration of the different risk factors of (the long-term course of) ADHD. 
Samenvatting 
Het algemene doel van deze thesis was het begrip over ADHD in een schoolpopulatie van 67 jaar te verbeteren. De studies in deze thesis concentreerden zich op vier aan elkaar gerelateerde doelstellingen. Deze hebben betrekking op de kenmerken van de ADHD symptomen, de frequentie van voorkomen op jonge leeftijd, de aanwezigheid van comorbide stoornissen, en de diagnostische stabiliteit en de prevalentie van behandeling.

Hoofdstuk 1 begon met een korte beschrijving van het ADHD concept. Een aantal methodologische aspecten van het bestuderen van ADHD werden besproken. Daarna werd een inleiding gegeven over de vier belangrijkste doelstellingen van de studie d.w.z. de kenmerken van de ADHD symptomen, de frequentie van voorkomen op jonge leeftijd, de aanwezigheid van comorbide stoornissen, de diagnostische stabiliteit en de prevalentie van behandeling. Dit hoofdstuk eindigde met een uiteenzetting van de opzet van het grote onderzoeksprogramma, 'Study of Attention disorders Maastricht' (SAM) en een kort overzicht van de volgende hoofdstukken.

Hoofdstuk 2 gaf een overzicht van de huidige kennis en inzichten over ADHD, meer in het bijzonder de symptomatologie, de diagnose en de behandeling.

Hoofdstuk 3 beschreef de symptoomdistributie en onderzoekt de validiteit van het DSM-IV algoritme van ADHD in onze uitgebreide groep schoolkinderen van 6 tot 8 jaar oud. In een eerste fase, werden 2466 kinderen gescreend aan de hand van een Gedragsvragenlijst, de Child Behavior Checklist (CBCL). In een tweede fase werden 789 kinderen verder onderzocht met de ADIKA, een gestructureerd kinderpsychiatrisch interview. Vanuit de symptoomdistributie en de diagnostische determinanten werd een generalisatie gemaakt naar de oorspronkelijk gescreende groep $(\mathrm{N}=2466)$. Wij vonden dat 4 van de 18 symptomen ADHD zeldzaam zijn. Het ging om symptomen zoals problemen met volgehouden aandacht, moeilijkheden om taken te organiseren, vermijden van taken die volgehouden aandacht vragen en moeilijkheden om stil te spelen op de leeftijd van 7. Deze symptomen kwamen bij minder dan $10 \%$ van de kinderen voor. Zes van de 18 ADHD symptomen waren voldoende om ADHD kinderen van de niet- ADHD kinderen te onderscheiden. Er werden geen geslachtspecifieke symptomen gevonden. De distributie van het totale aantal Onoplettende (IA) en Hyperactive \& Impulsieve symptomen (HI) leidde niet tot goed te onderscheiden ADHD subtypes. Een en ander onderschrijft de stelling dat er sprake is van een heterogene distributie. De nood aan steun op gebied van de geestelijke gezondheidszorg bij ADHD kinderen werd voorspeld door een groep van 3 symptomen met inbegrip van 'schijnt niet te luisteren ', 'loopt/ klimt voortdurend' en 'onderbreekt of verstoord anderen'. Deze bevindingen lijken aan te geven dat er een aantal van de 18 DSM-IV symptomen niet nodig zijn voor het stellen van de diagnose 'ADHD'. Onderzoekspopulaties gebaseerd op klinische patiënten zijn verschillend van populatie gebaseerd onderzoek ten aanzien van de aard van de symp- 
tomen. Deze resultaten kunnen nuttig zijn in het ontwikkelen van een algoritme voor ADHD in de DSM-V.

Hoofdstuk 4 onderzocht de diagnostische continuïteit van ADHD bij 6 tot 9 jarige kinderen, een leeftijdsfase waarin de prevalentie van ADHD piekt. We onderzochten in welke mate de ADHD diagnose bij onze onderzoekspopulatie (initieel $\mathrm{N}=1317$ ) tussen 6 en 9 jaar stabiel bleef en welke determinanten hierbij van invloed zijn. De resultaten van de CBCL op de leeftijd van 6 jaar werden gebruikt om een hoogrisico groep met externaliserende gedragsproblemen $(\mathrm{N}=173)$, een hoogrisico groep met internaliserende gedragsproblemen $(\mathrm{N}=59)$, en een normale controle populatie $(\mathrm{N}=220)$ te selecteren. Vervolg onderzoek op 7 en 9 jaar bestond uit een gestructureerd kinderpsychiatrisch interview (ADIKA), een gedragsvragenlijst voor leerkrachten (TRF), een globale beoordelingsschaal (CGAS) en een IQ schatting. Wij vonden dat externaliserend gedrag op de leeftijd van zes jaar in belangrijke mate een ADHD diagnose op de leeftijd van zeven en negen voorspelde. Van de 21 kinderen die op de leeftijd van zeven jaar met ADHD werden gediagnosticeerd, hadden 15 kinderen op de leeftijd van negen jaar nog ADHD (71\%). Belangrijke voorspellers voor de continuïteit van ADHD waren: mannelijk geslacht, de aanwezigheid van een hoge symptoom pervasiviteit en hoge behoefte aan geestelijke gezondheidszorg. Van de 40 kinderen die ADHD op de leeftijd van negen jaar hadden, waren er 25 nieuw gediagnosticeerd (62\%). Een vergelijking tussen deze twee groepen toonde dat de nieuw gediagnosticeerde kinderen op de leeftijd van 7 jaar net onder de diagnostische drempel bleven. Bovendien had de nieuw gediagnosticeerde groep op 9 jaar lagere totale TRF scores, minder comorbiditeit met een oppositioneelopstandige gedragsstoornis of antisociale gedragsstoornis en minder behoefte aan geestelijke gezondheidszorg. De nieuw gediagnosticeerde kinderen hadden ook minder hyperactieve/impulsieve symptomen en hadden lagere scores in de probleemgebieden. Deze bevindingen wijzen erop dat de kinderen bij wie op negenjarige leeftijd voor het eerst ADHD gediagnosticeerd werd, vaak al ADHD symptomen op de leeftijd van zeven vertoonden, maar dan net de drempelwaarde niet bereikten. Bovendien bevestigen deze bevindingen dat ADHD symptomen in belangrijke mate persisteren bij kinderen op lagere schoolleeftijd.

Hoofdstuk 5 concentreerde zich op de comorbiditeitspatronen in een algemene bevolking. Er is beperkte informatie over de prevalentie en de comorbiditeit van psychiatrische stoornissen op de leeftijd van zeven jaar. Dit hoofdstuk beschreef de prevalentie van psychiatrische aandoeningen en de comorbiditeitspatronen in een uitgebreide schoolpopulatie op deze leeftijd. In een eerste fase werden 2466 kinderen gescreend aan de hand van een Gedragsvragenlijst, de Child Behavior Checklist (CBCL). In een tweede fase werden 789 kinderen verder onderzocht met de ADIKA, een gestructureerd kinderpsychiatrisch interview. Prevalentie cijfers werden gegeneraliseerd naar de totale onderzoekspopulatie $(\mathrm{N}=2,466)$ en de comorbiditeitspatronen werden met univariate en multivariate logistische regressie onderzocht. Wij vonden dat de verschillende ADIKA diagnoses, met inbegrip van enuresis en 
simpele fobie, in 55,7\% van de ondervraagden aanwezig was. Wanneer de behoefte voor geestelijke gezondheidszorg gebruikt werd als een maat om de hinder te bepalen, daalde de prevalentie tot $5 \%$. Comorbiditeit was aanwezig bij $41 \%$ tot $75 \%$ van de diagnoses. Het voorkomen van comorbiditeit werd geassocieerd met ernstige functionele belemmering en het mannelijk geslacht. Comorbiditeit tussen ADHD-ODD/CD en ODD/CDangststoornissen bleef in de multivariate logistische modellen bestaan en wezen op een causale relatie. Depressieve en angstige stoornissen waren sterk verwante maar toch afzonderlijke entiteiten. De stoornissen op gebied van enuresis en encopresis waren in het algemeen niet gerelateerd aan een of andere stoornis, maar in de klinische gevallen waren ze geassocieerd met ODD/CD. Wij besloten dat kinderpsychiatrische stoornissen niet beschreven kunnen worden in goed gedefinieerde, aparte entiteiten. Evidence-based diagnostische richtlijnen en behandelingsprotocollen zouden zich meer op comorbiditeitspatronen moeten richten.

In Hoofdstuk 6 onderzochten wij het gebruik van de geestelijke gezondheidszorg en de psychotrope medicatie in een algemene onderzoekspopulatie $(\mathrm{N}=283)$ van 9-jaar-oude schoolkinderen. Meer specifiek evalueerden we het gebruik van stimulantia. De gegevens van de tweede vervolgfase van de SAM studie werden geanalyseerd. Het onderzoek op de leeftijd van 9 jaar omvatte een gestructureerd psychiatrisch interview met de ouders, een gedrag- en familiesituatie vragenlijst, een IQ schatting en globale beoordelingsschaal. (CGAS). Informatie over het gebruik van de geestelijke gezondheidszorg en het gebruik van medicatie werd verkregen uit de ADIKA en uit de verslagen van de schoolartsdienst van de GGD. In onze geselecteerde steekproef hadden 190 kinderen minstens één kinderpsychiatrische diagnose, 26 (14\%) van hen werden klinisch verwezen en 12 (6\%) ontvingen stimulantia. Van de kinderen met ADHD ( $\mathrm{N}=45)$, ontving 10/45 (22\%) stimulantia. Omgekeerd, 2 van de 12 kinderen die met stimulantia werden behandeld hadden niet alle DSM-IV diagnostische criteria, maar hadden subtreshold ADHD. De behandelingsstatus was vooral afhankelijk van het feit of het kind al of niet verwezen werd. De belangrijkste bevinding van ons onderzoek was dat kinderen minder dan wat opportuun zou zijn verwezen worden naar geestelijke gezondheidscentra. Daarom is er in belangrijke mate sprake van onderdiagnosticeren en onderbehandelen, in het bijzonder bij kinderen met ADHD. Er is in de dagelijkse klinische praktijk een kritieke behoefte om de diagnostische richtlijnen en behandelingsprotocollen te vertalen en te implementeren.

Hoofdstuk 7 verstrekte in het licht van de recente wetenschappelijke ontwikkelingen een aantal concluderende bemerkingen over de thema's die in dit proefschrift behandeld werden. Globaal, is het hier beschreven onderzoek één van de eerste die meer inzicht verleent in de epidemiologie van ADHD in een algemene schoolbevolking van 6 tot 8 jaar oude kinderen. Wij concentreerden ons eerst op de distributie van de AD/ HD symptomen en de validiteit van het DSM-IV algoritme. We vonden aanwijzingen die ertoe kunnen leiden dat het aantal 
symptomen dat nodig is voor een positieve ADHD diagnose minder wordt. De klinische onderzoekspopulaties verschillen bij ADHD op symptoomniveau duidelijk van een op de algemene bevolking gebaseerde onderzoekpopulatie. Deze resultaten kunnen nuttig zijn in de ontwikkeling van een algoritme voor de nadere beschrijving van ADHD in de DSM-V. Vervolgens toonde de prevalentie en de diagnostische stabiliteit van ADHD dat een grote groep kinderen met een positieve ADHD diagnose op de leeftijd van negen jaar reeds op zeven jarige leeftijd gekenmerkt was door subtreshold symptomen van ADHD. Deze bevindingen bevestigen dat ADHD symptomen in een belangrijke mate persisteren bij kinderen op lagere schoolleeftijd. Er werd geconcludeerd dat kinderpsychiatrische stoornissen niet beschreven kunnen worden in goed gedefinieerde, aparte entiteiten en dat comorbiditeiten sterk aanwezig zijn. Comorbiditeit tussen ADHD-ODD/CD en ODD/CD-angststoornissen bleven in de multivariate logistische modellen verder bestaan en wijzen in de richting van een causaal verband, terwijl alle andere significante comorbiditeiten van de univariate analyse verdwenen. Tot slot werd het gebruik van de geestelijke gezondheidszorg en de psychotrope medicatie, meer specifiek van stimulantia onderzocht. De belangrijkste bevinding hierbij was dat kinderen slechts in beperkte mate verwezen worden naar geestelijke gezondheidscentra en dat er sprake is van onderdiagnosticeren en onderbehandelen, in het bijzonder bij kinderen met ADHD. Er is een prangende behoefte om de diagnostische richtlijnen en behandelingsprotocollen te vertalen en te implementeren in de dagelijkse klinische praktijk. Meer studies zouden zich moeten richten op de interactie en de integratie van de verschillende risicofactoren bij de (lange termijn ) ontwikkeling van ADHD. 


\section{Dankwoord}

Een promotieonderzoek is een dusdanig langdurige en complexe onderneming, dat - om het te doen slagen - de medewerking en goede wil van een groot aantal mensen onmisbaar is. Het is onmogelijk om iedereen met name te noemen. Maar natuurlijk wil ik allen bedanken die door de jaren heen hun interesse hebben getoond. Jullie bemoedigende woorden en luisterende oren waren van onschatbare waarde! Een aantal mensen wil ik hier expliciet noemen.

Allereerst ben ik dank verschuldigd aan alle kinderen en ouders die hun medewerking aan dit onderzoek hebben verleend. Door de vaak tomeloze inzet van de ouders en hun kinderen waren de urenlange interviews en huisbezoeken de leukste periode van het onderzoek.

Mijn dank gaat ook uit naar mijn promotoren. Prof. Dr. J. Jolles, Jelle, tijdens een eerste interview had je het over een tandem, waar we toch voor enige tijd samen zouden opzitten. We hebben veel en lang gefietst! Bedankt voor het vertrouwen dat je in me gesteld hebt. Ik heb veel geleerd van je onderzoeksmentaliteit en opbouwende kritiek, je bent een hele goede begeleider geweest. Ik waardeer je geduld en betrokkenheid. Prof. Dr. J. Buitelaar, Jan, je bent een goede leermeester voor mij geweest en je hebt het beste in mij naar boven gehaald. Bedankt voor alle expertise, tijd en energie die je in dit onderzoek en de artikelen gestoken hebt en het feit dat je altijd en overal voor me klaarstond met advies. Prof. Dr. G. Molenberghs, Geert, je hebt me de wondere wereld van de biostatistics leren kennen. De interactie van de getallen was vaak even boeiend en complex als de menselijke communicatie. Je inzichten, adviezen en opmerkingen zijn van onschatbare waarde geweest. Maar evenzeer blijven me je hartelijkheid, humor en levenswijsheid bij!

Van grote invloed zijn ook de andere leden van de SAM-stuurgroep, Jean Steyaert, Jos Hendriksen, Hans Vles, Thea van Zeben en Frans Feron en de verschillende inmiddels gepromoveerde onderzoekers, Ariane Kalff, Marielle Kroes en Petra Hurks geweest. Jean, als toenmalige stagemeester heb je me warm gemaakt voor dit onderzoek. Nu het achter de rug is, kijk ik met tevredenheid terug naar een bijzonder leerzame tijd die ik mede aan jou te danken heb. Beste Frans, waar waren wij op 11 september? Bedankt dat de deur van de GGD voor mij altijd open stond! Speciale dank ook aan Charlotte Aerts, wat was het verzamelen van al die gegevens leuk met jou erbij!

Ik denk ook met veel plezier terug aan de vele fijne mensen die ik in Maastricht heb leren kennen. Er is één iemand die eruit springt: Elsa Misdom. Elsa, je precisie, je continue hulp en je enthousiasme waren een grote steun voor mij. 
Naast alle Maastrichtse medewerkers zijn er nog twee mensen die ik in het bijzonder wil danken. Mevrouw Baronnes Patricia Van Caenegem- Carson, jij hebt al mijn Engelse teksten gelezen en eindeloze correcties aangebracht. Ik twijfel sterk of deze literatuur je evenzeer heeft kunnen boeien als jouw succesvolle boeken over de geschiedenis van Vlaanderen mij hebben geboeid, maar mijn dank is groot. Beste Ward, toffe collega en 'statistiekmaatje', we hebben ons samen door de opleiding biostatistics geworsteld en nadien kon ik steeds bij jou terecht voor statistische raad en daad. Ann en jij wonen jammer genoeg aan de andere kant van het land, maar tot nu toe stond dit de vriendschap niet in de weg. Ik hoop dat het zo zal blijven.

Lieve mama en zus Tine. Mama, toen ik je bij het schrijven van dit dankwoordje lachend vroeg waarvoor ik je moest danken, antwoordde je me: 'voor niets'. Ik weet wel beter! Je leerde mij en mijn zus dat opgeven geen optie is, tenzij het echt niet anders kan. Ook voor dit proefschrift een gouden raad!

Jan, mijn liefste man, dankjewel voor ons goede leven, voor het meedenken, voor het coachen en voor je steun. Ik had nooit kunnen weten dat het leven met onze prachtige dochters Marie, Clara en Ella zo mooi zou zijn! 


\section{Curriculum Vitae}

Sabine Tremmery werd geboren op 5 oktober 1971 te Kortrijk, België. Op het SintPietersinstituut te Gent voltooide zij in 1989 haar humaniora, richting LatijnWetenschappen, waarna ze geneeskunde studeerde aan de universiteit te Gent. Ze studeerde in 1996 met onderscheiding af en kon aansluitend starten met de specialisatie opleiding tot psychiater, meer bepaald kinderpsychiater aan de Universiteit van Gent. Het was in haar tweede stagejaar dat zij onder impuls van Prof. Dr. Jean Steyaert, haar toenmalige stagemeester te Maastricht een begin maakte aan het SAM project. In 2002 beëindigde ze de specialisatie opleiding en werd ze erkend als kinderpsychiater. Ze was nadien een korte tijd werkzaam in het revalidatiecentrum en Medisch Pedagogisch Instituut ' Sint-Lievenspoort' te Gent. Eind 2003 startte ze als voltijdse resident het 'Universitair Centrum voor Infant Kind en Adolescent Psychiatrie' (UCIKAP) in het Universitair Ziekenhuis te Gent. Ze startte mee het UCIKAP op en was verantwoordelijk voor het poliklinische en residentiële kinderteam. In 2003 behaalde ze haar Masters of Biostatistics aan het toenmalige Limburgs Universitair Centrum, heden Universiteit Hasselt. Zoekend naar een therapeutisch kader, volgde ze in 2002 een eerste cursus aan de Interactie Academie te Antwerpen, waarna ze de drie jarige opleiding 'systeemtheoretische psychotherapie' aanvatte en beëindigde in 2005 . Momenteel is ze sinds oktober 2007 als behandeld kinderpsychiater betrokken bij de oprichting van de Oost-Vlaamse forensische jongerenafdeling 'Varekai' in het Psychiatrisch Centrum te Sleidinge en tevens consultant bij de school 'de Oase', een gemeenschapsschool voor kinderen met emotionele en gedragsproblemen. Ze is gehuwd met Jan De Varé en is mama van Marie ( $\left.{ }^{\circ} 2002\right)$, Clara ( $\left.{ }^{\circ} 2004\right)$ en Ella $\left({ }^{\circ} 2006\right)$. 


\section{List of publications}

\section{Articles}

Tremmery S., Jan K. Buitelaar, Jean Steyaert, Geert Molenberghs, Frans J.M. Feron, Ariane C. Kalff, Petra P.M. Hurks, Jos G.M.Hendriksen, Johan S.H. Vles, Jelle Jolles, The Use of Health Care Services and Psychotropic Medication in a Community Sample of 9-Year-Old Schoolchildren with ADHD, European Child and Adolescent Psychiatry, Aug 2007;16(5):327-336.

Tremmery S., Jan K. Buitelaar, Jean Steyaert, Geert Molenberghs, Frans J.M. Feron, Ariane C. Kalff, Petra P.M. Hurks, Jos G.M.Hendriksen, Johan S.H. Vles, Jelle Jolles, Diagnostic Continuity of ADHD in a Community Sample of Primary School Children: a Three Year Follow-up Study, European Child and Adolescent Psychiatry, Submitted for publication.

Tremmery S., Jan K. Buitelaar, Jean Steyaert, Geert Molenberghs, Frans J.M. Feron, Ariane C. Kalff, Petra P.M. Hurks, Jos G.M.Hendriksen, Johan S.H. Vles, Jelle Jolles, Comorbidity Patterns in a Community Sample of Seven Year Old Dutch School Children , Journal of Abnormal Child Psychology, Submitted for publication.

Tremmery S., Jan K. Buitelaar, Jean Steyaert, Geert Molenberghs, Frans J.M. Feron, Ariane C. Kalff, Petra P.M. Hurks, Jos G.M.Hendriksen, Johan S.H. Vles, Jelle Jolles, Distribution of DSM-IV symptoms in a Large Community Sample of 7 Year Old Dutch School Children, Submitted for publication.

Van Zandweghe C., Tremmery S., Deboutte D., Prevalentie van psychiatrische stoornissen bij dove kinderen en adolescenten, Submitted for publication.

\section{Miscellaneous}

J. Steyaert J., Symons A., Tremmery S., Prevalence of Identifial Genetic Conditions in two Child Psychiatric Outpatient Clinics, American Journal of Medical Genetics, 2002, 114(7) - Posterabstract

Wetenschappelijke Prijs Eli Lilly (2003) 'Bekroond wetenschappelijk werk arts-assistenten’ 